\title{
Comprehensive phenotypic analysis of the Dp1Tyb mouse strain reveals a broad range of Down Syndrome-related phenotypes
}

Eva Lana-Elola ${ }^{1 \S}$, Heather Cater $^{2 \S}$, Sheona Watson-Scales ${ }^{1}$, Simon Greenaway ${ }^{2}$, Jennifer Müller-Winkler ${ }^{1}$, Dorota Gibbins ${ }^{1}$, Mihaela Nemes ${ }^{1}$, Amy Slender ${ }^{1}$,

Tertius Hough ${ }^{2}$, Piia Keskivali-Bond ${ }^{2}$, Cheryl L Scudamore ${ }^{2}$, Eleanor Herbert ${ }^{2}$, Gareth T Banks ${ }^{2}$, Helene Mobbs ${ }^{3}$, Tara Canonica ${ }^{4}$, Justin Tosh ${ }^{1,5}$, Suzanna Noy ${ }^{5}$, Miriam Llorian ${ }^{1}$, Patrick M. Nolan ${ }^{2}$, Julian L. Griffin ${ }^{3,6}$, Mark Good ${ }^{4}$, Michelle Simon ${ }^{2}$, Ann-Marie Mallon ${ }^{2}$, Sara Wells ${ }^{2}$, Elizabeth M. C. Fisher ${ }^{5 *}$, Victor L. J. Tybulewicz ${ }^{1,7 *}$

${ }^{1}$ The Francis Crick Institute, London, NW1 1AT, UK

${ }^{2}$ MRC Harwell Institute, Harwell Campus, OX11 ORD, UK

${ }^{3}$ Department of Biochemistry and Cambridge Systems Biology Centre, University of Cambridge, Cambridge, UK

${ }^{4}$ School of Psychology, Cardiff University, CF10 3AT, UK

${ }^{5}$ UCL Queen Square Institute of Neurology, London, WC1N 3BG, UK

${ }^{6}$ Imperial College Dementia Research Institute, Imperial College London, London, W12 7TA, UK

${ }^{7}$ Department of Immunology and Inflammation, Imperial College London, London W12 ONN, UK

$\S$ These authors contributed equally

Key words: Down syndrome, mouse model, craniofacial development, memory, sleep, hearing, diabetes, haematopoiesis.

\section{Summary Statement}

The Dp1Tyb mouse model of Down syndrome has an extra copy of $63 \%$ of Hsa21orthologous mouse genes. Comprehensive phenotyping shows that Dp1Tyb mice have a broad range of DS-related phenotypes.

\section{${ }^{*}$ Correspondence to:}

Victor L. J. Tybulewicz

The Francis Crick Institute, 1 Midland Road,

London, NW1 1AT, UK

Tel: +442037961612

Email: Victor.T@crick.ac.uk

ORCID iD: 0000-0003-2439-0798

or

Elizabeth M. C. Fisher

UCL Queen Square Institute of Neurology,

London, WC1N 3BG, UK

Tel: +44 2034484441

Email: elizabeth.fisher@ucl.ac.uk 


\section{ABSTRACT}

Down syndrome (DS), trisomy 21 , results in many complex phenotypes including cognitive deficits, heart defects and craniofacial alterations. Phenotypes arise from an extra copy of human chromosome 21 (Hsa21) genes. However, these dosagesensitive causative genes remain unknown. Animal models enable identification of genes and pathological mechanisms. The Dp1Tyb mouse model of DS has an extra copy of $63 \%$ of Hsa21-orthologous mouse genes. In order to establish if this model recapitulates DS phenotypes, we comprehensively phenotyped Dp1Tyb mice using 28 tests of different physiological systems and found that 468 out of 1800 parameters were significantly altered. We show that Dp1Tyb mice have wide-ranging DS-like phenotypes including aberrant erythropoiesis and megakaryopoiesis, reduced bone density, craniofacial changes, altered cardiac function, a pre-diabetic state and deficits in memory, locomotion, hearing and sleep. Thus, Dp1Tyb mice are an excellent model for investigating complex DS phenotype-genotype relationships for this common disorder.

\section{INTRODUCTION}

Down syndrome, which arises from trisomy of Hsa21, is a complex condition affecting many tissues with different severity and penetrance (Antonarakis et al., 2020). Individuals with DS have learning and memory impairment, motor deficits, disrupted sleep, shorter stature, reduced bone density, craniofacial alterations, congenital heart defects, leukaemia, diabetes, and impaired hearing and vision. People with DS are high-risk for Alzheimer's disease (AD); $~ 50 \%$ have signs of dementia by age 60 (Wiseman et al., 2015). With a prevalence of $\sim 1$ in 800 live births, DS is the most common genetic cause of intellectual disability, AD and heart defects (Antonarakis, 2017; Wiseman et al., 2015). 
Trisomy 21 was shown as the cause of DS in 1959 (Gautier and Harper, 2009; Jacobs et al., 1959; Lejeune et al., 1959), but there are still no effective treatments for most DS phenotypes, including cognitive aspects. Phenotypes likely result from increased dosage of Hsa21 genes, which comprise $~ 230$ coding genes, and many more non-coding elements (Antonarakis, 2017). Identification of dosage-sensitive Hsa21 genes causing DS phenotypes would facilitate studies of underlying pathological mechanisms, and development of new treatments. However, for most DS phenotypes, causative genes are unknown (Lana-Elola et al., 2011).

By modelling DS in mice, we can use the power of mouse genetics to find dosagesensitive genes and so investigate pathology. Two approaches have been taken. Firstly, mice have been generated with an extra human chromosome comprising most of Hsa21 (Tc1 and TcMac21 mice) (Kazuki et al., 2020; O'Doherty et al., 2005). Secondly, chromosome engineering has been used to create mouse strains with an additional copy of regions orthologous to Hsa21 (Herault et al., 2017; Moyer et al., 2020). The largest region of Hsa21 orthology (23 Mb) is on mouse chromosome 16 (Mmu16), with smaller regions on Mmu10 (3 Mb) and Mmu17 (2 Mb) (Herault et al., 2017). The Dp1Tyb and Dp1Yey strains have an extra copy of the entire Hsa21orthologous region of Mmu16 (Lana-Elola et al., 2016; Li et al., 2007). Other strains have been generated with an extra copy of smaller Hsa21-orthologous regions, allowing mapping of causative genes (Brault et al., 2015; Duchon et al., 2008; LanaElola et al., 2016; Liu et al., 2014; Liu et al., 2011; Olson et al., 2004; Pereira et al., 2009; Raveau et al., 2012; Yu et al., 2010b).

However, while several DS mouse models have been investigated for individual phenotypes, there has been no comprehensive analysis to determine if a single DS model recapitulates the breadth of DS phenotypes, validating them for the human condition. 
The Dp1Tyb mouse strain has an extra copy of 148 coding genes on Mmu16, comprising $63 \%$ of Hsa21-orthologous genes in the mouse genome, and thus replicates the majority of the gene dosage increase in DS, making it an excellent genetic model of the condition (Lana-Elola et al., 2016; Moyer et al., 2020). Here we use the extensive tests in the International Mouse Phenotyping Consortium (IMPC) (Meehan et al., 2017), augmented with further bespoke assays to comprehensively phenotype this model. We find that Dp1Tyb mice have significant changes in 468 out of 1800 parameters, displaying wide-ranging DS-like features, including decreased bone density, craniofacial changes, altered cardiac function, aberrant erythropoiesis and megakaryopoiesis, a pre-diabetic state, defective hearing, learning and memory deficits, impaired motor activity, and disrupted sleep. Thus, Dp1Tyb mice faithfully recapitulate many of the complex phenotypes found in DS and are an excellent tool for discovering causative genes and their pathological mechanisms.

\section{RESULTS}

\section{Phenotyping pipelines}

To carry out a broad phenotypic analysis, we generated Dp1Tyb and control wildtype (WT) animals on a C57BL/6J background, and analysed cohorts using wideranging procedures arranged into pipelines, with animals given specific tests at particular ages (Fig. 1). We used the IMPC pipeline (Meehan et al., 2017) to carry out a broad physiological analysis of Dp1Tyb and WT animals (cohort 1). Since cognitive and behavioural changes are DS hallmarks, we set up three pipelines for neurological aspects (cohorts 2, 3 and 6). We used flow cytometric analysis to investigate the haematopoietic system (cohort 4). Lastly, we analysed older mice $\sim 1$ year of age, for pathological changes and cardiac function (cohort 5). 
In total, mice were analysed in 28 different procedures, generating data for 1800 parameters (where both sexes were used, males, females and both sexes together are counted as separate parameters). Statistical analysis showed that using a false discovery rate of less than $5 \%$ ( $q \leq 0.05)$, Dp1Tyb mice had significant changes in 468 parameters from 22 procedures compared to WT mice (Table S1). Where there were differences between Dp1Tyb and WT mice, these were similar for both sexes, except for 15 parameters in 6 procedures showing significant sexual dimorphism $(q \leq 0.05)$.

It has been suggested that aneuploidy results in greater phenotypic variability (Beach et al., 2017). We investigated the variance of the 1450 parameters that had a numerical value and found that just 39 parameters showed a significant difference in variance between the genotypes ( $q \leq 0.05)$, with 22 and 17 of these showing larger variation in WT and Dp1Tyb mice, respectively. There was no significant difference in the coefficient of variation for these 1450 parameters between either female or male Dp1Tyb mice compared to WT controls (Fig. S1A, Table S1). Thus, Dp1Tyb mice do not show greater phenotypic variation in the parameters measured in this study.

\section{Decreased viability of Dp1Tyb mice}

Analysis at weaning from Dp1Tyb x C57BL/6J crosses, showed that only $31 \%$ of the female pups and $38 \%$ of the male pups carried the Dp1Tyb mutation, significantly less than the expected $50 \%$ proportion (Fig. S1B). This implies that $54 \%$ of female Dp1Tyb pups and 39\% of male Dp1Tyb pups had been lost prior to weaning. Since the proportion of Dp1Tyb embryos was not altered at embryonic day 14.5 (E14.5) of gestation (Lana-Elola et al., 2016), the loss must be occurring between E14.5 and weaning. 


\section{Increased expression of duplicated genes in Dp1Tyb hippocampus}

We investigated whether the additional $23 \mathrm{Mb}$ of Mmu16 in Dp1Tyb mice results in increased expression of the 148 coding genes in this region. RNA sequencing of Dp1Tyb and WT adult hippocampus showed that of the 87 expressed genes in the duplicated region, 75 were significantly upregulated, and no genes were significantly downregulated (Fig. 2). The mean $( \pm S D)$ upregulation was $1.43( \pm 0.28)$-fold, similar to the expected 1.5-fold increase. Thus, the additional $23 \mathrm{Mb}$ region of Mmu16 results in increased gene expression in line with gene copy number.

\section{Dp1Tyb mice have altered skeletal development}

Body weights from 4 to 16 weeks of age, showed that male Dp1Tyb mice weighed less than WT mice at 4 weeks, but caught up afterwards, with no differences at later ages (Fig. 3A); there were no significant differences in female mice.

People with DS are typically short in stature, have lower bone density and characteristic changes in craniofacial morphology, such as brachycephaly (front to back shortening of the skull), and increased body fat content (Baptista et al., 2005; Costa et al., 2018; Gutierrez-Hervas et al., 2020; Korenberg et al., 1994; LaCombe and Roper, 2020; Vicente et al., 2020). X-ray analysis at 14 weeks of age showed that Dp1Tyb mice had shorter tibia and skulls (Fig. 3B, C), and the Combined SHIRPA and Dysmorphology (CSD) analysis (Rogers et al., 1997) revealed that they had abnormally shaped heads, snouts and lips (Tables S2, S3). Dual Energy X-Ray Absorption (DEXA) showed that Dp1Tyb mice had reduced bone mineral density and content, without changes in fat or lean mass which was confirmed by ECHO-MRI (Fig. 3D, Fig. S1C). Thus, Dp1Tyb mice have substantially altered bone growth resulting in skeletal dysmorphology. 


\section{Dp1Tyb mice have enlarged spleens and no $A \beta$ deposition in the hippocampus}

Organ weights showed that at 16 weeks Dp1Tyb mice had slightly altered weights of heart and kidneys and at 57 weeks had reduced liver weights (Fig. S1D, E). However, the largest change was an increase in Dp1Tyb spleen weights at both ages (Fig. S1D, E). Histology showed increased extramedullary haematopoiesis in Dp1Tyb spleens (Fig. S2A, Table S4). Significant changes were also seen in the portal areas of the liver with bile duct hyperplasia and vascular anomalies (Fig. S2B).

With the exception of ears (see later), histological analysis of other organs in Dp1Tyb mice showed no significant findings with any changes recorded being within the expected normal variation in pathology for the C57BL/6J background (Table S4). Given the high prevalence of AD in DS (Wiseman et al., 2015), we also examined the hippocampus of 1-year old mice for the presence of $A \beta$ amyloid. While $A \beta$ deposition was readily seen in the $A \beta$-overexpressing J20 mouse AD model, we detected no deposition in Dp1Tyb or control mice (Fig. S2C).

\section{Increased metabolic rate in Dp1Tyb mice}

People with DS have a reduced resting metabolic rate (Allison et al., 1995; Luke et al., 1994). In contrast, indirect calorimetry showed that Dp1Tyb mice produced more $\mathrm{CO}_{2}\left(\mathrm{VCO}_{2}\right)$, used more $\mathrm{O}_{2}\left(\mathrm{VO}_{2}\right)$, and had higher heat production indicating an increased metabolic rate and an elevated respiratory exchange ratio (RER) (Fig. S3A). The latter suggests that the mice may be using a higher ratio of carbohydrate to fat as a fuel source. 


\section{Dp1Tyb mice have altered heart function}

$\sim 40 \%$ of neonates with DS have congenital heart defects, typically ventricular or atrioventricular septal defects (VSD or AVSD) (Vis et al., 2009). Dp1Tyb embryos have a high prevalence of VSD and AVSD at E14.5 of gestation, resembling defects seen in DS (Lana-Elola et al., 2016). Analysis of heart function at 12 weeks by echocardiography showed that Dp1Tyb animals had a slower heart rate, increased stroke volume, increased cardiac output, increased end-diastolic and end-systolic diameters, and increased left ventricular internal diameter at diastole and systole compared to WT mice (Fig. 4A). ECG measurements showed longer QT, corrected QT (QTC), JT and T peak times and larger amplitude of the $R$ wave, consistent with increased left ventricle size (Fig. 4B, C). These changes were not progressive, since echocardiography showed no changes in cardiac function in 57-week old Dp1Tyb mice (Fig. S3B).

\section{Increased breathing volumes in Dp1Tyb mice}

To analyse lung function, mice were placed into whole body plethysmography chambers and breathing recorded for $5 \mathrm{~min}$ in normoxic conditions, then for $5 \mathrm{~min}$ in hypoxia $\left(10 \% \mathrm{O}_{2} / 3 \% \mathrm{CO}_{2}\right)$ and finally the mice were returned to normoxia for $5 \mathrm{~min}$. WT and Dp1Tyb mice responded to hypoxia by increasing breathing volumes as measured per minute and per breath (tidal). However, under both normoxic and hypoxic conditions, Dp1Tyb mice had increased minute and tidal volumes compared to WT mice (Fig. 5A). This increased rate of breathing may be related to the increased $\mathrm{O}_{2}$ consumption.

\section{Dp1Tyb mice have otitis media and impaired hearing}

More than half of children with DS have impaired hearing caused by otitis media, a middle-ear inflammation (Kreicher et al., 2018; Maris et al., 2014; Shott et al., 2001). Notably, pathological analysis showed that Dp1Tyb mice had otitis media (Table S4). 
To examine if this might cause hearing deficits in Dp1Tyb mice, we analysed their auditory brainstem response, and found that compared to WT controls, Dp1Tyb mice had substantially higher minimum sound intensity thresholds required to elicit a brainstem response when challenged with sounds at $8 \mathrm{kHz}$ and $16 \mathrm{kHz}$ and with clicks consisting of mixed frequencies (Fig. 5B), indicating impaired hearing.

Children and adults with DS have an increased prevalence of eyesight defects in multiple eye structures, including the lid, iris, cornea, lens and retina (Krinsky-McHale et al., 2014). We examined the eyes of Dp1Tyb mice but found no visible defects within the eye (Table S5).

\section{Dp1Tyb mice show characteristics of a pre-diabetic state}

DS results in increased prevalence of type 1 and type 2 diabetes (Alexander et al., 2016; Anwar et al., 1998; Bergholdt et al., 2006; Johnson et al., 2019). Thus, we measured the ability of Dp1Tyb and WT mice to clear an intra-peritoneal injection of glucose; we found no difference, thus Dp1Tyb are not diabetic at 13 weeks of age (Fig. S3C).

We collected plasma from free-fed and fasted mice, and measured levels of multiple analytes and hormones. We found reduced levels of glucose in fasted but not freefed Dp1Tyb male mice (Fig. S3D, E). Other analytes were unaffected, except for raised levels of inorganic phosphorus and aspartate aminotransferase (AST), decreased alpha-amylase in free-fed mice, and increased glucagon and adiponectin in fasted mice (Fig. S3D, F). A slightly elevated AST/alanine aminotransferase (ALT) ratio (1.66 $\vee 1.19$ in Dp1Tyb $\vee$ WT mice, Table S1) may indicate liver pathology (Salaspuro, 1987), but this will require further investigation. Increased adiponectin has been reported in people with DS (Corsi et al., 2009). 
We used mass spectrometry to measure levels of lipids in plasma from free-fed and fasted mice. Orthogonal partial least squares discriminant analysis (OPLS-DA) showed that for both free-fed and fasted mice, lipid composition was distinct between Dp1Tyb and WT mice and between males and females (Fig. 5C, D). The differences in lipid composition were larger for fasted mice, with 85 out of 285 lipids showing a significant difference, compared to 11 out of 285 lipids in free-fed mice (Table S1). Dp1Tyb mice had significantly reduced levels of many species of both saturated and unsaturated lysophosphatidylcholine (LPC) and phosphatidylcholine (PC) lipids, and increased levels of many triglycerides (Fig. 5E). Decreased levels of LPC phospholipids and increased triglycerides are associated with a pre-diabetic state (Barber et al., 2012; Ferrannini et al., 2013; Kotronen et al., 2009; Suvitaival et al., 2018; Wang-Sattler et al., 2012). Furthermore, higher plasma triglycerides are found in people with non-alcoholic fatty liver disease (NAFLD) and in hepatic steatosis, a clinical subtype of NAFLD (Oresic et al., 2013; Sanders et al., 2018), suggesting that Dp1Tyb mice have characteristics of a pre-diabetic state with associated liver pathology.

\section{Increased erythropoiesis and megakaryopoiesis in Dp1Tyb mice}

$10-15 \%$ of neonates with DS present with transient abnormal myelopoiesis (TAM), a pre-leukaemic condition characterised by an accumulation of circulating megakaryoblasts (Bhatnagar et al., 2016; Garnett et al., 2020). Most children with TAM undergo spontaneous regression, but in $10-20 \%$ of cases, the condition progresses to an acute megakaryoblastic leukaemia (Bhatnagar et al., 2016; Garnett et al., 2020). In addition, children with DS have a 20 -fold higher risk of developing acute lymphoblastic leukaemia (DS-ALL), usually derived from B-cell progenitors (Lee et al., 2016). 
Haematological analysis showed that Dp1Tyb mice have a macrocytic anaemia characterised by reduced numbers of erythrocytes, a reduced haematocrit, and reduced haemoglobin concentration, but larger erythrocytes with more haemoglobin per cell (Fig. 6A). Analysis of other haematological parameters showed no changes, except for an increase in monocytes (Fig. 6A, Fig. S4).

We carried out comprehensive flow cytometric analysis of haematopoietic cells in the bone marrow, spleen, lymph nodes, peritoneal cavity and blood of Dp1Tyb and control mice (Fig. S5, S6). Dp1Tyb bone marrow had unchanged numbers of erythroid progenitors and immature and mature megakaryocytes (Fig. S7A), but reduced percentages of developing $B$-lineage subsets (pro- $B$, pre- $B$, immature and mature B cells) (Fig. S7B). Dp1Tyb mice had an increased number of splenocytes (Fig. 6B), in keeping with the increased splenic size (Fig. S1D). Many splenic lymphoid subsets were altered, including increased numbers of marginal zone B cells, germinal centre B cells, plasma cells, and multiple subsets of $\mathrm{CD} 4^{+} \mathrm{T}$ cells naïve, effector, regulatory and $T$ follicular helper $T$ cells (Fig. 6B). However, the largest changes were substantial increases in the numbers and percentages of splenic pro-erythroblasts (ProE), EryA and EryB erythroid progenitors and immature and mature megakaryocytes (Fig. 6B, Fig. S8), explaining the increased extramedullary haematopoiesis of Dp1Tyb spleens (Fig. S2A, Table S4).

Blood analysis showed no changes in percentages of leukocytes, including monocytes (Fig. S9A), whereas in Dp1Tyb peripheral and mesenteric lymph nodes we found small increases in B cells, and small reductions in $\mathrm{CD}^{+}$and $\gamma \delta \mathrm{T}$ cells (Fig. S9B, C). In the peritoneal cavity conventional B2 cells were increased, with reduced percentages of B1a cells (Fig. S9D). Finally, analysis of developing T cell subsets in the thymus showed that Dp1Tyb mice had reduced numbers and percentages of the early double negative 1 (DN1), DN2 and DN4 cells, but increased numbers of 
intermediate and mature $\mathrm{CD}^{+}$single positive thymocytes (Fig. S10A, B). Thus, Dp1Tyb mice have increased erythropoiesis and megakaryopoiesis in the spleen and increases in some B and $\mathrm{T}$ cell subsets. Other lymphoid tissues showed small changes in B and $T$ cell subsets.

\section{Dp1Tyb mice have impaired short-term associative memory}

DS is the most common genetic cause of intellectual disability (Grieco et al., 2015), arising from cognitive impairment, with delayed acquisition of many developmental milestones (Lott and Dierssen, 2010). Children and adults with DS have a decreased ability to learn and show deficits in both short-term and long-term memory. DS results in poorer processing of verbal information, slower language acquisition, impaired attention, poor response inhibition and slower task planning.

We analysed Dp1Tyb mice in behavioural tests. The open field test assesses anxiety, activity and exploratory behaviour: mice are placed in an arena and monitored for the time they spend in the centre of the arena compared to the periphery, as well as movement speed and distance travelled. Compared to controls, Dp1Tyb mice visited the centre of the arena less frequently, spent less time in the centre, moved at slower speeds and travelled shorter distances (Fig. 7A). Thus, Dp1Tyb mice are less active and the reduced time spent in the centre indicates that they may be more anxious, although this may also be the result of reduced movement. This analysis was extended using an elevated zero maze which assesses the conflict between exploratory behaviour of novel environments and avoidance of well-lit open areas. This showed no difference between Dp1Tyb and WT mice in the time spent in open versus closed arms of the maze, implying that at least in this assay Dp1Tyb mice do not have increased anxiety (Fig. S11A). This apparent difference in anxiety may be due to differences in anxiolytic drivers between the two tests. 
Dp1Tyb and control mice were assessed using the pre-pulse inhibition of acoustic startle test, which measures sensorimotor gating mechanisms through exposing mice to a loud startle sound, which may be preceded by a quieter pre-pulse tone. As the intensity of the pre-pulse tone increases, the neural response to the following startle noise is hindered, resulting in decreased flinching. Such pre-pulse inhibition (PPI) is often impaired in neurological conditions such as schizophrenia (Braff et al., 2001). Dp1Tyb and WT mice showed increased PPI with increasing pre-pulse tone intensity, but male Dp1Tyb mice were significantly impaired in this response (Fig. 7B). Since Dp1Tyb mice have impaired hearing (Fig. 5B), it is unclear if the decreased PPI is due to this sensory deficit or to defective sensorimotor gating.

In a fear conditioning test, we assessed memory of an aversive foot shock experience, determining if the animal can associate it with context, a novel chamber, or with a cue in the form of an auditory conditioned stimulus. Responses to the context or cue were measured by the time the animal spent freezing. Dp1Tyb mice responded at least as well as WT mice to both context and cue, indicating no defect in associative memory of the aversive response (Fig. 7C). However, Dp1Tyb mice spent more time freezing when placed into novel chambers (baseline and pre-cue responses) again suggesting that they may be more anxious.

We measured spatial memory using an object-in-place test. The mice were placed in an arena with three distinct objects for two 10-min sample phases, 10 min apart. The mice were then removed for either 10 min or $3 \mathrm{~h}$ before being placed back in the arena for the test phase in which the locations of two of the objects had been switched. Contact times with objects that had been moved were compared to contact time with the object that had not been moved using a discrimination ratio. We found that Dp1Tyb mice performed worse than WT mice when placed back into the arena after a 10 min delay - unlike WT mice, their discrimination ratio was not significantly 
different from chance (0.5) (Fig. 7D). Conversely, Dp1Tyb mice performed as well as WT mice after a $3 \mathrm{~h}$ delay. Thus, in this paradigm, Dp1Tyb mice have impaired shortterm (10 min) but not longer-term (3 h) associative recognition memory.

\section{Dp1Tyb mice have disrupted sleep}

A notable co-morbidity in DS is sleep disruption characterised by poor sleep initiation and maintenance, both of which may contribute to cognitive impairment (Grieco et al., 2015). We assessed sleep in Dp1Tyb mice by tracking movement over a $24 \mathrm{~h}$ period in a $12 \mathrm{~h}$ light/12 $\mathrm{h}$ dark cycle, scoring cumulative periods of immobility of $>40$ s, which show high correlation with sleep (Fisher et al., 2012). Compared to WT mice, this cumulative immobility score was substantially reduced in Dp1Tyb mice, while immobility bout lengths were significantly shorter, particularly during the light phase where most sleep is scored (Fig. 7E). Thus, Dp1Tyb mice sleep less than WT controls and show a higher number of short-duration bouts, indicating a disrupted sleep pattern.

\section{Dp1Tyb mice have impaired motor function}

Children with DS have impaired motor skills and postural control (Cardoso et al., 2015; Malak et al., 2015; Spano et al., 1999). We assessed motor function in Dp1Tyb mice using multiple assays. Dp1Tyb mice spent less time in spontaneous wheel running, carrying out fewer runs and rotations, running at lower speeds and for shorter distances (Fig. 8A). In the Locotronic test where mice walk along a horizontal ladder with evenly spaced rungs, Dp1Tyb mice made more errors, indicating defects in motor coordination (Fig. 8B). Defective movement of Dp1Tyb mice was also seen in the CSD test (Fig. 8C). Dp1Tyb mice had normal grip strength indicating that altered locomotor activity was not due to altered muscle tone (Fig. S11B). Thus, Dp1Tyb mice have substantially impaired motor function. 


\section{DISCUSSION}

To understand pathological mechanisms in DS, we need animal models that reflect the genetic and phenotypic complexity of this chromosomal disorder. Comprehensive phenotyping of the Dp1Tyb mouse model of DS, shows significant differences compared to WT mice in 468 out of 1800 parameters across 22 different tests. Thus, an extra copy of 148 genes has substantial phenotypic consequences in many physiological domains. Importantly, many of the phenotypes in Dp1Tyb mice resemble those in people with DS (Table S6).

The reduced perinatal viability of Dp1Tyb pups may be caused by congenital heart defects. At E14.5, around 25\% of Dp1Tyb embryos have AVSD, and a further $35 \%$ have VSD (Lana-Elola et al., 2016), similar to the defects reported in $\sim 40 \%$ of babies with DS. It is possible that pups with AVSD die perinatally, potentially accounting for the reduced viability.

Analysis of skeletal structures showed that Dp1Tyb mice have reduced bone density, shorter tibia and altered craniofacial structures, in particular brachycephaly, all of which are typical of DS (Baptista et al., 2005; Costa et al., 2018; Herrera et al., 2020; LaCombe and Roper, 2020; Vicente et al., 2020). In agreement with this, Dp1Tyb mice have shorter body and femur length (Thomas et al., 2020). Similar craniofacial changes have been seen in the Dp1Yey mouse strain (Starbuck et al., 2014; Takahashi et al., 2020), which, like Dp1Tyb mice, was generated by Cre/loxP chromosome engineering and has an extra copy of the same Hsa21-orthologous genes as Dp1Tyb (Li et al., 2007). Indeed, where comparable analysis has been carried out, Dp1Tyb and Dp1Yey mice have very similar phenotypes (Table S6). 
ECG studies in DS individuals without congenital heart defects showed increased Twave length, similar to that seen in Dp1Tyb mice (Küçük et al., 2018). Cardiac function was altered in 12-week old Dp1Tyb mice with a slower heart rate, and increased cardiac output, stroke volume and left ventricular diameters. Increased cardiac output and stroke volume could be caused by abnormal fluid loading from a left-right shunt such as a septal defect. However, this would be expected to cause an increased heart rate. A more likely explanation is that a shunt during embryonic development would reduce the effective stroke volume leading to renal hypoperfusion and compensatory salt and water retention to increase circulatory volume. If the shunt closed perinatally, the increased circulatory volume would result in the observed increased stroke volume and cardiac output with a reactive lower heart rate. Subsequent diuresis may have normalised the circulatory volume thereby resulting in normal cardiac function in the older 57-week old mice.

Lipidomic and clinical chemistry analysis of plasma showed that Dp1Tyb mice have characteristics of a pre-diabetic state with hepatic steatosis, conditions that are seen in people with DS (Dierssen et al., 2020). Further work is needed to determine if the animals could be induced to develop glucose intolerance, for example by being fed a high-fat diet.

Dp1Tyb mice have a macrocytic anaemia alongside increased splenic erythropoiesis, and megakaryopoiesis, resembling a pre-leukaemic condition. However, they do not develop overt megakaryoblastic leukaemia, likely because progression to leukaemia requires mutations in Gata1 and other genes (Bhatnagar et al., 2016; Garnett et al., 2020). Similar macrocytic anaemia and elevated megakaryopoiesis are found in several other mouse DS models carrying three copies of Hsa21-orthologous Mmu16 genes (Alford et al., 2010; Carmichael et al., 2009; Kirsammer et al., 2008). We 
detected no DS-ALL, however this leukaemia also requires additional mutations (Lee et al., 2016).

Sensory deficits are often seen in DS, including in hearing and vision (Grieco et al., 2015). Dp1Tyb mice have defective hearing, which is likely due to otitis media, a common condition in DS (Kreicher et al., 2018; Maris et al., 2014; Shott et al., 2001). We found no eye defects in the mice, but further studies are needed to evaluate visual acuity. In a previous study we found no defects in nociception or proprioception in Dp1Tyb mice (Watson-Scales et al., 2018).

Dp1Tyb mice have defective short-term memory, disrupted sleep and motor deficits, neurological features that have also been reported in people with DS (Cardoso et al., 2015; Grieco et al., 2015; Malak et al., 2015; Spano et al., 1999). Previously we showed that these animals have reduced theta wave frequency in the medial prefrontal cortex and the hippocampus, and increased theta to high gamma phaseamplitude coupling in the hippocampus, along with deficits in spatial working memory (Chang et al., 2020). Memory and motor deficits have also been reported in the related Dp1Yey mice (Aziz et al., 2018; Pinto et al., 2020; Watson-Scales et al., 2018; Yu et al., 2010a). The motor deficits in these mice may be partly due to motor neuron loss, which we also found in human DS (Watson-Scales et al., 2018). The disrupted sleep of Dp1Tyb mice may have a neurological basis, but analysis of Dp1Yey mice showed reduced upper airway volume, suggesting that apnoea may affect sleep in these animals (Takahashi et al., 2020). 
$A D$ in $D S$ is most likely caused by a third copy of the APP gene on Hsa21 (Wiseman et al., 2015). Dp1Tyb mice have three copies of $A p p$ but show no deposition of $A \beta$ in the hippocampus. This is not surprising, because amyloid pathology is only seen in mice expressing mutant amyloidogenic human APP proteins; overexpression of wildtype mouse APP is not sufficient (Myers and McGonigle, 2019).

Muscle hypotonia and increased body fat are features of DS (Antonarakis et al., 2004; Gutierrez-Hervas et al., 2020), but neither was seen in Dp1Tyb mice. Furthermore, Dp1Tyb mice have higher $\mathrm{VO}_{2}, \mathrm{VCO}_{2}$, breathing rates and a higher $\mathrm{RER}$, in contrast to people with $\mathrm{DS}$ who show lower $\mathrm{VO}_{2}$ and $\mathrm{VCO}_{2}$, and reduced breathing rates and RER (Boonman et al., 2019). Thus, Dp1Tyb mice do not model the reduced cardiorespiratory function in DS. These 'missing' phenotypes may be due to increased dosage of Hsa21 genes whose orthologues are in the Mmu10 and Mmu17 regions. To investigate this, a broad phenotypic analysis will be needed of mice that have extra copies of these regions (Yu et al., 2010b). Furthermore, the analysis presented here was carried out on a single genetic background (C57BL/6J). It is possible that analysis on other backgrounds would reveal further phenotypes.

In summary, we have performed the first comprehensive phenotypic analysis of a single mouse model for DS, revealing that Dp1Tyb mice have many DS-like phenotypes and thus can be used to investigate complex underlying pathogenetic mechanisms. Importantly, the existence of a complete panel of mouse strains with extra copies of shorter regions of Mmu16 will allow mapping and identification of the causative dosage-sensitive genes (Lana-Elola et al., 2016). 


\section{Acknowledgments}

We thank the Flow Cytometry and Biological Research Facility of the Francis Crick Institute for flow cytometry and animal husbandry respectively and Probir Chakravarty for help with bioinformatics analysis. We thank Timothy Dawes for useful discussions. VLJT and EMCF were supported by the Wellcome Trust (grants 080174, 098327 and 098328) and VLJT was supported by the UK Medical Research Council (Programme U117527252) and by the Francis Crick Institute which receives its core funding from Cancer Research UK (FC001194), the UK Medical Research Council (FC001194), and the Wellcome Trust (FC001194). HC, PK-B and SW were supported by the EC FP7 Infrafrontier-13 project (grant number 312325). SG, MS and AMM were supported by the Medical Research Council (MC_U142684171) and National Human Genome Research Institute of the National Institutes of Health (UM1HG006370). For the purpose of Open Access, the author has applied a CC-BY public copyright licence to any Author Accepted Manuscript version arising from this submission.

\section{Competing interests}

The authors declare no financial or competing interests.

\section{Author contributions}

EL-E, HC, SW-S, JM-W, DG, MN, AS, TH, PK-B, CLS, ER, GTB, HM, TC, JT and SN performed experiments; EL-E, HC, SG, JM-W, TH, GTB, HM, TC, MLS, PMN, JG, MG, MS, and VLJT analysed data; HC, PMN, JG, MG, MS, A-MM, SW, EMCF and VLJT supervised the work; EL-E and VLJT wrote the manuscript. 


\section{MATERIALS AND METHODS}

\section{Mice}

C57BL/6J.129P2-Dp(16Lipi-Zbtb21)1TybEmcf (Dp1Tyb) mice (Lana-Elola et al., 2016) were bred in specific-pathogen free conditions at the Mary Lyon Centre (MRC Harwell) and at the Francis Crick Institute by backcrossing to C57BL/6J mice. All mice analysed had been backcrossed to the C57BL/6J background for at least 10 generations. Mice in cohorts 1 and 2 were weighed once a week for the duration of each phenotyping pipeline. All tests were carried out by experimenters who were blind to the genotype of the mouse. Zbtb20 ${ }^{\text {Tg(PDGFB-APPSwInd)20Lms }}$ mice (J20) (Mucke et al., 2000) were bred on a C57BL/6J background at the UCL Institute of Neurology. All animal work was carried out under Project Licences granted by the UK Home Office.

\section{Analysis of RNA sequencing data}

Using our RNA sequencing data from the hippocampi of 5 WT and 5 Dp1Tyb mice aged 18.5-19 weeks (Ahlfors et al., 2019), we calculated the fold change in expression for the genes in the duplicated region on Mmu16 (Lipi to Zbtb21), using the TPM (transcripts per million reads) measure, excluding genes whose expression summed over all 10 samples was < 1 TPM. Significantly differentially expressed genes were identified using DEseq2 (Love et al., 2014).

\section{International Mouse Phenotyping Consortium (IMPC) pipelines}

The pipeline of tests for cohort 1 is closely based on those used by the IMPC pipeline (Meehan et al., 2017). More detailed descriptions of these protocols are available on the IMPRESS website (www.mousephenotype.org/impress). 


\section{X-ray analysis}

X-Ray images of the mice were collected whilst the mice were anaesthetised with isoflurane. A lateral view, a dorsal-ventral view and a skull image were all taken to enable a full qualitative assessment of the integrity of the skeleton. A $2 \mathrm{~cm}$ lead bar was utilised to provide a calibration scale for the measurement of the tibia length.

\section{Combined SHIRPA and dysmorphology analysis (CSD)}

The combined SHIRPA and dysmorphology test identifies physical and behavioural abnormalities through observation (Rogers et al., 1997). Mice were individually observed in a series of environments to test a range of attributes including hearing, visual placement, activity, motor coordination, righting ability as well as morphological features.

\section{DEXA}

The body composition of the mice was assessed using the PIXImus Dual Energy XRay Absorption machine (GE Medical Systems, USA). Mice were anaesthetised with ketamine/xylazine and high energy X-Ray images were automatically analysed for fat tissue content, lean tissue content, bone mineral density and bone mineral content. While anaesthetised, the mice also underwent the auditory brain stem response test (see below).

\section{ECHO-MRI}

Body composition of the mice was assessed using an EchoMRI whole body composition analyser (Echo Medical System, Houston, USA). The analysis output quantified fat mass, lean mass and water content of the mice. 


\section{Histopathology}

Histopathology was performed on all major organs of four male and four female mice of each genotype (WT and Dp1Tyb) at the end of the cohort 1 pipeline. Following necropsy, heart, spleen, and kidneys were weighed. These and other tissues were fixed in $10 \%$ neutral buffered formalin, wax embedded, sectioned and stained with haematoxylin and eosin. Slides were reviewed by two veterinary pathologists. Significant findings were scored using a non-linear semi-quantitative approach (Scudamore, 2014).

\section{Histology for $A \beta$}

Immediately following euthanasia, the brain was removed and immersion fixed in $10 \%$ buffered formal saline (Pioneer Research Chemicals, UK). After 48-72 $\mathrm{h}$, the brain was blocked into $3 \mathrm{~mm}$ coronal slices using an adult mouse brain matrix and slices were embedded in paraffin wax using a Sakura VIP6 Automated Vacuum Tissue Processor. A series of $4 \mu \mathrm{m}$ sections comprising the dorsal hippocampus were cut and mounted onto SuperFrost Plus glass slides. For amyloid- $\beta$ immunostaining, sections were dewaxed, rehydrated through an alcohol series to water, pre-treated with $80 \%$ formic acid for $8 \mathrm{~min}$ followed by washing in distilled water for 5 min. Sections were loaded as wet mounts into a Ventana Discovery XT automated stainer, where further pre-treatment for $30 \mathrm{~min}$ with mild CC1 (EDTA Boric Acid Buffer, $\mathrm{pH}$ 9.0) and blocking for 8 min with Superblock (Medite, \#88-4101-00), were performed prior to incubation for $8 \mathrm{~h}$ with biotinylated mouse monoclonal antibody $4 \mathrm{G} 8(2 \mu \mathrm{g} / \mathrm{ml}$, Sigma-Aldrich SIG-39240 Beta-Amyloid). Staining was completed with the Ventana XT DABMap kit and a haematoxylin counterstain, followed by dehydration and permanent mounting with DPX. All images were acquired using a Leica DM2000 LED microscope fitted with a MC190 HD camera. 


\section{Calorimetry}

The metabolic rate of the mice was assessed using indirect calorimetry. Mice were individually housed overnight for $21 \mathrm{~h}$ in Phenomaster cages (TSE Systems, Germany) with standard bedding and igloos. Oxygen consumption $\left(\mathrm{VO}_{2}\right)$ and carbon dioxide production $\left(\mathrm{VCO}_{2}\right)$ were simultaneously measured through an indirect gas calorimetry system air sampling, and from this the respiratory exchange ratio $\left(\mathrm{VCO}_{2} / \mathrm{VO}_{2}\right)$ and heat production were calculated. Activity was monitored using a photobeam-based system from which speed of movement of the animal was calculated.

\section{Echocardiogram and ECG}

The cardiac phenotype was assessed using both echocardiogram and electrocardiogram (ECG). For mice in cohort 1, these procedures were conducted at the same time. Mice were anaesthetised under isoflurane and the ECG was recorded using BioAmp (AD Instruments, Australia) and LabChart Pro software (AD Instruments). For the echocardiogram, the left ventricle of the heart was imaged and analysed using the Vevo770 (Fujifilm Visualsonics, USA).

\section{Plethysmography}

Mice were individually placed into whole body plethysmography chambers (Data Sciences International) and allowed to acclimatise for $30 \mathrm{~min}$. Breathing volumes of the mice were recorded initially for $5 \mathrm{~min}$ in room air (baseline, normoxia), then for 5 min in $10 \% \mathrm{O}_{2} / 3 \% \mathrm{CO}_{2}$ (hypoxia) and a further $5 \mathrm{~min}$ in room air (recovery, normoxia). Any mice experiencing breathing problems were removed from the chambers immediately. 


\section{Auditory brain stem response}

To determine their hearing range, mice were anaesthetised with ketamine/xylazine and the auditory brain stem response was recorded in response to either a click sound or to tones at $8 \mathrm{kHz}, 16 \mathrm{kHz}$ and $32 \mathrm{kHz}$, using subdermal electrodes placed on the vertex and the left and right bulla (Hardisty-Hughes et al., 2010; Ingham et al., 2011). Intensity of the sounds was increased from $0 \mathrm{~dB}$ to $85 \mathrm{~dB}$ sound pressure level (SPL) and the threshold of the response was determined as the lowest sound intensity that gave a recognisable ABR waveform response.

\section{Opthalmoscopy}

Eye morphology and visual response of the mice was assessed using a slit lamp and an opthalmascope. Tropicamide was used to dilate the pupils and observations were manually scored for morphological or response abnormalities.

\section{Glucose tolerance test}

Mice were fasted overnight for $18 \mathrm{~h}$. A sample of blood was analysed from the tail, to determine the fasted blood glucose concentration using the Accu-Chek glucose meter (Abbott, UK). The mice were injected intraperitoneally with $20 \%$ glucose solution ( $2 \mathrm{~g}$ glucose/kg body weight). Blood glucose measurements were taken again at 15, 30, 60 and 120 min after injection of glucose.

\section{Blood collection}

Mice were anaesthetised with isoflurane and blood collected under anaesthesia from the retro-orbital sinus into either Lithium-Heparin coated tubes for clinical chemistry and into EDTA-coated tubes for haematology. The mice were either free-fed (cohort 1) or fasted overnight for $18 \mathrm{~h}$ (cohort 2). 


\section{Clinical chemistry and ELISA}

Lithium heparin samples from free-fed and fasted mice were kept on wet ice and centrifuged within $1 \mathrm{~h}$ of collection for $10 \mathrm{~min}$ at 5,000 $\mathrm{xg}$ in a refrigerated centrifuge at $8^{\circ} \mathrm{C}$. The resulting plasma samples were frozen until analysis. Clinical chemistry of free-fed plasma was analysed with a Beckman Coulter AU680 clinical chemistry analyser using reagents and settings recommended by the manufacturer for the analysis of alanine aminotransferase (ALT), albumin, alkaline phosphatase (ALP), alpha-amylase, aspartate aminotransferase (AST), calcium, chloride, creatinine kinase, free fatty acids, fructosamine, glucose, glycerol, HDL-cholesterol, inorganic phosphorus, iron, potassium, sodium, total bilirubin, total protein, triglycerides and urea. In addition, glucose and triglycerides were also measured in plasma from fasted mice. Insulin, glucagon, leptin and adiponectin were measured in plasma from fasted mice using ELISA kits from Millipore (EZRMI-13K), Mercodia (10-1281-01), Biovendor (RD291001200R) and R\&D Systems (MRP300) respectively.

\section{Lipidomic analysis of plasma}

To profile the lipidome, $15 \mu \mathrm{L}$ plasma from either free-fed or fasted mice was analysed. Lipids were extracted using $250 \mu \mathrm{L}$ methanol, sonicated, centrifuged and the supernatant was dried under nitrogen. Extracts were reconstituted in $150 \mu \mathrm{L}$ of $1 / 2(\mathrm{v} / \mathrm{v})$ methanol/water and $2 \mu \mathrm{L}$ was analysed using a Waters Xevo G2 Quadrupole Time of Flight (Q-ToF) mass spectrometer (MS) connected to a Waters Acquity ultra-performance liquid chromatogram (UPLC) (Milford, MA, USA). Chromatography was performed using a Waters Acquity UPLC CSH C18 $1.7 \mu \mathrm{m}$, $100 \times 2.1 \mathrm{~mm}$ column, a linear gradient consisting of solvent $\mathrm{A}$ (10 mM ammonium formate in 60/40 (v/v) acetonitrile/water) and solvent $\mathrm{B}$ (10 mM ammonium formate in 10/90 (v/v) acetonitrile/propan-2-ol) (flow rate $=0.4 \mathrm{~mL} / \mathrm{min}$; temp $=55^{\circ} \mathrm{C}$; starting

conditions $45 \% \mathrm{~B}, 7.5 \mathrm{~min} 98 \% \mathrm{~B})$. Ions were detected in positive mode with a source temperature of $12^{\circ} \mathrm{C}$, desolvation temperature of $550^{\circ} \mathrm{C}$, capillary voltage of 
$1.5 \mathrm{kV}$, cone voltage of $30 \mathrm{~V}$, cone gas flow of $50 \mathrm{~L} / \mathrm{h}$ and desolvation gas flow of 900 L/h. Data was converted to netCDF format and the matchedFilter peak-finding algorithm of the xcms software (Smith et al., 2006) was used to identify mass peaks. Annotation of lipids was based on exact mass using the LipidMaps database (https://lipidmaps.org/), fragmentation and chromatographic retention time. Data was processed using OPLS-DA within the SIMCA package (Umetrics, Umea, Sweden) and univariate statistics as described below.

\section{Haematology}

Full blood counts and differential analyses of whole blood samples collected from free-fed mice (cohort 1) in EDTA-coated tubes were performed with a Siemens Advia 2120 analyser using reagents and settings recommended by the manufacturer.

\section{Flow Cytometry}

Single cell suspensions from spleen, bone marrow, thymus, mesenteric and peripheral lymph nodes, peritoneal cavity and blood were depleted of erythrocytes using ACK lysis buffer as previously described (Schweighoffer et al., 2013), before staining cells with a mixture of antibodies in PBS containing the live/dead marker Zombie Aqua (BioLegend). Antibodies against the following antigens were used [indicating antigen-fluorophore (clone)]: B220-BV605 (RA3-6B2), B220-FITC, B220PE, CD3e-PE (145-2c11), CD11b-FITC (M1/70), CD11c-PerCP/Cy5.5 (N418), CD19 APC (1D3), CD23-APC (B3B4), CD38-PE (90), CD42d-APC (1C2), CD62L-BV711 (MEL-14), CD49b-FITC (Dx5), CD115-PE (AFS98), CD138-PE/cy7 (281-2), CXCR5BV785 (L138D7), Gr-1-PE (RB6-8C5), GR-1-FITC, Ly6C-BV711 (HK1.4), Ly6G-FITC (1A8), PD-1-PE/Cy7 (29F.1A12), TCR $\gamma \delta-B V 605$ (GL3) and Thy1.2-BV605 (30-H12) from BioLegend; B220-APC/eF780, CD2-PE (RM2-5), CD3\&-FITC, CD4-APC (RM45), CD5-PE (53-7.3), CD8-FITC (53-6.7), CD8-PE, CD11b-eF450, CD21-APC/eF780 
(4E3), CD25-PE (PC61.5), CD44-APC (IM7), CD71-PE (RI7 217.1.4), CD73-PE/Cy7 (eBioTY-11.8), CD93-APC (AA4.1), Fas-PE/Cy7 (Jo), F4/80-APC (BM8), IgD-eF450 (11-26), NK1.1-PE/Cy7 (PK136) and TCR $3-P e r C P / C y 5.5$ (H57-597) from eBioscience; CD41-FITC (MWReg30), Fas-PE-CF594, IgG1-APC (X56), PD-L2BV421 (Ty25) and TER-119-BV421 (TER-119) from BD Biosciences. Goat-antimouse IgM Fab-FITC was purchased from Jackson ImmunoResearch. To exclude lineage $^{+}$cell populations, cells were stained with antibodies against B220, CD $3 \varepsilon$, CD11b and Gr-1 for erythrocyte and megakaryoblast staining in spleen and bone marrow, B220 and CD3 $\varepsilon$ for myeloid cell staining in spleen and blood and B220, CD4, CD8, TCR $\beta, T C R \gamma \delta, ~ G r-1, C D 11 b, C D 11 c, C D 49 b$ and NK1.1. for double negative thymocyte staining. An unlabelled antibody against CD16/32 (Fc-block, eBioscience) was used in all stainings to avoid non-specific binding of fluorophorelabelled antibodies to Fc $\gamma$ receptors. Data was acquired on an LSRII flow cytometer (Becton Dickinson) and analyzed using FlowJo v10.5 (TreeStar).

\section{Open field habituation}

The open field habituation test assesses anxiety, activity and exploratory behaviour in first novel and then familiar environments. Mice were placed in well-lit arenas (150200 lux, $44 \times 44 \mathrm{~cm})$ for 30 min and the activity of the mice in the centre zone $(40 \%$ of the total area), periphery (area $8 \mathrm{~cm}$ towards the centre from the wall) and whole arena was captured in 5 min bins using Ethovision software (version 8.5). Mice were returned to the arena on the following day and measurements repeated to assess habituation. 


\section{Elevated Zero maze}

The elevated zero maze assesses the conflict between exploratory behaviour of novel environments and avoidance of well-lit open areas (Crawley, 1999) and uses an elevated maze ( $53 \mathrm{~cm}$ off the ground) in the shape of a circle which is divided equally into two open sections and two closed sections, with each section being approximately $30 \mathrm{~cm}$ long. Mice were placed onto an open section and allowed to explore for $5 \mathrm{~min}$. The video was analysed using Ethovision software and the total amount of time spent in either the open or closed sections was determined.

\section{Acoustic startle and pre-pulse inhibition (PPI)}

The acoustic pre-pulse startle test measures sensorimotor gating mechanisms through exposing the mice to a loud startle noise which may or may not be preceded by a quieter tone of differing sound levels. As the intensity of the pre-pulse tone increases, the brain should increasingly disregard the following startle noise, resulting in decreased flinching. Mice were placed in an acoustic startle chamber (Med Associates Inc, USA) and acclimatised to a background noise level of $50 \mathrm{~dB}$ for $5 \mathrm{~min}$. Mice were then exposed to a startle tone of white noise at $110 \mathrm{~dB}$ for $40 \mathrm{~ms}$, either on its own or preceded $50 \mathrm{~ms}$ earlier by a $10 \mathrm{~ms}$ pre-pulse white noise at 55 , 65 or $70 \mathrm{~dB}$ (PPI1, PPI2 or PPI3) in pseudorandom order. Responses to the startle tone were measured for $100 \mathrm{~ms}$ following the start of the startle tone using a piezoelectric transducer in the floor of the chamber which detected movement of the animal. Each trial condition was tested 10 times.

\section{Fear conditioning}

Fear conditioning assesses the memory of an aversive experience and determines if it is based on the cue, the context or both (Crawley, 1999). Mice were placed into square chambers $\left(17 \mathrm{~cm}^{2}\right)$ on day one and allowed to explore for $150 \mathrm{~s}$ during which the amount of freezing behaviour was measured (baseline). An auditory stimulus (70 
$\mathrm{dB}$ ) was presented for $30 \mathrm{~s}$ and was followed by one foot shock $(0.5 \mathrm{~mA}, 0.5 \mathrm{~s})$. After an interval, the auditory stimulus and foot shock were repeated twice more before the mouse was returned to its home cage. On day 2 , the mice were placed into the same chambers and the amount of freezing behaviour was measured over a 5 min period (context). Four hours later, the mice were placed into circular chambers $(20 \mathrm{~cm}$ in diameter) with additional vanillin essence to reinforce the novel environment setting. Freezing in the new arena was measured for $180 \mathrm{~s}$ (pre-cue), after which the auditory stimulus was presented alone and again the amount of freezing behaviour was measured (post-cue). The comparison of baseline versus context or pre-cue versus post-cue percentage freezing behaviour was used to evaluate associative memory to context or cue respectively.

\section{Object-in-Place}

Mice were first habituated to a transparent Plexiglas arena $(60 \times 60 \times 40 \mathrm{~cm})$ for 10 min for two consecutive days. To test for object-in-place associations, mice were placed in the arena with three distinct objects for $10 \mathrm{~min}$, returned to their home cage for $10 \mathrm{~min}$ and brought back into the arena for a further $10 \mathrm{~min}$ (sample phases 1 and 2). The mice were returned to their home cage for either $10 \mathrm{~min}$ or $3 \mathrm{~h}$ and then once again brought into the arena for $10 \mathrm{~min}$, but this time the position of two of the objects in the arena had been exchanged (test phase). Behaviour of mice was recorded with an overhead video camera, and subsequently contact times of the mice with each object were determined; contact was defined by the mouse being $\leq 1 \mathrm{~cm}$ from the object and facing towards it. A discrimination ratio was calculated to reflect the preference for contact with the two switched objects compared to the object that had not been moved. The ratio ranged from 0 to 1 , ratios over 0.5 indicated a preference for the switched objects, and thus intact object-in-place associative memory. 


\section{Sleep analysis}

Analysis of sleep/wake cycles was performed using video tracking as previously described (Fisher et al., 2012). Briefly, mice were singly housed and placed in lightcontrolled chambers with near infra-red miniature CCD cameras positioned above the cages (Maplin, UK). Monitoring during dark periods was performed using infrared illumination. Mice were allowed to acclimatize to the home cage for $24 \mathrm{~h}$ in a $12 \mathrm{~h}$ light/dark cycle (100 lux light intensity) before data collection. Video monitoring was then performed for a $24 \mathrm{~h}$ period in a $12: 12 \mathrm{~h}$ light/dark cycle. Video files were uploaded to ANY-maze video analysis software (Stoelting, US), which was used to track mouse mobility and to score cumulative periods during which the animals remained immobile for $40 \mathrm{~s}$ or more, a measure showing very high correlation with sleep (Fisher et al., 2012).

\section{Motor function}

Mice were singly housed in cages equipped with modular running wheels (TSESystems, Germany) (Mandillo et al., 2014). The average number of rotations, duration of each running bout and distance travelled every night was calculated using TSE-systems software over the course of 21 days. At the end of 14 days, the wheel was changed for a complex wheel in which a number of rungs had been removed, allowing assessment of the ability of the mice to adjust to a more difficult locomotor activity.

\section{Locotronic test}

The Locotronic test (Intellibio, France) is a test of motor co-ordination capability. Mice traverse a horizontal ladder with evenly spaced rungs, along a narrow corridor to reach the exit. The number of rungs that the mouse stepped on or missed was recorded automatically; a missed rung was considered an error. Each animal was tested 2-3 times. Trials where mice took more than $60 \mathrm{~s}$ to traverse the ladder were 
excluded from the analysis; a total of 11 out of 146 trials were excluded, 5 from WT mice and 6 from Dp1Tyb mice, indicating no difference in motivation between genotypes.

\section{Grip strength}

Grip strength was measured using a grip strength meter (Bioseb, France), recording the maximum force generated by a mouse using just its forelimbs or all four limbs. Grip strength measures were carried out in triplicate for each mouse.

\section{Statistical analysis}

For each of the above procedures we took all the phenotype measurements for the Dp1Tyb mice and compared these to values from wild-type control mice. Using fitted linear models the null hypothesis was that a fitted model without a genotype term is as good a fit to the data as a model with the addition of a genotype term. The significance of the good fit is taken as the p-value for a genotype effect between the mutant and wild-types ( $p($ genotype)). In order to adjust for parameters that have nonnormal distributions, a Box-Cox procedure (Box and Cox, 1964) was applied to the data prior to analysis. For continuous variables, a mixed model approach was used to compensate for any batch effects within the data. We constructed a linear-mixedmodel of phenotype value as a function of genotype ('value $1+$ sex+experimentrepeat $+(1 \mid \mathrm{dop})+$ genotype') and compared this with the model without a genotype term ('value $1+$ sex+experimentrepeat+(1|dop)'), where 'dop' is the date of procedure. An ANOVA test was used to generate a p(genotype) value for the genotype effect. Where there were no repeated measurements for a parameter, or only a single sex was measured the 'sex' and 'experiment repeat' formula terms were dropped from the models. For discrete variables an analogous logistical regression model method was used with a model formula similar to the one used for the continuous method but removing the date of procedure mixed effect (as 
logistical regression does not support it). Once the p(genotype) value was determined for a parameter, the false discovery rate (FDR) adjustment (Storey, 2002) was used to generate FDR-adjusted q-values: q(genotype). A q-value of $\leq 0.05$ was considered significant, and q(genotype) values are indicated on Figures.

A comparison of variances between the WT and Dp1Tyb data for each parameter was carried out using Brown-Forsythe Levene-type test for equality of variances (Brown and Forsythe, 1974), which produces a p-value with the null hypothesis that each group has the same variance. FDR adjustment was then carried out on this set of $p$-values, to produce FDR adjusted q-values for the similarity of variances: $q($ variance). Sexual dimorphism (sexdim) was assessed by using a mixed-model comparing a model with sex-genotype interaction ('value $1+$ sex+experimentrepeat+(1|dop)+sex:genotype') with a model without the interaction ("value $1+$ sex+experimentrepeat+(1|dop)+genotype'). ANOVA was used to determine the significance of the sexdim and FDR was then applied to this set of p-values to produced q-values, q(sexdim). Metadata fields such as 'experimenter id' or 'anaesthesia' were analysed to see if the metadata field had a significant effect to the phenotype calls. If the metadata field produced a significant effect on the model (ANOVA, $p \leq 0.05$ ), it was added as a factor to the linear model, compensating for its effect. Coefficient of variation (CoV) for each parameter with continuous variables was calculated by dividing the standard deviation by the mean, treating each sex and genotype separately. 


\section{REFERENCES}

Adams, A. D., Guedj, F. and Bianchi, D. W. (2020). Placental development and function in trisomy 21 and mouse models of Down syndrome: Clues for studying mechanisms underlying atypical development. Placenta 89, 58-66.

Adams, A. D., Hoffmann, V., Koehly, L., Guedj, F. and Bianchi, D. W. (2021). Novel insights from fetal and placental phenotyping in 3 mouse models of Down syndrome. Am J Obstet Gynecol.

Ahlfors, H., Anyanwu, N., Pakanavicius, E., Dinischiotu, N., Lana-Elola, E., Watson-Scales, S., Tosh, J., Wiseman, F., Briscoe, J., Page, K., et al. (2019). Gene expression dysregulation domains are not a specific feature of Down syndrome. Nat Commun 10, 2489.

Alexander, M., Petri, H., Ding, Y., Wandel, C., Khwaja, O. and Foskett, N. (2016). Morbidity and medication in a large population of individuals with Down syndrome compared to the general population. Dev Med Child Neurol 58, 246-254.

Alford, K. A., Slender, A., Vanes, L., Li, Z., Fisher, E. M. C., Nizetic, D., Orkin, S. H., Roberts, I. and Tybulewicz, V. L. J. (2010). Perturbed hematopoiesis in the Tc1 mouse model of Down Syndrome. Blood 115, 2928-2937.

Allison, D. B., Gomez, J. E., Heshka, S., Babbitt, R. L., Geliebter, A., Kreibich, K. and Heymsfield, S. B. (1995). Decreased resting metabolic rate among persons with Down Syndrome. Int J Obes Relat Metab Disord 19, 858-861.

Antonarakis, S. E. (2017). Down syndrome and the complexity of genome dosage imbalance. Nat Rev Genet 18, 147-163.

Antonarakis, S. E., Lyle, R., Dermitzakis, E. T., Reymond, A. and Deutsch, S. (2004). Chromosome 21 and down syndrome: from genomics to pathophysiology. Nat Rev Genet 5, 725-738.

Antonarakis, S. E., Skotko, B. G., Rafii, M. S., Strydom, A., Pape, S. E., Bianchi, D. W., Sherman, S. L. and Reeves, R. H. (2020). Down syndrome. Nat Rev Dis Primers 6, 9.

Anwar, A. J., Walker, J. D. and Frier, B. M. (1998). Type 1 diabetes mellitus and Down's syndrome: prevalence, management and diabetic complications. Diabet Med 15, 160-163.

Aziz, N. M., Guedj, F., Pennings, J. L. A., Olmos-Serrano, J. L., Siegel, A., Haydar, T. F. and Bianchi, D. W. (2018). Lifespan analysis of brain development, gene expression and behavioral phenotypes in the Ts1Cje, Ts65Dn and Dp(16)1/Yey mouse models of Down syndrome. Dis Model Mech 11.

Baptista, F., Varela, A. and Sardinha, L. B. (2005). Bone mineral mass in males and females with and without Down syndrome. Osteoporos Int 16, 380-388.

Barber, M. N., Risis, S., Yang, C., Meikle, P. J., Staples, M., Febbraio, M. A. and Bruce, C. R. (2012). Plasma lysophosphatidylcholine levels are reduced in obesity and type 2 diabetes. PLoS One 7, e41456.

Beach, R. R., Ricci-Tam, C., Brennan, C. M., Moomau, C. A., Hsu, P. H., Hua, B., Silberman, R. E., Springer, M. and Amon, A. (2017). Aneuploidy Causes Non-genetic Individuality. Cell 169, 229-242.e221.

Bergholdt, R., Eising, S., Nerup, J. and Pociot, F. (2006). Increased prevalence of Down's syndrome in individuals with type 1 diabetes in Denmark: A nationwide population-based study. Diabetologia 49, 1179-1182.

Bhatnagar, N., Nizery, L., Tunstall, O., Vyas, P. and Roberts, I. (2016). Transient Abnormal Myelopoiesis and AML in Down Syndrome: an Update. Curr Hematol Malig Rep 11, 333-341.

Bhutta, M. F., Cheeseman, M. T., Herault, Y., Yu, Y. E. and Brown, S. D. (2013). Surveying the Down syndrome mouse model resource identifies critical regions responsible for chronic otitis media. Mamm Genome 24, 439-445. 
Boonman, A. J. N., Schroeder, E. C., Hopman, M. T. E., Fernhall, B. O. and Hilgenkamp, T. I. M. (2019). Cardiopulmonary Profile of Individuals with Intellectual Disability. Med Sci Sports Exerc 51, 1802-1808.

Box, G. E. P. and Cox, D. R. (1964). An analysis of transformations. J Royal Stat Soc, Series B 26, 211-252.

Braff, D. L., Geyer, M. A. and Swerdlow, N. R. (2001). Human studies of prepulse inhibition of startle: normal subjects, patient groups, and pharmacological studies. Psychopharmacology 156, 234-258.

Brault, V., Duchon, A., Romestaing, C., Sahun, I., Pothion, S., Karout, M., Borel, C., Dembele, D., Bizot, J. C., Messaddeq, N., et al. (2015). Opposite phenotypes of muscle strength and locomotor function in mouse models of partial trisomy and monosomy 21 for the proximal Hspa13-App region. PLoS Genet 11, e1005062.

Brown, M. B. and Forsythe, A. B. (1974). Robust Tests for the Equality of Variances. J Am Stat Assoc 69, 364-367.

Cardoso, A. C., Campos, A. C., Santos, M. M., Santos, D. C. and Rocha, N. A. (2015). Motor performance of children with Down syndrome and typical development at 2 to 4 and 26 months. Pediatr Phys Ther 27, 135-141.

Carmichael, C. L., Majewski, I. J., Alexander, W. S., Metcalf, D., Hilton, D. J., Hewitt, C. A. and Scott, H. S. (2009). Hematopoietic defects in the Ts1Cje mouse model of Down syndrome. Blood 113, 1929-1937.

Chang, P., Bush, D., Schorge, S., Good, M., Canonica, T., Shing, N., Noy, S., Wiseman, F. K., Burgess, N., Tybulewicz, V. L. J., et al. (2020). Altered Hippocampal-Prefrontal Neural Dynamics in Mouse Models of Down Syndrome. Cell Rep 30, 1152-1163.

Corsi, M. M., Dogliotti, G., Pedroni, F., Galliera, E., Malavazos, A. E., Villa, R., Chiappelli, M. and Licastro, F. (2009). Adipocytokines in Down's syndrome, an atheroma-free model: Role of adiponectin. Arch Gerontol Geriatr 48, 106109.

Costa, R., Gullon, A., De Miguel, R., de Asua, D. R., Bautista, A., Garcia, C., Suarez, C., Castaneda, S. and Moldenhauer, F. (2018). Bone Mineral Density Distribution Curves in Spanish Adults With Down Syndrome. J Clin Densitom 21, 493-500.

Crawley, J. N. (1999). Behavioral phenotyping of transgenic and knockout mice: experimental design and evaluation of general health, sensory functions, motor abilities, and specific behavioral tests. Brain Res 835, 18-26.

Dierssen, M., Fructuoso, M., Martinez de Lagran, M., Perluigi, M. and Barone, E. (2020). Down Syndrome Is a Metabolic Disease: Altered Insulin Signaling Mediates Peripheral and Brain Dysfunctions. Front Neurosci 14, 670.

Duchon, A., Besson, V., Pereira, P. L., Magnol, L. and Herault, Y. (2008). Inducing Segmental Aneuploid Mosaicism in the Mouse Through Targeted Asymmetric Sister Chromatid Event of Recombination. Genetics 180, 51-59.

Fernhall, B. and Otterstetter, M. (2003). Attenuated responses to sympathoexcitation in individuals with Down syndrome. J Appl Physiol 94, 2158-2165.

Ferrannini, E., Natali, A., Camastra, S., Nannipieri, M., Mari, A., Adam, K. P., Milburn, M. V., Kastenmuller, G., Adamski, J., Tuomi, T., et al. (2013). Early metabolic markers of the development of dysglycemia and type 2 diabetes and their physiological significance. Diabetes 62, 1730-1737.

Fisher, S. P., Godinho, S. I., Pothecary, C. A., Hankins, M. W., Foster, R. G. and Peirson, S. N. (2012). Rapid assessment of sleep-wake behavior in mice. J Biol Rhythms 27, 48-58.

Garnett, C., Cruz Hernandez, D. and Vyas, P. (2020). GATA1 and cooperating mutations in myeloid leukaemia of Down syndrome. IUBMB Life 72, 119-130. 
Gautier, M. and Harper, P. S. (2009). Fiftieth anniversary of trisomy 21: returning to a discovery. Hum Genet 126, 317-324.

Goodliffe, J. W., Olmos-Serrano, J. L., Aziz, N. M., Pennings, J. L., Guedj, F., Bianchi, D. W. and Haydar, T. F. (2016). Absence of Prenatal Forebrain Defects in the Dp(16)1Yey/+ Mouse Model of Down Syndrome. J Neurosci 36, 2926-2944.

Grieco, J., Pulsifer, M., Seligsohn, K., Skotko, B. and Schwartz, A. (2015). Down syndrome: Cognitive and behavioral functioning across the lifespan. Am J Med Genet C Semin Med Genet 169, 135-149.

Gutierrez-Hervas, A., Gomez-Martinez, S., Izquierdo-Gomez, R., Veiga, O. L., Perez-Bey, A., Castro-Pinero, J. and Marcos, A. (2020). Inflammation and fatness in adolescents with and without Down syndrome: UP \& DOWN study. J Intellect Disabil Res 64, 170-179.

Hardisty-Hughes, R. E., Parker, A. and Brown, S. D. (2010). A hearing and vestibular phenotyping pipeline to identify mouse mutants with hearing impairment. Nat Protoc 5, 177-190.

Herault, Y., Delabar, J. M., Fisher, E. M. C., Tybulewicz, V. L. J., Yu, E. and Brault, V. (2017). Rodent models in Down syndrome research: impact and future opportunities. Dis Model Mech 10, 1165-1186.

Herrera, C. L., Hussamy, D. J., McIntire, D. D., Twickler, D. M. and Dashe, J. S. (2020). Femur length parameters in fetuses with Down syndromedagger. $J$ Matern Fetal Neonatal Med 33, 2516-2521.

lellamo, F., Galante, A., Legramante, J. M., Lippi, M. E., Condoluci, C., Albertini, G. and Volterrani, M. (2005). Altered autonomic cardiac regulation in individuals with Down syndrome. Am J Physiol Heart Circ Physiol 289, H2387-2391.

Ingham, N. J., Pearson, S. and Steel, K. P. (2011). Using the Auditory Brainstem Response (ABR) to Determine Sensitivity of Hearing in Mutant Mice. Curr Protoc Mouse Biol 1, 279-287.

Jacobs, P. A., Baikie, A. G., Court Brown, W. M. and Strong, J. A. (1959). The somatic chromosomes in mongolism. Lancet 1, 710.

Jiang, X., Liu, C., Yu, T., Zhang, L., Meng, K., Xing, Z., Belichenko, P. V., Kleschevnikov, A. M., Pao, A., Peresie, J., et al. (2015). Genetic dissection of the Down syndrome critical region. Hum Mol Genet 24, 6540-6551.

Johnson, M. B., De Franco, E., Greeley, S. A. W., Letourneau, L. R., Gillespie, K. M., International, D. S. P. C., Wakeling, M. N., Ellard, S., Flanagan, S. E., Patel, K. A., et al. (2019). Trisomy 21 is a Cause of Permanent Neonatal Diabetes That Is Autoimmune but Not HLA Associated. Diabetes 68, 15281535.

Kazuki, Y., Gao, F. J., Li, Y., Moyer, A. J., Devenney, B., Hiramatsu, K., Miyagawa-Tomita, S., Abe, S., Kazuki, K., Kajitani, N., et al. (2020). A nonmosaic transchromosomic mouse model of down syndrome carrying the long arm of human chromosome 21. Elife 9.

Kirsammer, G., Jilani, S., Liu, H., Davis, E., Gurbuxani, S., Le Beau, M. M. and Crispino, J. D. (2008). Highly penetrant myeloproliferative disease in the Ts65Dn mouse model of Down syndrome. Blood 111, 767-775.

Korenberg, J. R., Chen, X. N., Schipper, R., Sun, Z., Gonsky, R., Gerwehr, S., Carpenter, N., Daumer, C., Dignan, P., Disteche, C., et al. (1994). Down syndrome phenotypes: the consequences of chromosomal imbalance. Proc Natl Acad Sci U S A 91, 4997-5001.

Kotronen, A., Velagapudi, V. R., Yetukuri, L., Westerbacka, J., Bergholm, R., Ekroos, K., Makkonen, J., Taskinen, M. R., Oresic, M. and Yki-Jarvinen, H. (2009). Serum saturated fatty acids containing triacylglycerols are better markers of insulin resistance than total serum triacylglycerol concentrations. Diabetologia 52, 684-690. 
Kreicher, K. L., Weir, F. W., Nguyen, S. A. and Meyer, T. A. (2018). Characteristics and Progression of Hearing Loss in Children with Down Syndrome. J Pediatr 193, $27-33$ e22.

Krinsky-McHale, S. J., Silverman, W., Gordon, J., Devenny, D. A., Oley, N. and Abramov, I. (2014). Vision deficits in adults with Down syndrome. J Appl Res Intellect Disabil 27, 247-263.

Küçük, M., Karadeniz, C., Ozdemir, R. and Meşe, T. (2018). Prolonged T-wave peak-end interval in Down syndrome patients with congenitally normal hearts. Pediatr Int 60, 513-516.

LaCombe, J. M. and Roper, R. J. (2020). Skeletal dynamics of Down syndrome: A developing perspective. Bone 133, 115215.

Laguna, A., Barallobre, M. J., Marchena, M. A., Mateus, C., Ramirez, E., Martinez-Cue, C., Delabar, J. M., Castelo-Branco, M., de la Villa, P. and Arbones, M. L. (2013). Triplication of DYRK1A causes retinal structural and functional alterations in Down syndrome. Hum Mol Genet 22, 2775-2784.

Lana-Elola, E., Watson-Scales, S., Slender, A., Gibbins, D., Martineau, A., Douglas, C., Mohun, T., Fisher, E. M. and Tybulewicz, V. (2016). Genetic dissection of Down syndrome-associated congenital heart defects using a new mouse mapping panel. Elife 5, 10.7554/eLife.11614.

Lana-Elola, E., Watson-Scales, S. D., Fisher, E. M. and Tybulewicz, V. L. (2011). Down syndrome: searching for the genetic culprits. Dis Model Mech 4, 586595.

Lee, P., Bhansali, R., Izraeli, S., Hijiya, N. and Crispino, J. D. (2016). The biology, pathogenesis and clinical aspects of acute lymphoblastic leukemia in children with Down syndrome. Leukemia 30, 1816-1823.

Lejeune, J., Gautier, M. and Turpin, R. (1959). Étude des chromosomes somatiques de neuf enfants mongoliens. C R Hebd Seances Acad Sci 248, 1721-1722.

Levenga, J., Peterson, D. J., Cain, P. and Hoeffer, C. A. (2018). Sleep Behavior and EEG Oscillations in Aged Dp(16)1Yey/+ Mice: A Down Syndrome Model. Neuroscience 376, 117-126.

Li, Z., Yu, T., Morishima, M., Pao, A., LaDuca, J., Conroy, J., Nowak, N., Matsui, S., Shiraishi, I. and Yu, Y. E. (2007). Duplication of the entire 22.9-Mb human chromosome 21 syntenic region on mouse chromosome 16 causes cardiovascular and gastrointestinal abnormalities. Hum Mol Genet 16, 13591366.

Liu, C., Morishima, M., Jiang, X., Yu, T., Meng, K., Ray, D., Pao, A., Ye, P., Parmacek, M. S. and Yu, Y. E. (2014). Engineered chromosome-based genetic mapping establishes a $3.7 \mathrm{Mb}$ critical genomic region for Down syndrome-associated heart defects in mice. Hum Genet 133, 743-753.

Liu, C., Morishima, M., Yu, T., Matsui, S. I., Zhang, L., Fu, D., Pao, A., Costa, A. C., Gardiner, K. J., Cowell, J. K., et al. (2011). Genetic analysis of Down syndrome-associated heart defects in mice. Hum Genet.

Liu, C., Yu, T., Xing, Z., Jiang, X., Li, Y., Pao, A., Mu, J., Wallace, P. K., Stoica, G., Bakin, A. V., et al. (2018). Triplications of human chromosome 21 orthologous regions in mice result in expansion of megakaryocyte-erythroid progenitors and reduction of granulocyte-macrophage progenitors. Oncotarget 9, 4773-4786.

Lott, I. T. and Dierssen, M. (2010). Cognitive deficits and associated neurological complications in individuals with Down's syndrome. Lancet Neurol 9, 623-633.

Love, M. I., Huber, W. and Anders, S. (2014). Moderated estimation of fold change and dispersion for RNA-seq data with DESeq2. Genome Biol 15, 550.

Luke, A., Roizen, N. J., Sutton, M. and Schoeller, D. A. (1994). Energy expenditure in children with Down syndrome: correcting metabolic rate for movement. J Pediatr 125, 829-838. 
Malak, R., Kostiukow, A., Krawczyk-Wasielewska, A., Mojs, E. and Samborski, W. (2015). Delays in Motor Development in Children with Down Syndrome. Med Sci Monit 21, 1904-1910.

Mandillo, S., Heise, I., Garbugino, L., Tocchini-Valentini, G. P., Giuliani, A., Wells, S. and Nolan, P. M. (2014). Early motor deficits in mouse disease models are reliably uncovered using an automated home-cage wheel-running system: a cross-laboratory validation. Dis Model Mech 7, 397-407.

Maris, M., Wojciechowski, M., Van de Heyning, P. and Boudewyns, A. (2014). A cross-sectional analysis of otitis media with effusion in children with Down syndrome. Eur J Pediatr 173, 1319-1325.

Meehan, T. F., Conte, N., West, D. B., Jacobsen, J. O., Mason, J., Warren, J., Chen, C. K., Tudose, I., Relac, M., Matthews, P., et al. (2017). Disease model discovery from 3,328 gene knockouts by The International Mouse Phenotyping Consortium. Nat Genet 49, 1231-1238.

Menzies, C., Naz, S., Patten, D., Alquier, T., Bennett, B. M. and Lacoste, B. (2021). Distinct Basal Metabolism in Three Mouse Models of Neurodevelopmental Disorders. eNeuro 8.

Moyer, A. J., Gardiner, K. and Reeves, R. H. (2020). All Creatures Great and Small: New Approaches for Understanding Down Syndrome Genetics. Trends Genet.

Mucke, L., Masliah, E., Yu, G. Q., Mallory, M., Rockenstein, E. M., Tatsuno, G., Hu, K., Kholodenko, D., Johnson-Wood, K. and McConlogue, L. (2000). High-level neuronal expression of abeta 1-42 in wild-type human amyloid protein precursor transgenic mice: synaptotoxicity without plaque formation. $J$ Neurosci 20, 4050-4058.

Myers, A. and McGonigle, P. (2019). Overview of Transgenic Mouse Models for Alzheimer's Disease. Curr Protoc Neurosci 89, e81.

Nguyen, T. L., Duchon, A., Manousopoulou, A., Loaec, N., Villiers, B., Pani, G., Karatas, M., Mechling, A. E., Harsan, L. A., Limanton, E., et al. (2018). Correction of cognitive deficits in mouse models of Down syndrome by a pharmacological inhibitor of DYRK1A. Dis Model Mech 11.

O'Doherty, A., Ruf, S., Mulligan, C., Hildreth, V., Errington, M. L., Cooke, S., Sesay, A., Modino, S., Vanes, L., Hernandez, D., et al. (2005). An aneuploid mouse strain carrying human chromosome 21 with Down syndrome phenotypes. Science 309, 2033-2037.

Olson, L. E., Richtsmeier, J. T., Leszl, J. and Reeves, R. H. (2004). A Chromosome 21 Critical Region Does Not Cause Specific Down Syndrome Phenotypes. Science 306, 687-690.

Oresic, M., Hyotylainen, T., Kotronen, A., Gopalacharyulu, P., Nygren, H., Arola, J., Castillo, S., Mattila, I., Hakkarainen, A., Borra, R. J., et al. (2013). Prediction of non-alcoholic fatty-liver disease and liver fat content by serum molecular lipids. Diabetologia 56, 2266-2274.

Patel, A., Yamashita, N., Ascano, M., Bodmer, D., Boehm, E., Bodkin-Clarke, C., Ryu, Y. K. and Kuruvilla, R. (2015). RCAN1 links impaired neurotrophin trafficking to aberrant development of the sympathetic nervous system in Down syndrome. Nat Commun 6, 10119.

Peiris, H., Duffield, M. D., Fadista, J., Jessup, C. F., Kashmir, V., Genders, A. J., McGee, S. L., Martin, A. M., Saiedi, M., Morton, N., et al. (2016). A Syntenic Cross Species Aneuploidy Genetic Screen Links RCAN1 Expression to betaCell Mitochondrial Dysfunction in Type 2 Diabetes. PLoS Genet 12, e1006033. 
Pereira, P. L., Magnol, L., Sahún, I., Brault, V., Duchon, A., Prandini, P., Gruart, A., Bizot, J.-C., Chadefaux-Vekemans, B., Deutsch, S., et al. (2009). A new mouse model for the trisomy of the Abcg1-U2af1 region reveals the complexity of the combinatorial genetic code of down syndrome. Hum $\mathrm{Mol}$ Genet 18, 4756-4769.

Pinto, B., Morelli, G., Rastogi, M., Savardi, A., Fumagalli, A., Petretto, A., Bartolucci, M., Varea, E., Catelani, T., Contestabile, A., et al. (2020). Rescuing Over-activated Microglia Restores Cognitive Performance in Juvenile Animals of the $\mathrm{Dp}(16)$ Mouse Model of Down Syndrome. Neuron.

Raveau, M., Lignon, J. M., Nalesso, V., Duchon, A., Groner, Y., Sharp, A. J., Dembele, D., Brault, V. and Herault, Y. (2012). The App-Runx1 region is critical for birth defects and electrocardiographic dysfunctions observed in a Down syndrome mouse model. PLoS Genet 8, e1002724.

Raveau, M., Polygalov, D., Boehringer, R., Amano, K., Yamakawa, K. and McHugh, T. J. (2018). Alterations of in vivo CA1 network activity in Dp(16)1Yey Down syndrome model mice. Elife 7, 10.7554/eLife.31543.

Rogers, D. C., Fisher, E. M., Brown, S. D., Peters, J., Hunter, A. J. and Martin, J. E. (1997). Behavioral and functional analysis of mouse phenotype: SHIRPA, a proposed protocol for comprehensive phenotype assessment. Mamm Genome 8, 711-713.

Salaspuro, M. (1987). Use of enzymes for the diagnosis of alcohol-related organ damage. Enzyme 37, 87-107.

Sanders, F. W. B., Acharjee, A., Walker, C., Marney, L., Roberts, L. D., Imamura, F., Jenkins, B., Case, J., Ray, S., Virtue, S., et al. (2018). Hepatic steatosis risk is partly driven by increased de novo lipogenesis following carbohydrate consumption. Genome Biol 19, 79.

Schweighoffer, E., Vanes, L., Nys, J., Cantrell, D., McCleary, S., Smithers, N. and Tybulewicz, V. L. (2013). The BAFF Receptor Transduces Survival Signals by Co-opting the B Cell Receptor Signaling Pathway. Immunity 38, 475-488.

Scudamore, C. L. (2014). Practical approaches to reviewing and recording pathology data. In A Practical Guide to Histology of the Mouse (ed. C. L. Scudamore), pp. 25-41. Chichester, UK: Wiley-Blackwell.

Shott, S. R., Joseph, A. and Heithaus, D. (2001). Hearing loss in children with Down syndrome. Int J Pediatr Otorhinolaryngol 61, 199-205.

Smith, C. A., Want, E. J., O'Maille, G., Abagyan, R. and Siuzdak, G. (2006). XCMS: processing mass spectrometry data for metabolite profiling using nonlinear peak alignment, matching, and identification. Anal Chem 78, 779787.

Souchet, B., Duchon, A., Gu, Y., Dairou, J., Chevalier, C., Daubigney, F., Nalesso, V., Creau, N., Yu, Y., Janel, N., et al. (2019). Prenatal treatment with EGCG enriched green tea extract rescues GAD67 related developmental and cognitive defects in Down syndrome mouse models. Sci Rep 9, 3914.

Spano, M., Mercuri, E., Rando, T., Panto, T., Gagliano, A., Henderson, S. and Guzzetta, F. (1999). Motor and perceptual-motor competence in children with Down syndrome: variation in performance with age. Eur $J$ Paediatr Neurol 3, 7-13.

Starbuck, J. M., Dutka, T., Ratliff, T. S., Reeves, R. H. and Richtsmeier, J. T. (2014). Overlapping trisomies for human chromosome 21 orthologs produce similar effects on skull and brain morphology of Dp(16)1Yey and Ts65Dn mice. Am J Med Genet A 164A, 1981-1990.

Storey, J. D. (2002). A direct approach to false discovery rates. J Royal Stat Soc, Series $B$ 64, 479-498. 
Sullivan, K. D., Lewis, H. C., Hill, A. A., Pandey, A., Jackson, L. P., Cabral, J. M., Smith, K. P., Liggett, L. A., Gomez, E. B., Galbraith, M. D., et al. (2016). Trisomy 21 consistently activates the interferon response. Elife $\mathbf{5}$.

Suvitaival, T., Bondia-Pons, I., Yetukuri, L., Poho, P., Nolan, J. J., Hyotylainen, T., Kuusisto, J. and Oresic, M. (2018). Lipidome as a predictive tool in progression to type 2 diabetes in Finnish men. Metabolism 78, 1-12.

Takahashi, T., Sakai, N., Iwasaki, T., Doyle, T. C., Mobley, W. C. and Nishino, S. (2020). Detailed evaluation of the upper airway in the Dp(16)1Yey mouse model of Down syndrome. Sci Rep 10, 21323.

Thomas, J. R., LaCombe, J., Long, R., Lana-Elola, E., Watson-Scales, S., Wallace, J. M., Fisher, E. M. C., Tybulewicz, V. L. J. and Roper, R. J. (2020). Interaction of sexual dimorphism and gene dosage imbalance in skeletal deficits associated with Down syndrome. Bone 136, 115367.

Toussaint, N., Redhead, Y., Vidal-Garcia, M., Lo Vercio, L., Liu, W., Fisher, E. M. C., Hallgrímsson, B., Tybulewicz, V. L. J., Schnabel, J. A. and Green, J. B. A. (2021). A landmark-free morphometrics pipeline for high-resolution phenotyping: application to a mouse model of Down Syndrome. Development 148, dev188631.

Vicente, A., Bravo-Gonzalez, L. A., Lopez-Romero, A., Munoz, C. S. and Sanchez-Meca, J. (2020). Craniofacial morphology in down syndrome: a systematic review and meta-analysis. Sci Rep 10, 19895.

Victorino, D. B., Scott-McKean, J. J., Johnson, M. W. and Costa, A. C. S. (2020). Quantitative Analysis of Retinal Structure and Function in Two Chromosomally Altered Mouse Models of Down Syndrome. Invest Ophthalmol Vis Sci 61, 25.

Vis, J. C., Duffels, M. G., Winter, M. M., Weijerman, M. E., Cobben, J. M., Huisman, S. A. and Mulder, B. J. (2009). Down syndrome: a cardiovascular perspective. J Intellect Disabil Res 53, 419-425.

Wang-Sattler, R., Yu, Z., Herder, C., Messias, A. C., Floegel, A., He, Y., Heim, K., Campillos, M., Holzapfel, C., Thorand, B., et al. (2012). Novel biomarkers for pre-diabetes identified by metabolomics. Mol Syst Biol 8, 615.

Watson-Scales, S., Kalmar, B., Lana-Elola, E., Gibbins, D., La Russa, F., Wiseman, F., Williamson, M., Saccon, R., Slender, A., Olerinyova, A., et al. (2018). Analysis of motor dysfunction in Down Syndrome reveals motor neuron degeneration. PLoS Genet 14, e1007383.

Wiseman, F. K., Al-Janabi, T., Hardy, J., Karmiloff-Smith, A., Nizetic, D., Tybulewicz, V. L., Fisher, E. M. and Strydom, A. (2015). A genetic cause of Alzheimer disease: mechanistic insights from Down syndrome. Nat Rev Neurosci 16, 564-574.

Yu, T., Clapcote, S. J., Liu, C., Li, S., Pao, A., Bechard, A. R., Belichenko, P., Kleschevnikov, A., Asrar, S., Chen, R., et al. (2010a). Effects of individual segmental trisomies of human chromosome 21 syntenic regions on hippocampal long-term potentiation and cognitive behaviors in mice. Brain Res 1366, 162-171.

Yu, T., Li, Z., Jia, Z., Clapcote, S. J., Liu, C., Li, S., Asrar, S., Pao, A., Chen, R., Fan, N., et al. (2010b). A mouse model of Down syndrome trisomic for all human chromosome 21 syntenic regions. Hum Mol Genet 19, 2780-2791.

Zhang, L., Meng, K., Jiang, X., Liu, C., Pao, A., Belichenko, P. V., Kleschevnikov, A. M., Josselyn, S., Liang, P., Ye, P., et al. (2014). Human chromosome 21 orthologous region on mouse chromosome 17 is a major determinant of Down syndrome-related developmental cognitive deficits. Hum Mol Genet 23, 578-589. 


\section{FIGURES}

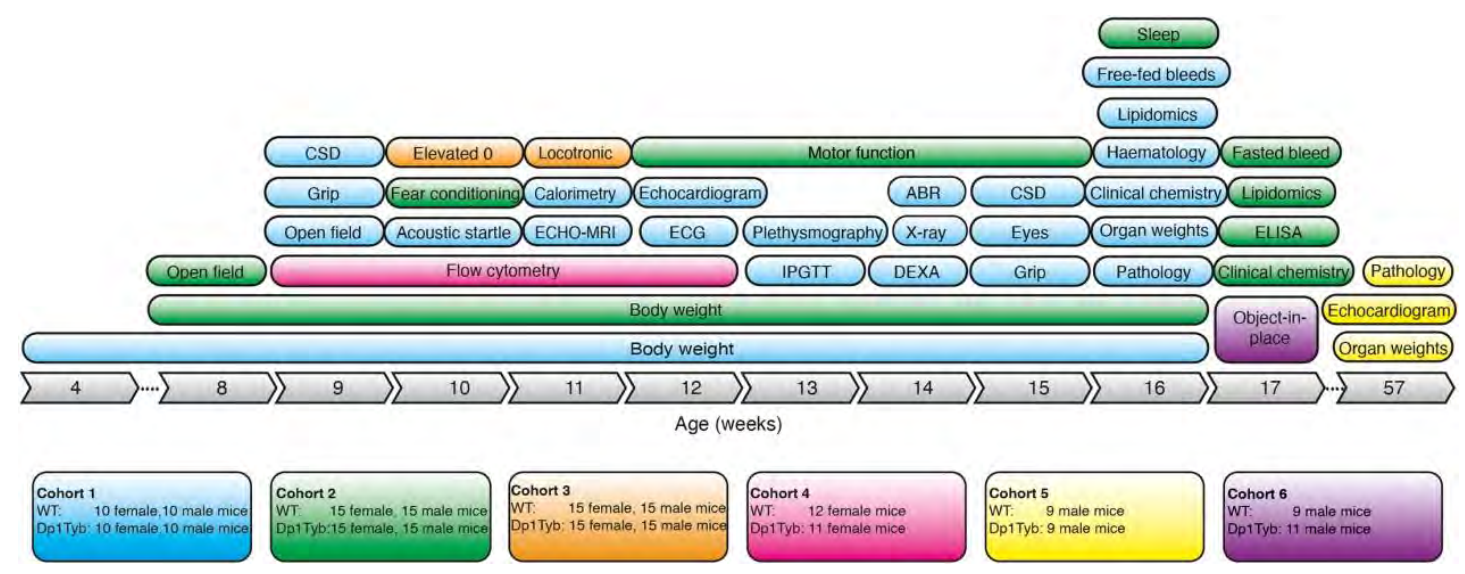

Figure 1. Broad phenotyping pipeline used for analysis of Dp1Tyb mice. Diagram shows the 6 cohorts of Dp1Tyb mice and WT controls that were used in the broad phenotyping analysis. Each cohort is indicated in a different colour, showing the tests it underwent, the numbers and sex of mice involved and the age at which the tests were administered. CSD, Combined SHIRPA and Dysmorphology test.; ECG, electrocardiogram; Elevated 0 , elevated 0 maze; IPGTT, intra-peritoneal glucose tolerance test; $A B R$, acoustic brainstem response; DEXA, dual energy X-ray absorption; ELISA, enzyme-linked immunosorbent assay for plasma hormones. 


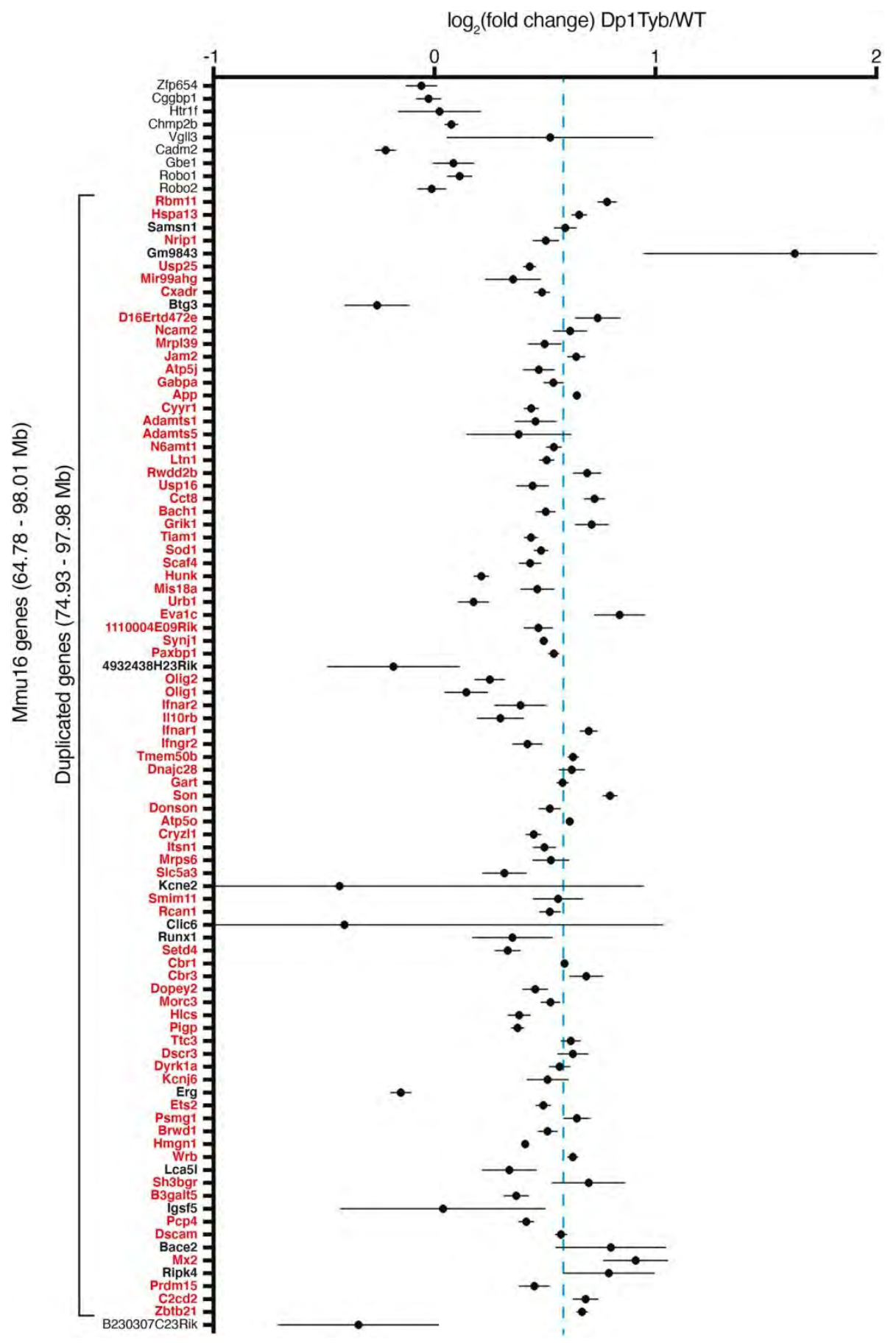

Figure 2. Upregulation of expression of genes in duplicated region of Dp1Tyb mice. Mean $\pm S E M \log _{2}$ fold change of gene expression in the hippocampus between Dp1Tyb and WT mice ( $n=5$ of each). Only expressed coding genes and one miRNA host gene shown; expressed genes were defined by sum of expression over all 10 samples > 1 TPM and having a measured p-value in DEseq2. Genes within the duplicated region of Mmu16 are shown in bold. Genes showing a significantly 
different expression in Dp1Tyb compared to WT (adjusted p-value <0.05) are listed in red. Ten genes that are not duplicated ( 9 on the centromeric and 1 on the telomeric side of the duplication) are included in the figure to allow comparison with duplicated genes. Dashed blue line indicates a fold change of 1.5 expected by the increased dosage of the duplicated genes. 

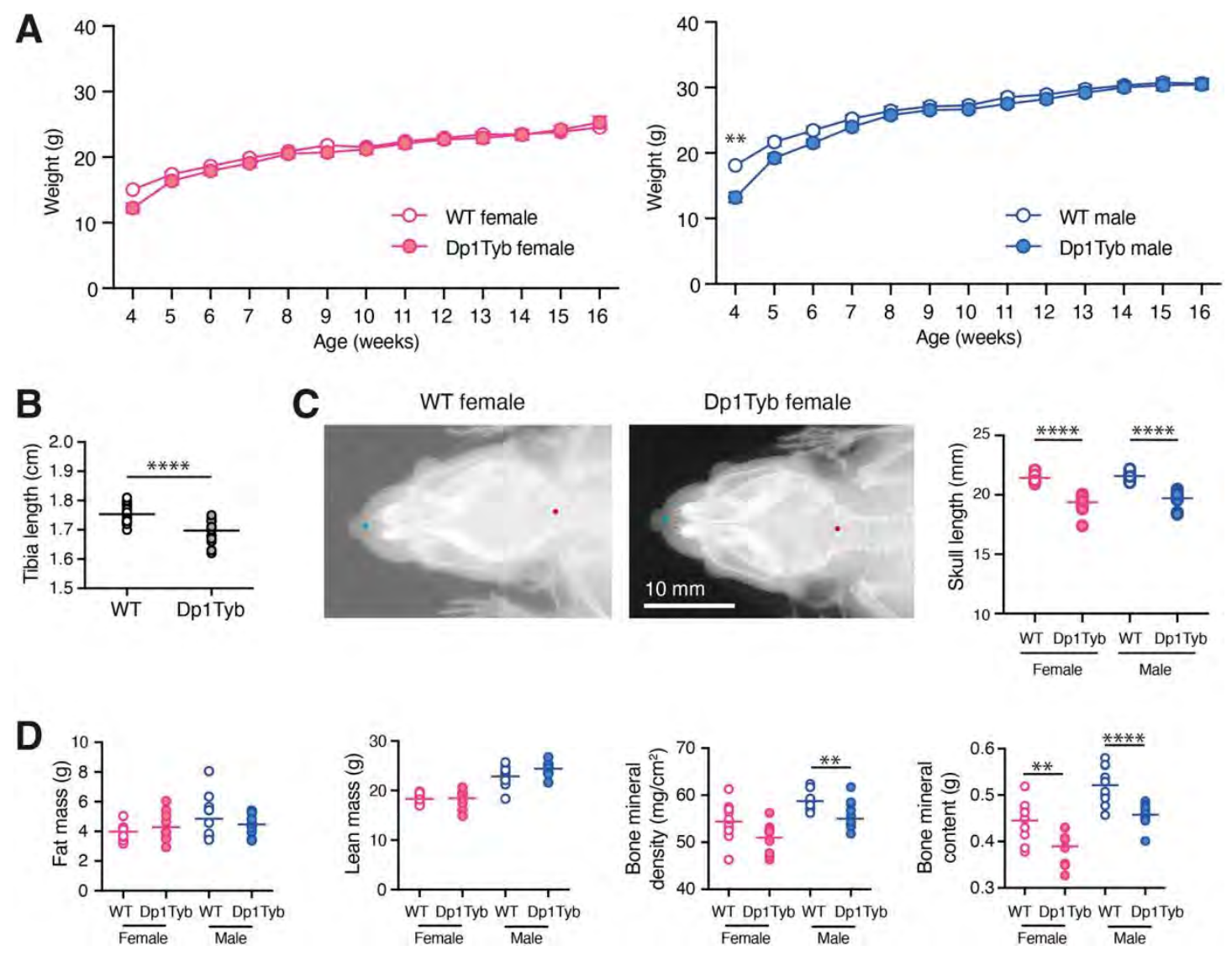

Figure 3. Skeletal changes and decreased bone mineral density and content in Dp1Tyb mice. A, Mean \pm SEM weight of Dp1Tyb and WT mice (cohort 1) as a function of age. B, Tibia length of WT and Dp1Tyb mice (cohort 1) showing combined data from females and males, determined from X-ray images. C, Example X-ray images of dorsal views of WT and Dp1Tyb female mouse skulls (cohort 1). Graph shows the length of the skull from the anterior tip of the nasal bone to the posterior of the occipital bone, which are indicated in blue and red dots on the images, from WT and Dp1Tyb mice (cohort 1). D, Fat mass, lean mass, bone mineral density and bone mineral content of Dp1Tyb and WT mice (cohort 1) determined by DEXA. Horizontal lines indicate mean. Here and in other figures where sexes are analysed separately, the graphs are coloured red and blue for females and males, respectively. Where both sexes are analysed together graphs use white and grey to distinguish the genotypes. ${ }^{* *} 0.001<q<0.01 ;{ }^{* * * *} q<0.0001$. 
A
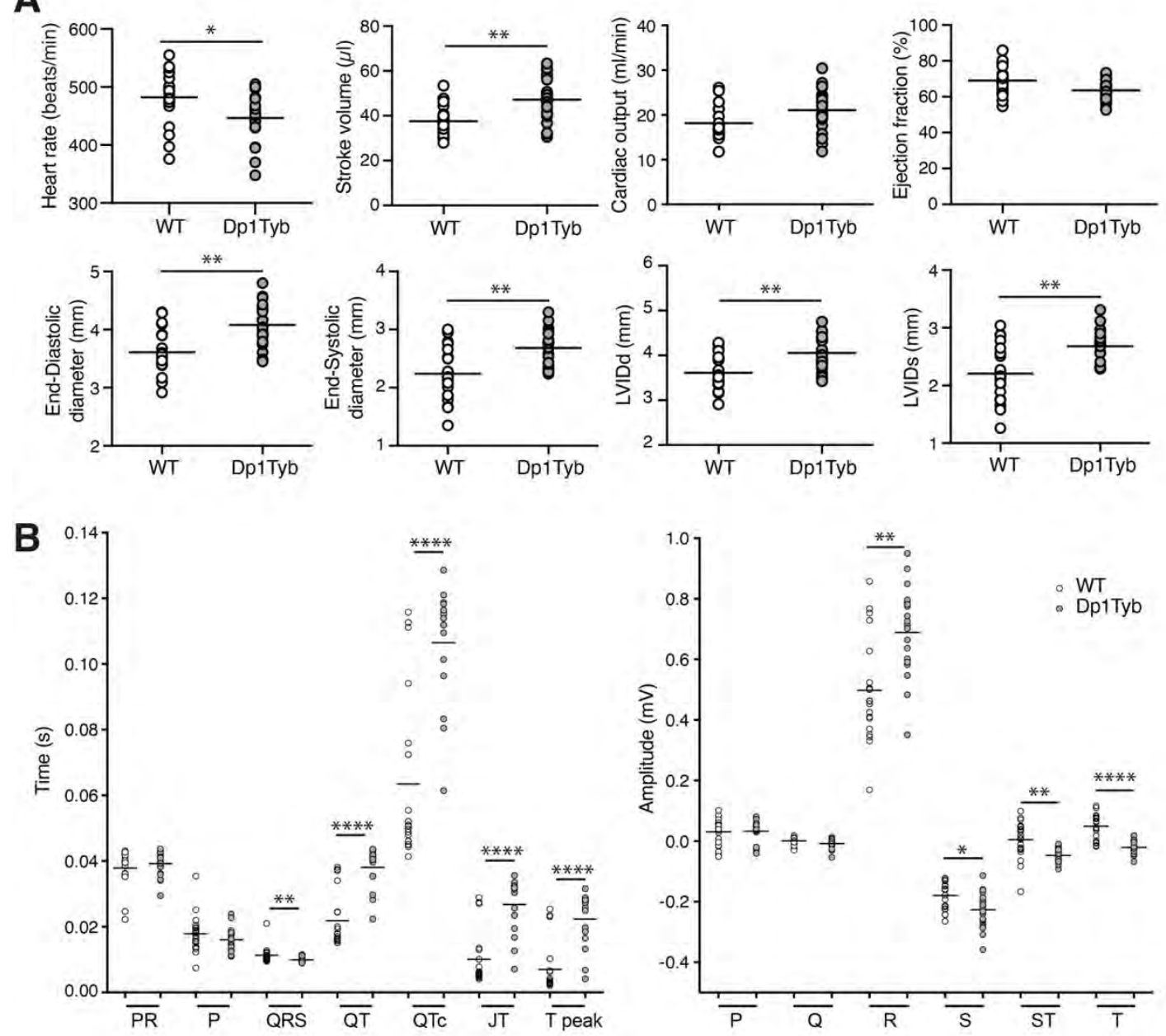

C

Female
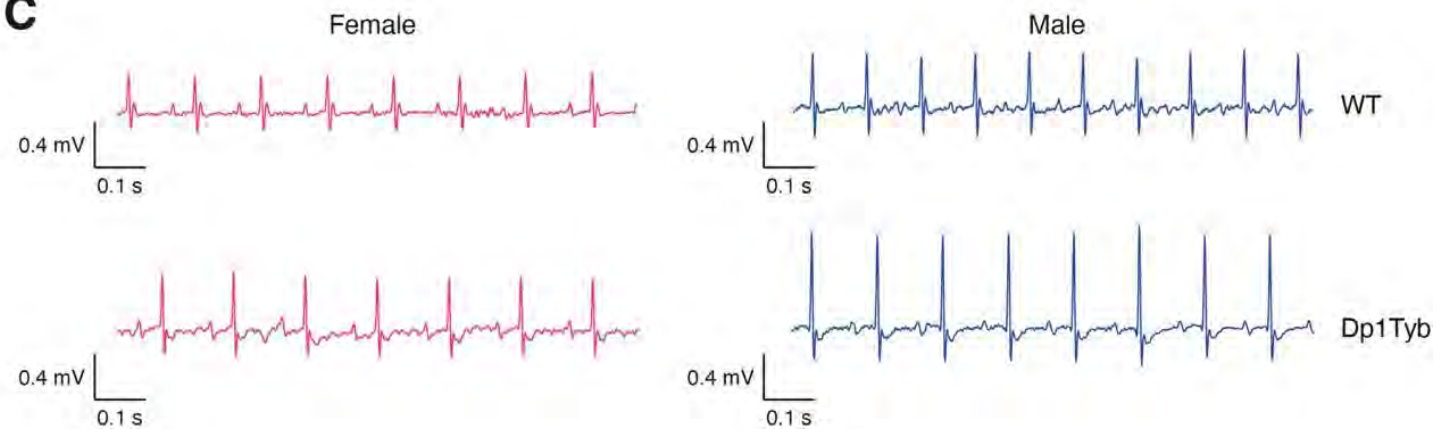

Figure 4. Altered cardiac function in Dp1Tyb mice. A, Heart rate, stroke volume, cardiac output, ejection fraction, end-diastolic diameter, end-systolic diameter, left ventricular inner diameter in diastole (LVIDd) and left ventricular inner diameter in systole (LVIDs) in WT and Dp1Tyb mice (females and males combined) from cohort 1 determined by echocardiography. B, Mean interval 
durations and wave amplitudes from electrocardiogram (ECG) analysis of WT and Dp1Tyb mice (females and males combined) from cohort 1. C, Representative ECG traces. Horizontal lines indicate mean. ${ }^{*} 0.01<q<0.05$; ${ }^{* *} 0.001<q<0.01 ;{ }^{* * *} q<0.0001$ 
A
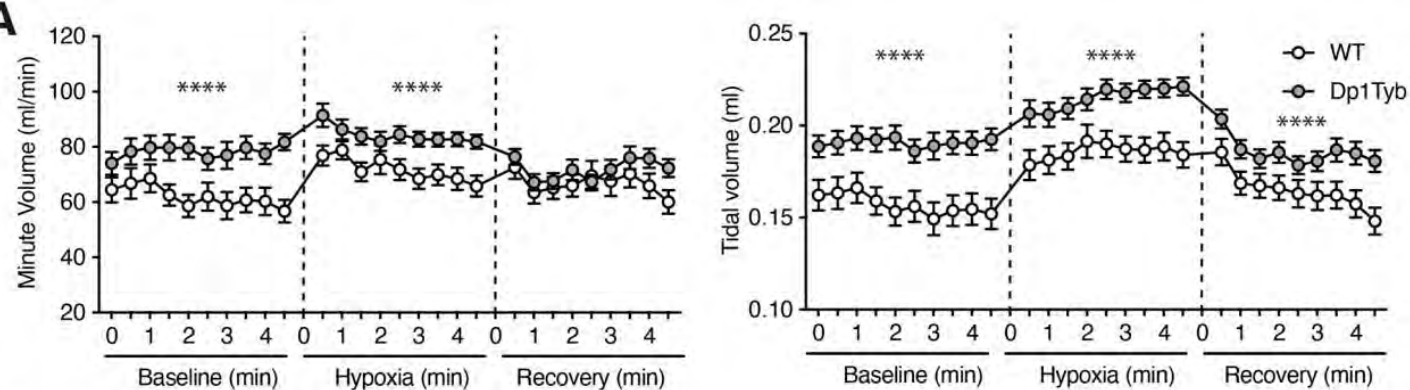

B

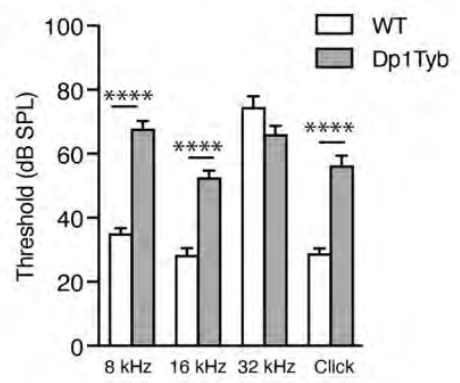

D

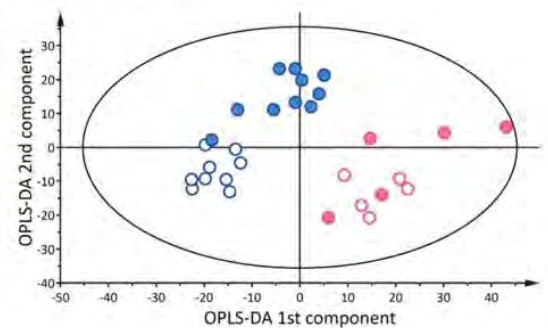

E
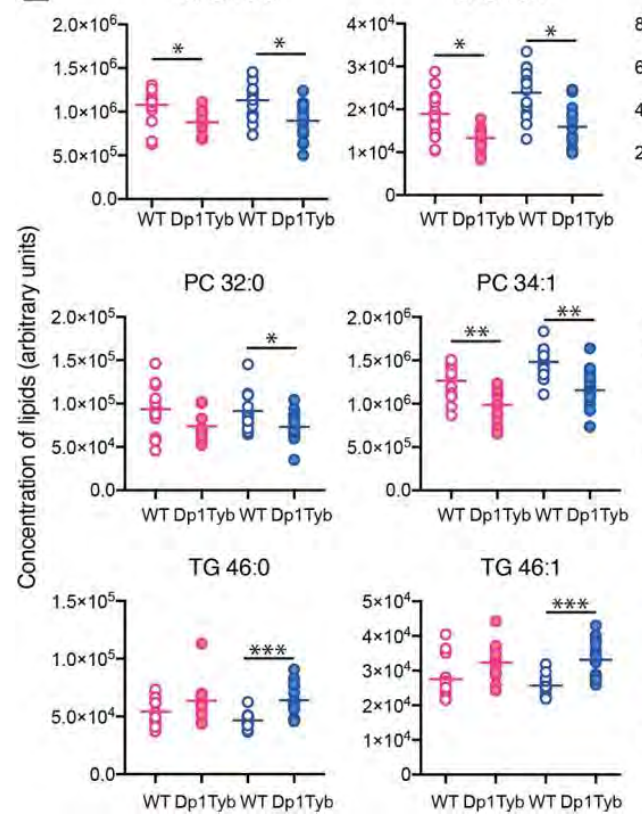

C
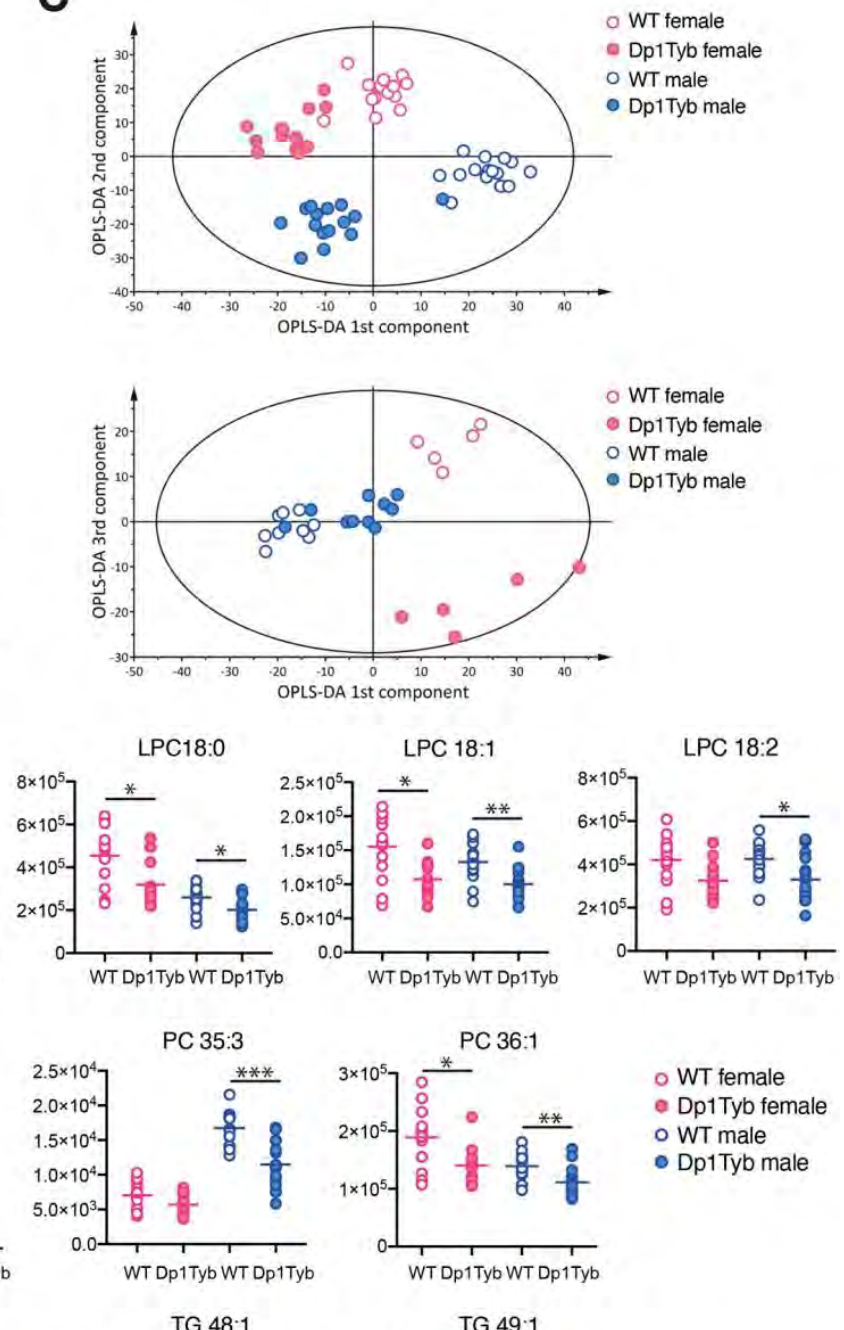

- WT female

e Dp1Tyb female - WT male - Dp1Tyb male
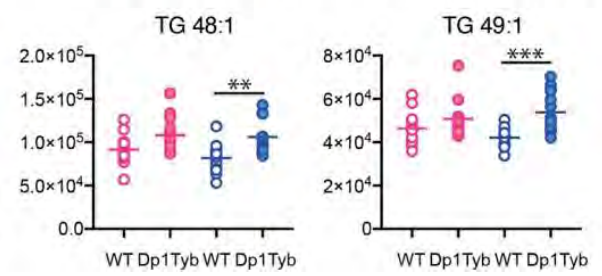

Figure 5. Altered breathing, auditory brainstem response and plasma lipids in

Dp1Tyb mice. A, Mean \pm SEM volume of breaths over a minute or single breaths (tidal) taken by WT or Dp1Tyb mice (cohort 1, females and males combined) 
analysed by whole body plethysmography over three periods of $5 \mathrm{~min}$ : baseline normoxia, hypoxia challenge $\left(10 \% \mathrm{O}_{2}, 3 \% \mathrm{CO}_{2}\right)$ and recovery in normoxia. $\mathrm{B}$, Mean \pm SEM auditory brainstem response of WT or Dp1Tyb mice from cohort 1 (females and males combined) at different frequencies ( $8 \mathrm{kHz}, 16 \mathrm{kHz}$ and $32 \mathrm{kHz}$ ) and to a click box of mixed tones. C, D, Graphs of orthogonal partial least squares discriminant analysis (OPLS-DA) of lipids in plasma from (c) fasted (cohort 2) and (d) free-fed mice (cohort 1 ) mice showing plots of $1^{\text {st }} \vee 2^{\text {nd }}$ or $1^{\text {st }} \vee 3^{\text {rd }}$ OPLS-DA components. The Hotelling $\mathrm{T}^{2}$ ellipse indicates the area within which $95 \%$ of the samples are expected to lie. E, Plasma levels of the indicated lipids (arbitrary units) in fasted WT and Dp1Tyb mice (cohort 2). Horizontal lines indicate mean. ${ }^{*} 0.01<q$ $<0.05 ;{ }^{* *} 0.001<q<0.01 ;{ }^{* *} 0.0001<q<0.001 ; * * * * q<0.0001$. LPC, lysophosphatidylcholine; PC, phosphatidylcholine. 
A
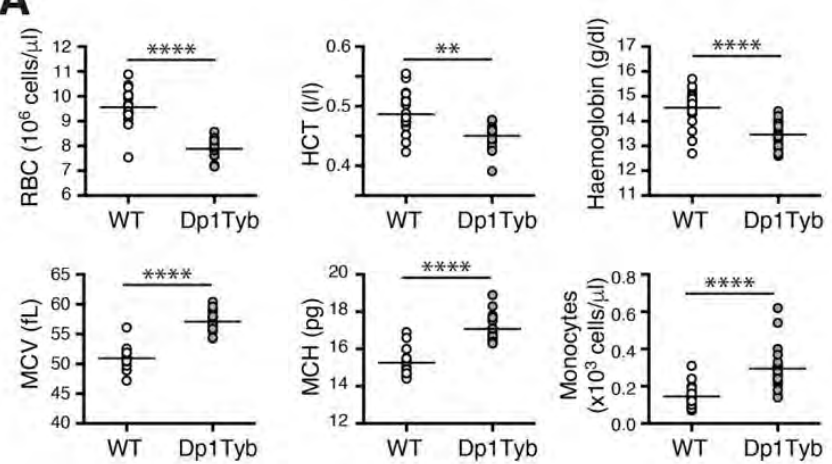

B


Figure 6. Macrocytic anaemia, splenomegaly, and increased erythropoiesis and megakaryopoiesis in Dp1Tyb mice. A, Red blood cell (RBC) concentrations, haematocrit (HCT), haemoglobin, mean corpuscular volume (MCV), mean corpuscular haemoglobin $(\mathrm{MCH})$, and monocytes in the blood of WT or Dp1Tyb mice (cohort 1, females and males combined). B, Flow cytometric analysis of splenocytes from female WT and Dp1Tyb mice (cohort 4), showing mean \pm SEM numbers of splenocytes, transitional type 1 (T1), T2, T3, marginal zone (MZ), follicular (FO), plasmablasts (PB), plasma cells (PC), IgM and lgG1 memory B cells (MBC), germinal centre $(\mathrm{GC}) \mathrm{B}$ cells, mean $\pm \mathrm{SEM}$ ratio of $\mathrm{CD} 4^{+} / \mathrm{CD} 8^{+} \mathrm{T}$ cells, and mean $\pm S E M$ numbers of total or naive $\mathrm{CD}^{+}$or $\mathrm{CD}^{+} \mathrm{T}$ cells, $\mathrm{CD} 2 \mathrm{~L}^{+}$or $\mathrm{CD} 6 \mathrm{~L}^{-}$ 
regulatory $\mathrm{T}$ cells (Treg), effector $\mathrm{T}$ cells, $\mathrm{T}$ follicular helper (Tfh) cells, $\mathrm{CD}^{+}$central memory $(\mathrm{CM})$ and effector memory $(\mathrm{EM}) \mathrm{T}$ cells, $\gamma \delta \mathrm{T}$ cells, NK cells, Ly6C hi and Ly6C $^{10}$ monocytes (mono), dendritic cells (DC), neutrophils (Neut), macrophages, pro-erythroblasts (ProE), EryA, EryB and EryC erythroid progenitors, and immature (imm) and mature (mat) megakaryoblasts (MK). ${ }^{*} 0.01<q<0.05 ;{ }^{* *} 0.001<q<$ $0.01 ;{ }^{* * *} 0.0001<q<0.001 ;{ }^{* * * *} q<0.0001$. 
A
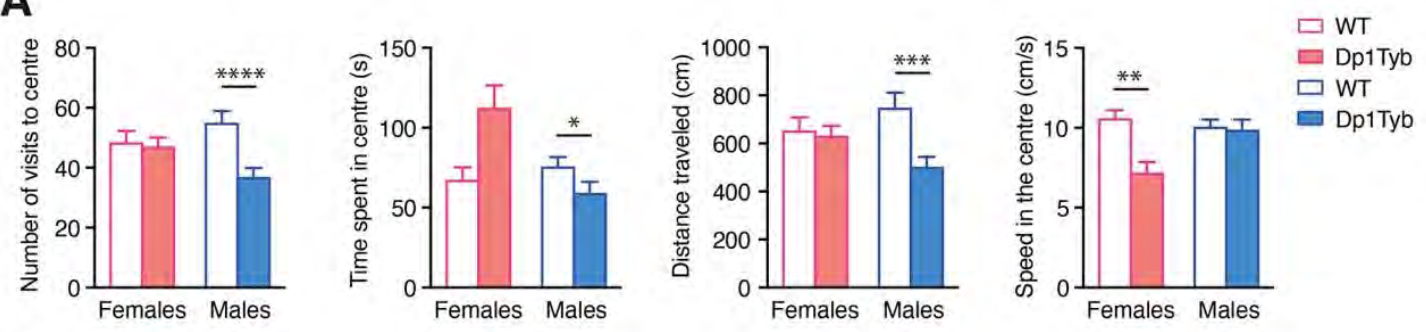

B
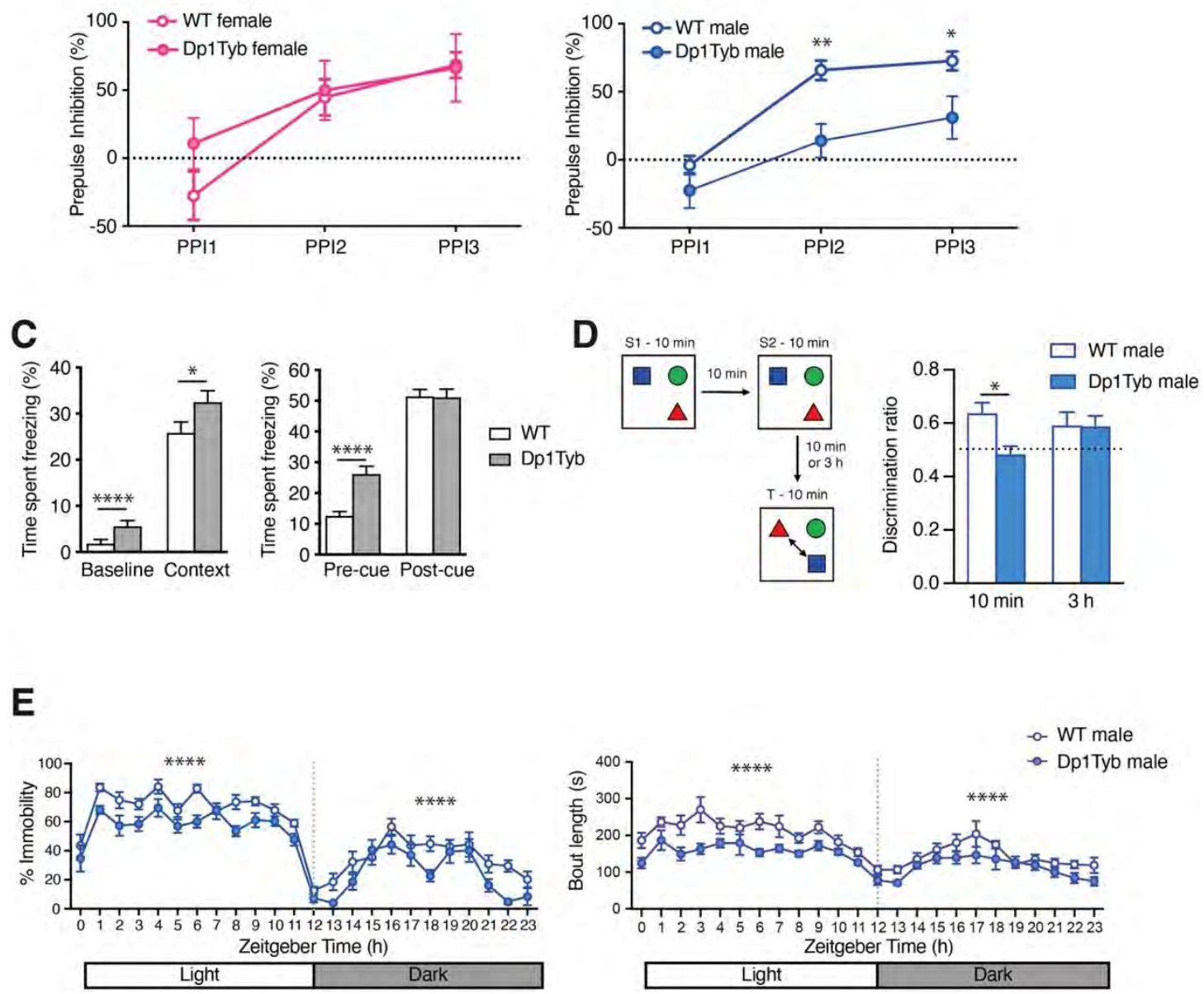

Figure 7. Decreased open field activity, sleep and object-in-place memory in

Dp1Tyb mice. A, Mean \pm SEM number of visits in the centre, time spent in the centre, distance travelled in the centre and speed in the centre of mice in cohort 2 undergoing the open field test. B, Mean \pm SEM pre-pulse inhibition in WT and Dp1Tyb mice (cohort 1) of a response to a startle tone $(110 \mathrm{~dB})$ to increasing volumes of prepulse tones $(55,65,70 \mathrm{~dB}$; PPI1 to PPI3). C, Fear conditioning test on WT and Dp1Tyb mice in cohort 2, showing mean \pm SEM time spent freezing in response to 
being placed in chamber associated with aversive experience (context) compared to response to the same chamber before conditioning (baseline), and also freezing time in a novel chamber before or after being given an auditory tone associated with an aversive experience (pre- and post-cue). D, WT and Dp1Tyb mice (cohort 6) were placed in an arena with 3 different objects for two 10 min sampling periods (S1, S2), then tested after a delay of either $10 \mathrm{~min}$ or $3 \mathrm{~h}$ for their ability to recognise which objects had changed location ( $T$, test phase). There were no differences between groups in object contact times during the sample phase. The discrimination ratio (mean \pm SEM) measures the preferential interaction with switched objects compared to the unchanged object for mice tested after a $10 \mathrm{~min}$ or $3 \mathrm{~h}$ delay. A ratio of 0.5 (dotted line) indicates performance at chance level, with no associative object-inplace memory. E, Mean \pm SEM \% immobility or length of immobile bouts of WT and Dp1Tyb mice (cohort 2) as a function of time showing the light and dark phases of a $24 \mathrm{~h}$ period. Immobility is taken as a proxy of sleep. ${ }^{*} 0.01<q<0.05 ;{ }^{*} 0.001<q<$ $0.01 ;{ }^{* * *} 0.0001<q<0.001 ;{ }^{* * * *} q<0.0001$. 
A
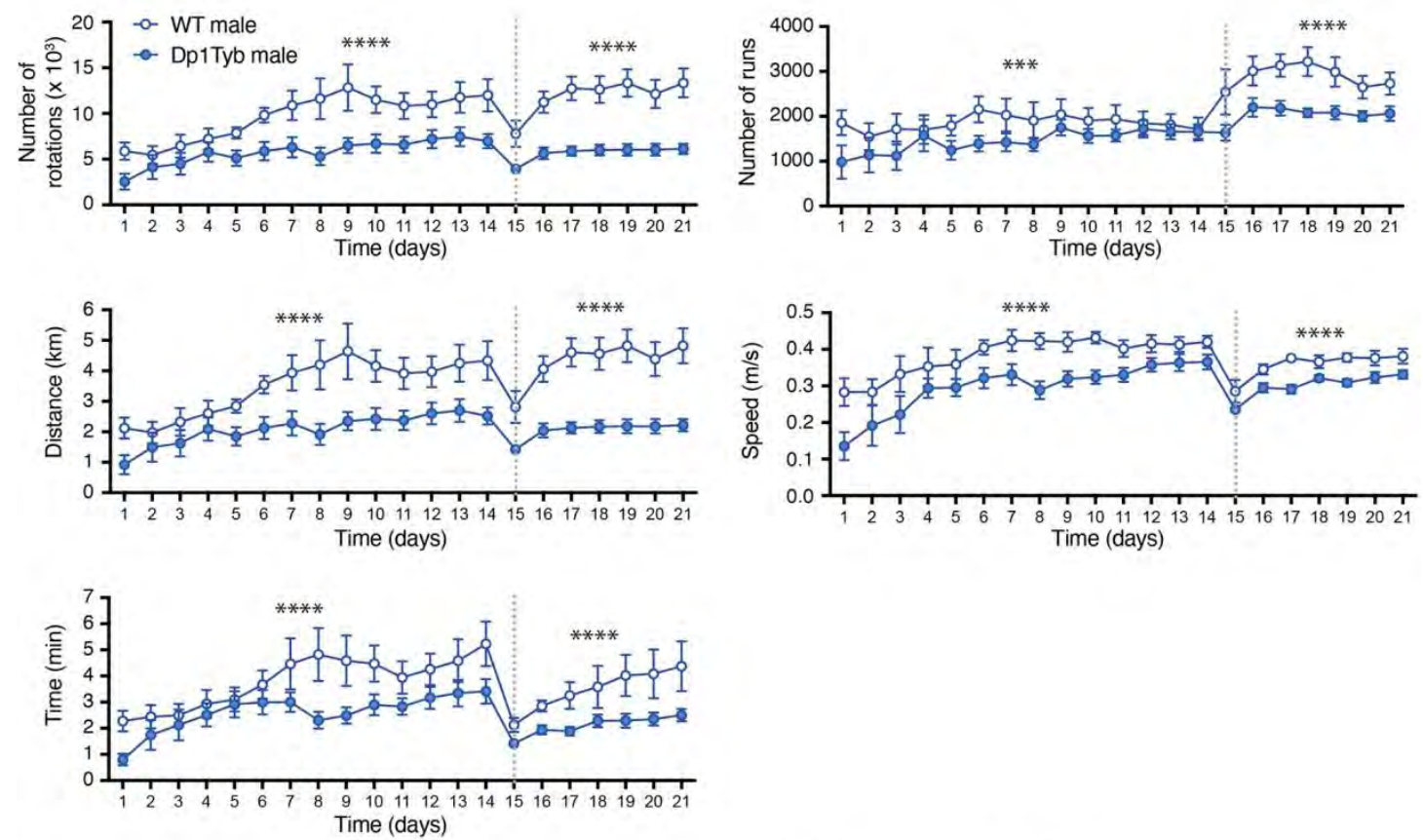

B
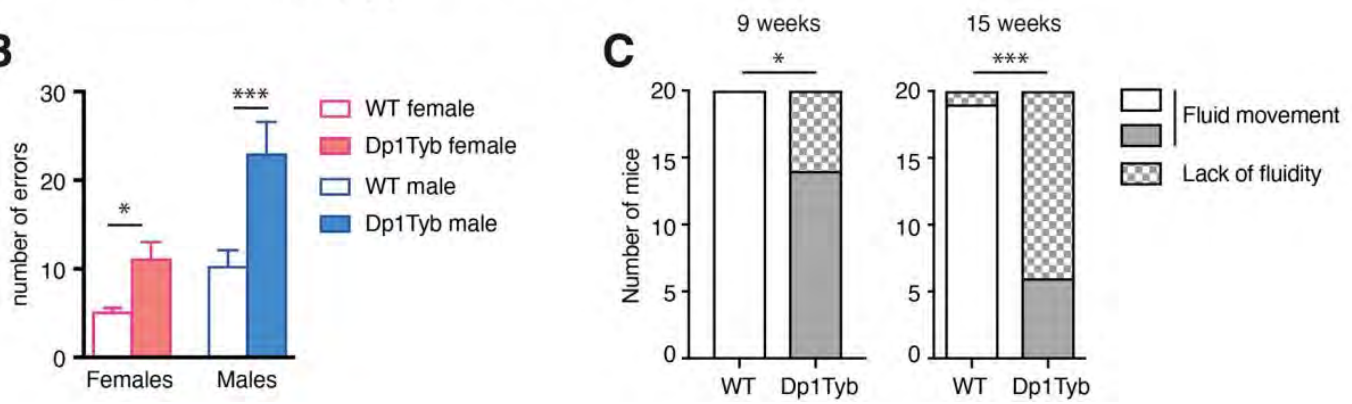

Figure 8. Impaired locomotor activity in Dp1Tyb mice. A, Analysis of home cage wheel running by WT and Dp1Tyb mice (cohort 2) over a 3-week period, showing mean $\pm S E M$ number of rotations, number of runs, distance run, speed and time spent running. Dotted line indicates transition from a simple to a complex wheel in which several rungs were missing. B, Mean \pm SEM number of foot errors made by WT and Dp1Tyb mice (cohort 3) traversing a horizontal ladder in a Locotronic apparatus. C, Graph of numbers of WT and Dp1Tyb mice (cohort 1, females and males combined) showing or lacking fluid movement as determined during a SHIRPA test at 9 and 15 weeks of age. ${ }^{*} 0.01<q<0.05 ;{ }^{* * *} 0.0001<q<0.001 ;{ }^{* * *} q<0.0001$. 
A

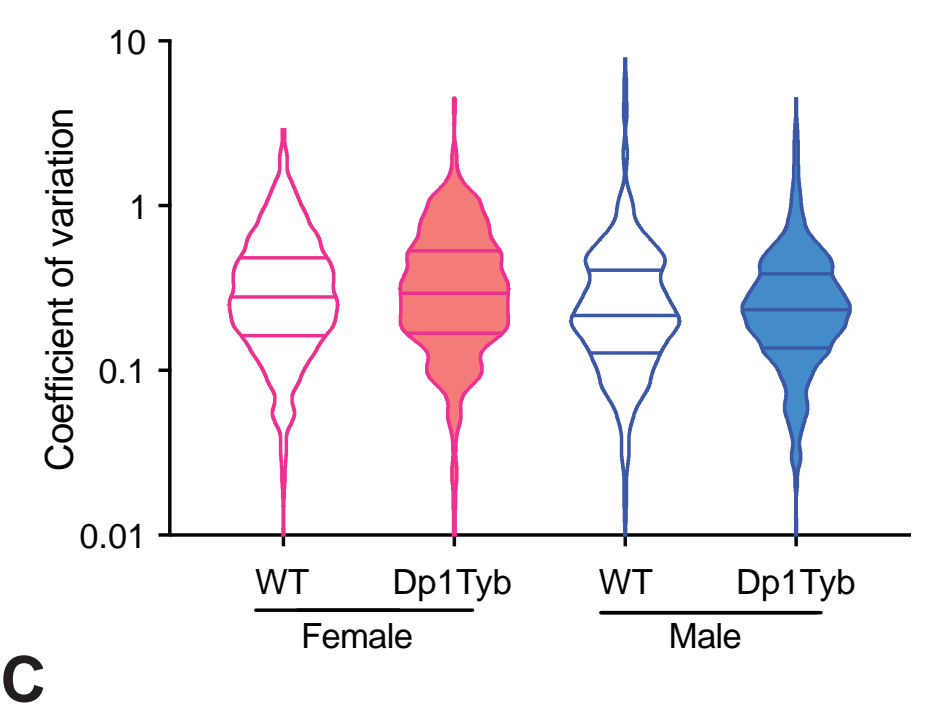

B

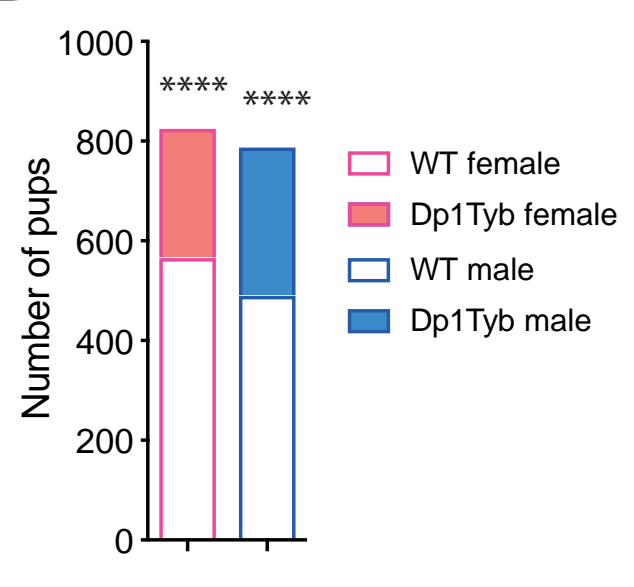

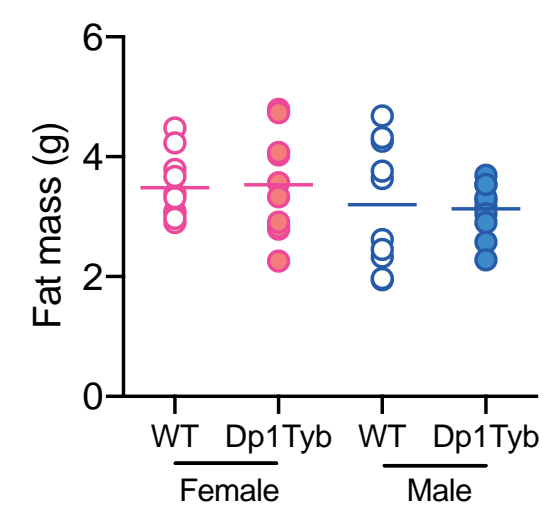

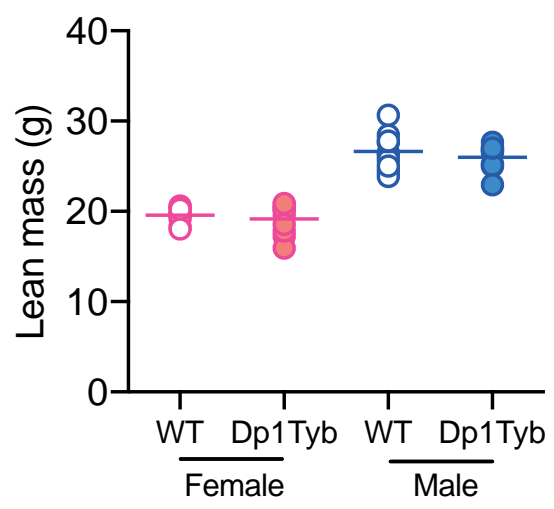

D

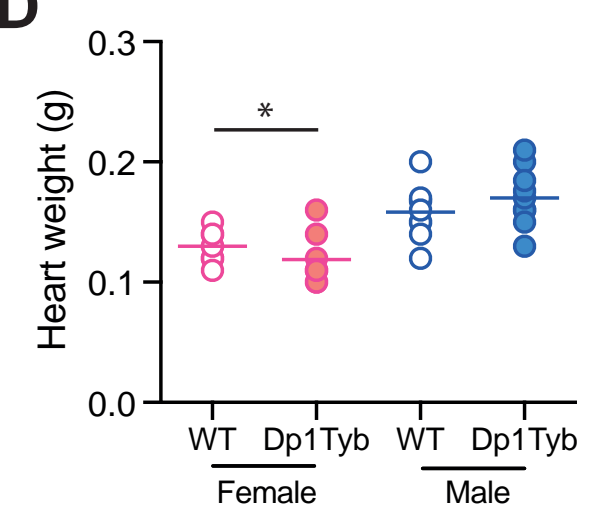

E
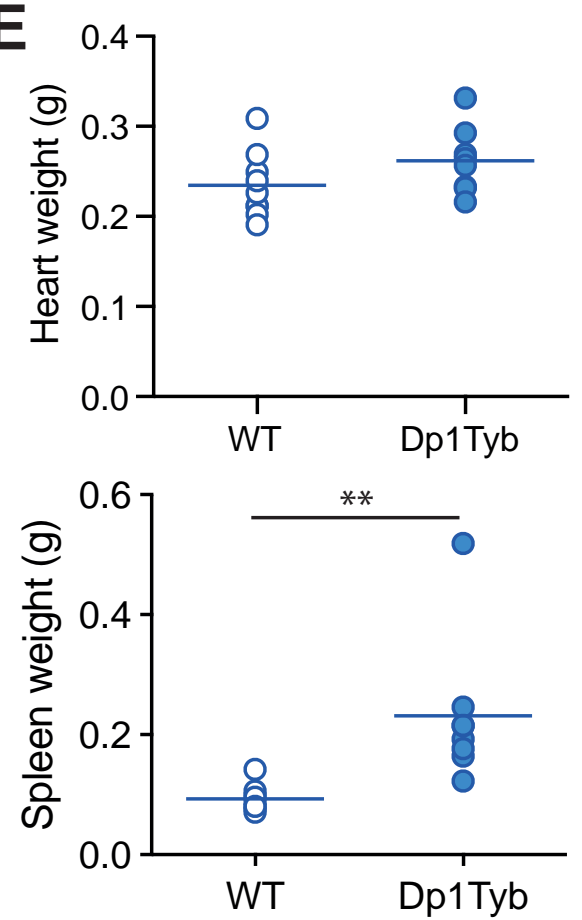
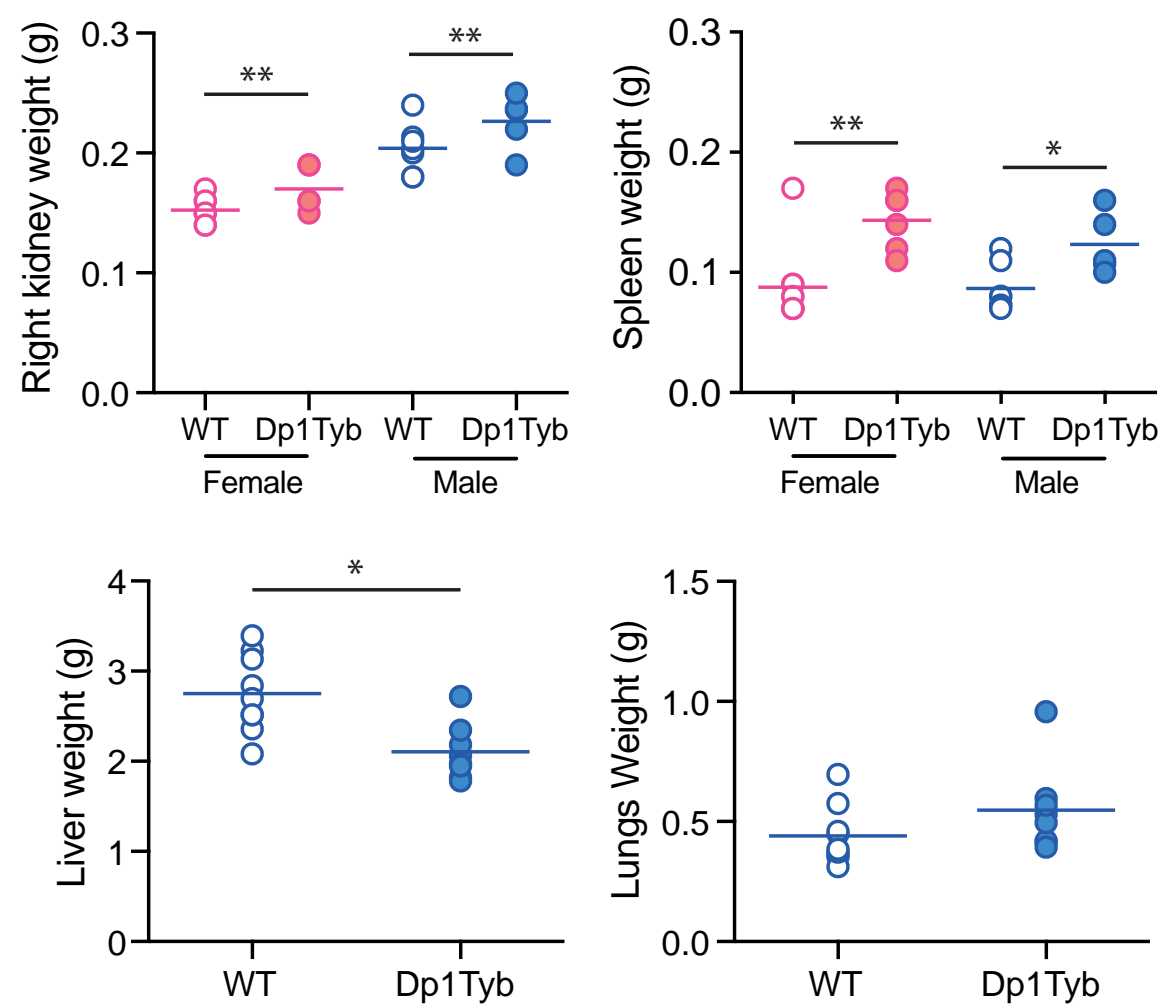
Fig. S1. Decreased viability of Dp1Tyb mice. A, Coefficient of variation (standard deviation/mean) for all numerical parameters analysed shown as violin plots, with horizontal lines indicating median and $25^{\text {th }}$ and $75^{\text {th }}$ centiles. There are no significant differences between WT and Dp1Tyb measurements. Note the medians differ between females and males because some tests were carried out on only one sex (e.g. flow cytometric analysis was only carried out on females). B, Number of WT and Dp1Tyb mice recovered at weaning. C, Fat mass and lean mass of WT and Dp1Tyb mice (cohort 1) determined using ECHO-MRI. D, E, Weights of organs determined at $16(\mathrm{D})$ and $57(\mathrm{E})$ weeks of age. Horizontal lines indicate mean. ${ }^{*} 0.01<q<0.05$; ${ }^{*}$ $0.001<q<0.01 ;{ }^{* * * *} q<0.0001$. 
A
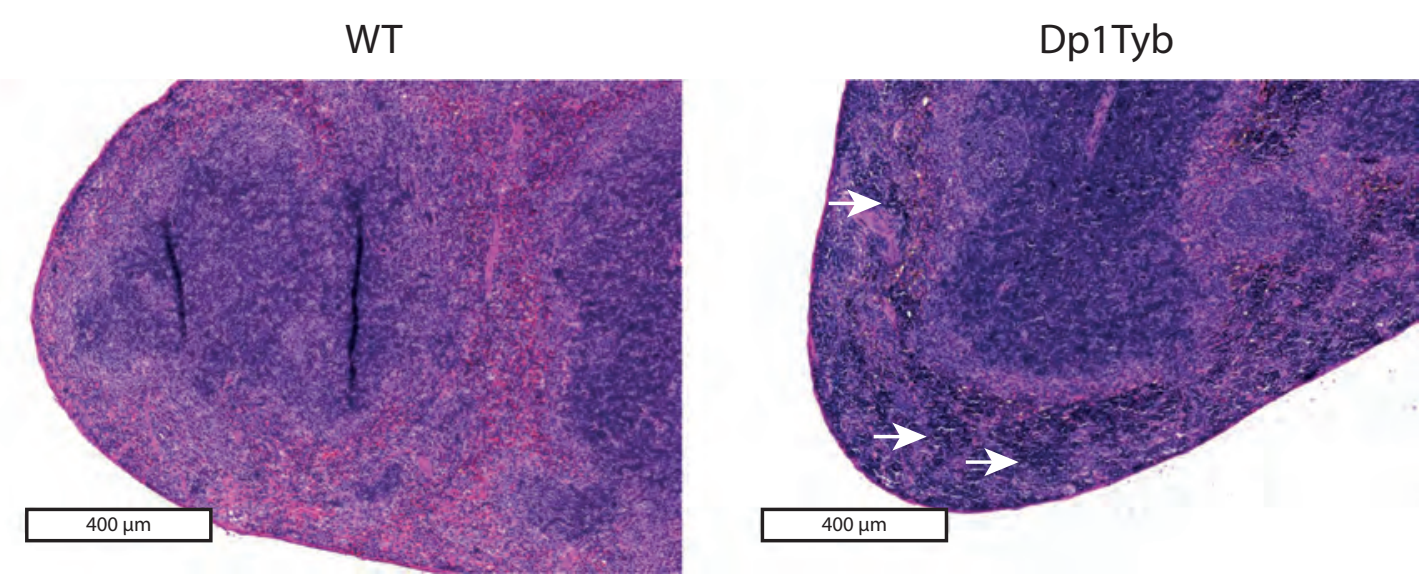

B

WT

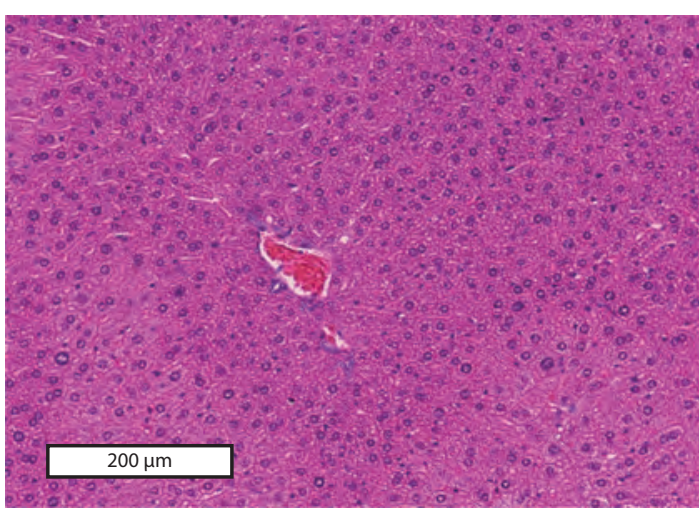

Dp1Tyb

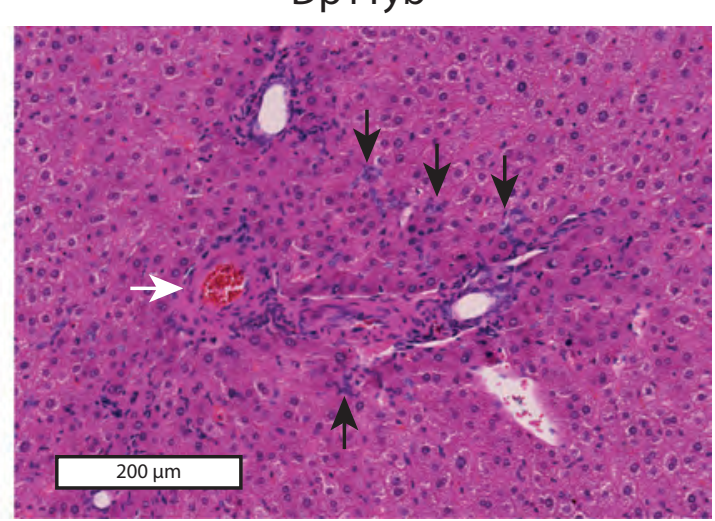

C

J20
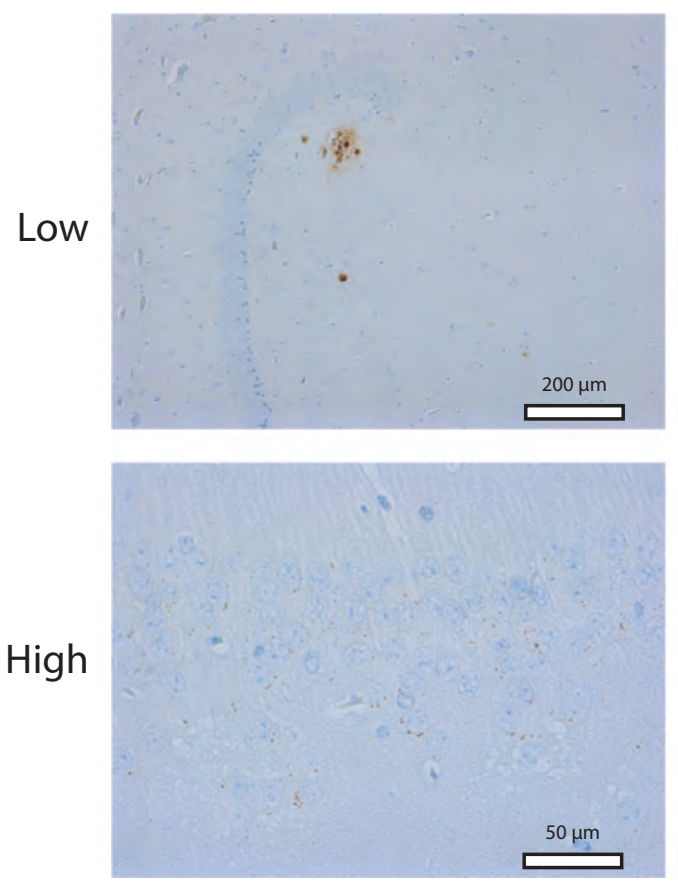

Wildtype
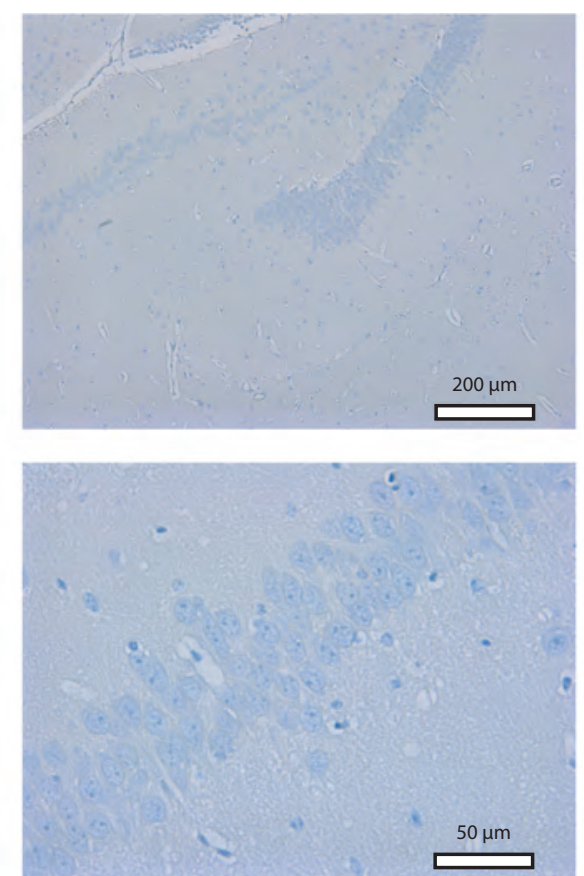

Dp1Tyb
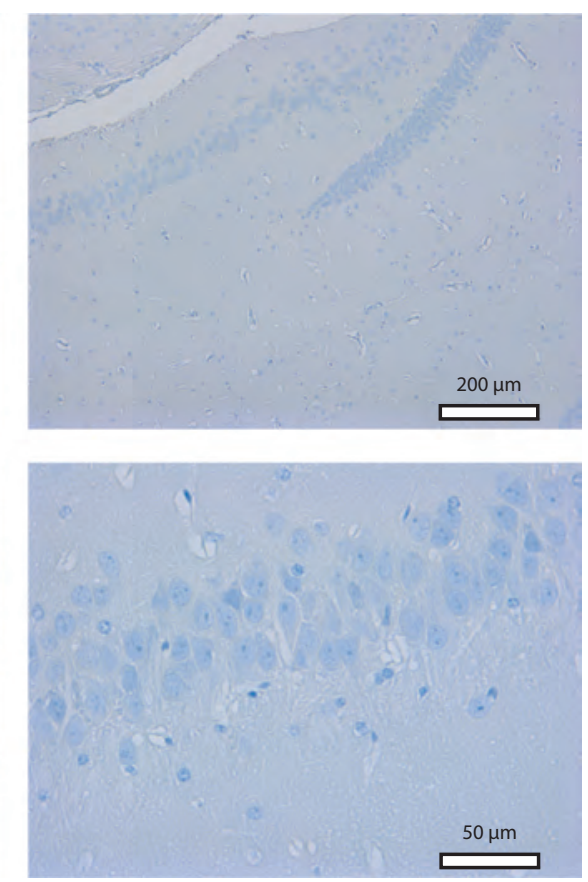

Fig. S2. Pathological changes in spleens and livers of Dp1Tyb mice. A, Sections of spleens from WT and Dp1Tyb mice (cohort 1) stained with haematoxylin and eosin showing increased extramedullary haematopoiesis in Dp1Tyb mice (white arrows). B, Sections of livers from WT and Dp1Tyb mice (cohort 1) stained with haematoxylin and eosin showing prominent vessels (white arrow) and bile duct hyperplasia in Dp1Tyb mice (black arrows). C, Immunohistochemistry staining of A $\beta$ positive extracellular plaques (brown) in the CA3/dentate gyrus region of the hippocampus of a 42-week old J20 mouse used as a positive control, and in 57-week old WT and Dp1Tyb mice. Images shown at low (10x) and high (40x) magnification. Intracellular A $\beta$-positive staining was evident in the J20 CA3 pyramidal neurons only; both WT and Dp1Tyb mice were negative for intracellular $C A 3$ neuronal $A \beta$ staining. 
A

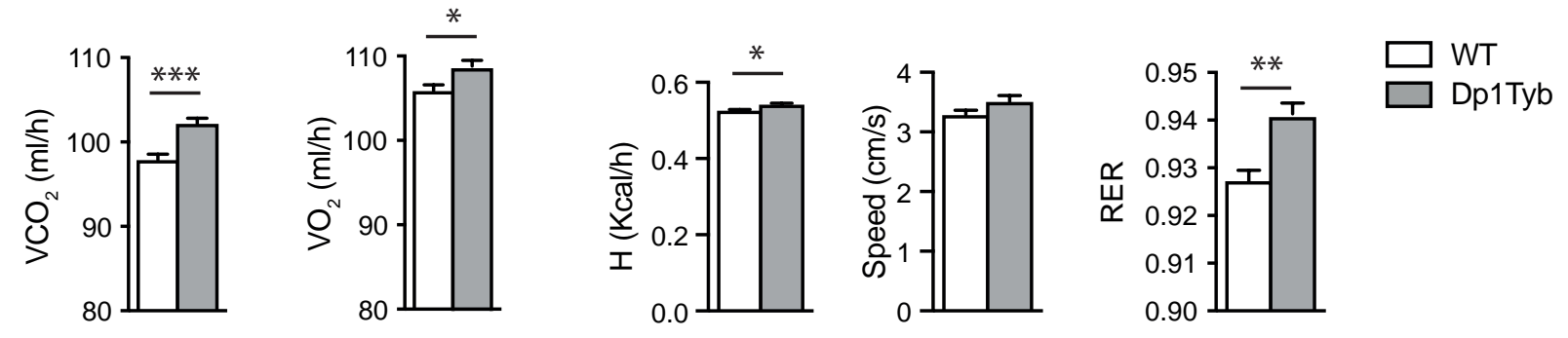

B
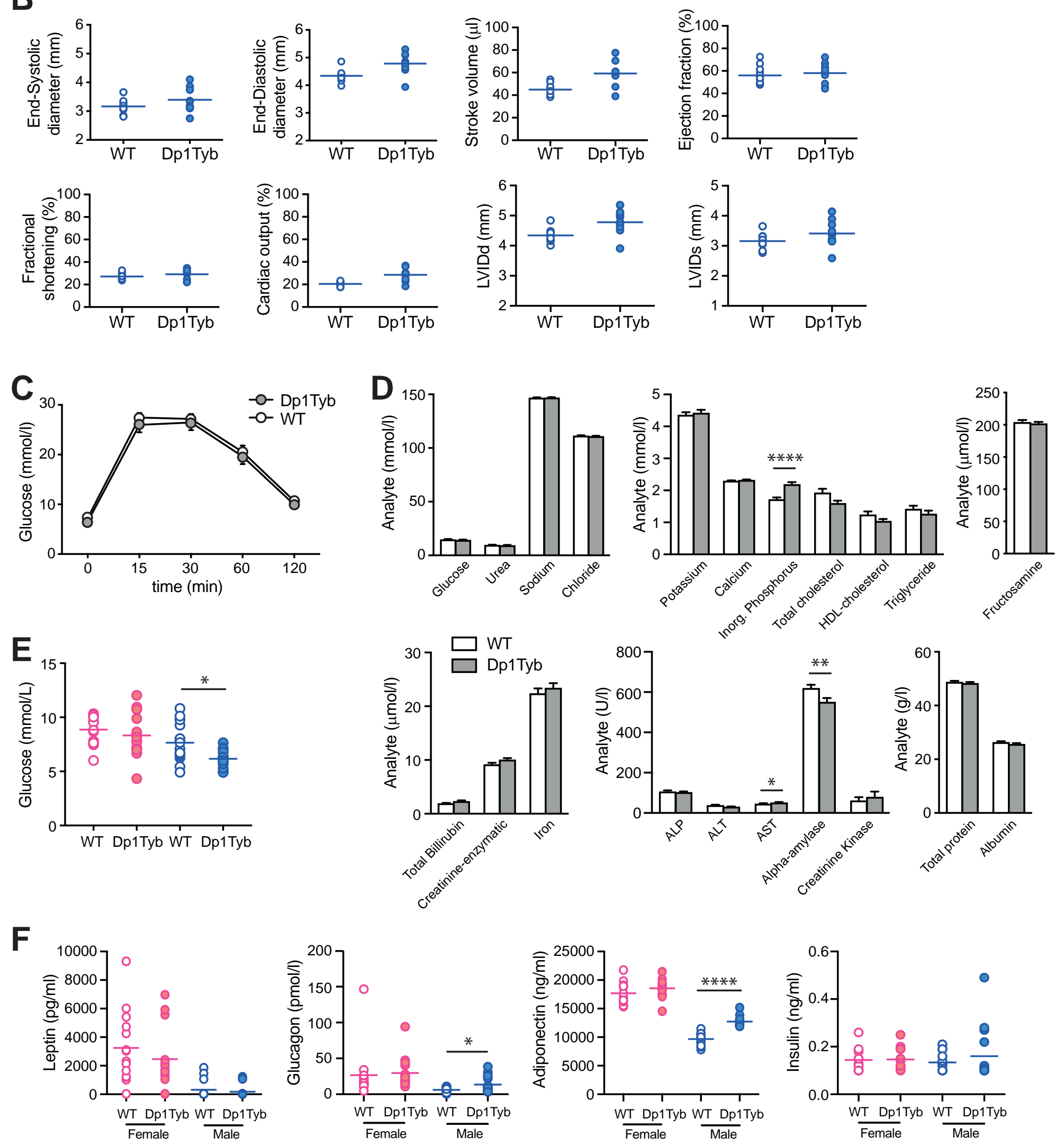

Fig. S3. Calorimetry, echocardiography, glucose tolerance and plasma clinical chemistry of Dp1Tyb mice. A, Mean \pm SEM $\mathrm{CO}_{2}$ production $\left(\mathrm{VCO}_{2}\right), \mathrm{O}_{2}$ consumption $\left(\mathrm{VO}_{2}\right)$, heat production $(\mathrm{H})$, movement speed and respiratory exchange ratio (RER) of WT and Dp1Tyb mice (cohort 1). B, End-systolic diameter, end-diastolic diameter, stroke volume, ejection fraction, fractional shortening, cardiac output, left ventricular inner diameter in diastole (LVIDd) and left ventricular inner diameter in systole (LVIDs) in WT and Dp1Tyb mice at 57 weeks of age (cohort 5) determined by echocardiography. Horizontal lines indicate mean. C, Mean \pm SEM blood glucose level in WT and Dp1Tyb mice (cohort 1) injected with $20 \%$ glucose solution. D, Mean \pm SEM concentrations of the indicated analytes in the blood of free-fed WT and Dp1Tyb mice (cohort 1). E, Levels of glucose in fasted WT and Dp1Tyb mice (cohort 2). F, Levels of the indicated hormones in the blood of fasted WT and Dp1Tyb mice (cohort 2). Horizontal lines indicate mean. ${ }^{*} 0.01<q<0.05 ;{ }^{* *} 0.001<q<0.01 ;{ }^{* * *} 0.0001<q<0.001 ;{ }^{* * * *} q<0.0001$. 

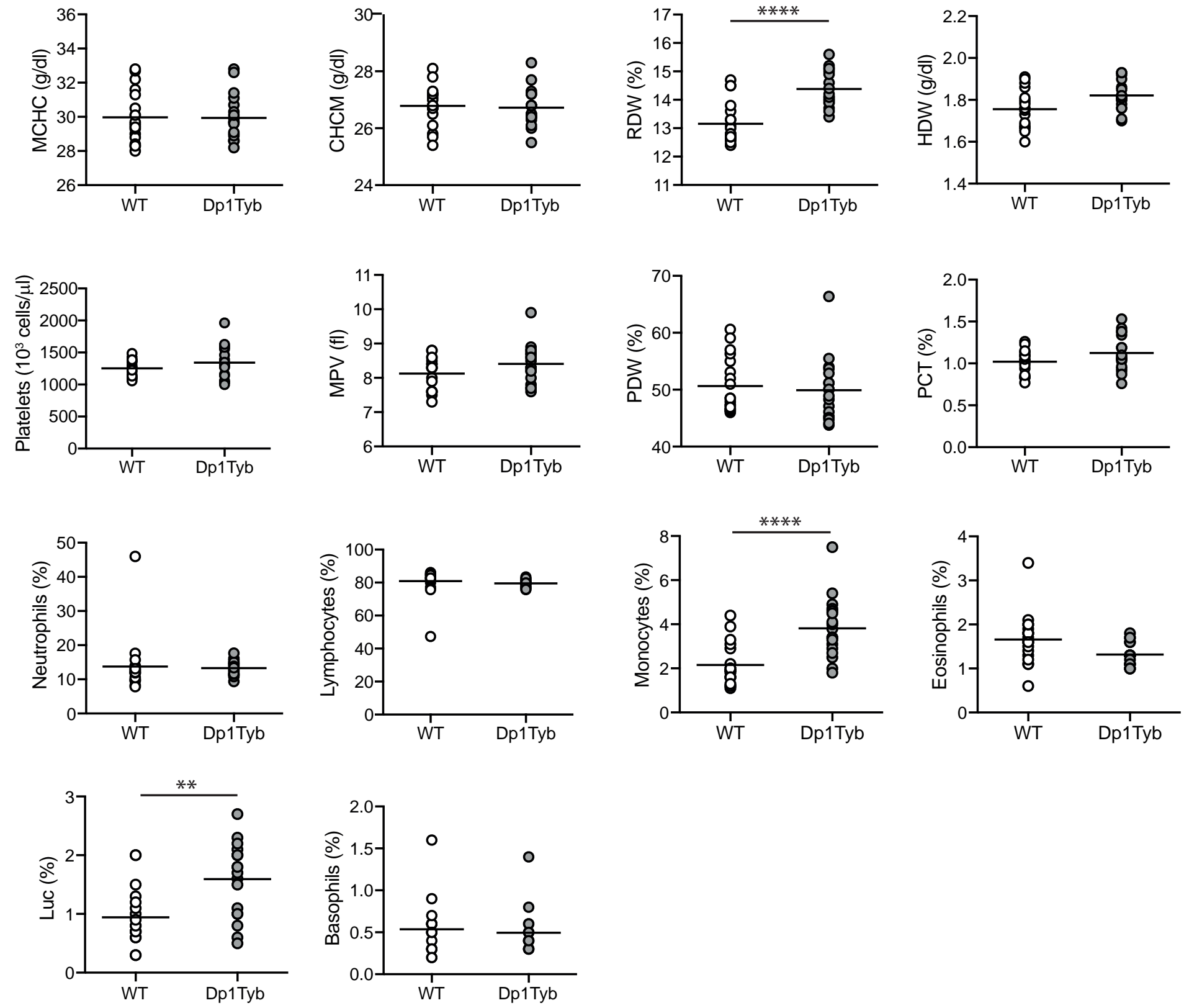

Fig. S4. Haematology of Dp1Tyb mice. Mean corpuscular haemoglobin concentration (MCHC), cell haemoglobin concentration mean (CHCM), red blood cell distribution width (RDW), haemoglobin distribution width (HDW), platelet concentration, mean platelet volume (MPV), platelet distribution width (PDW), plateletcrit (PCT), percentage of neutrophils, lymphocytes, monocytes, eosinophils, large unstained cells (Luc) and basophils in the blood of WT and Dp1Tyb mice (cohort 1). ** $0.001<q<0.01$; *** $q<0.0001$. 
A

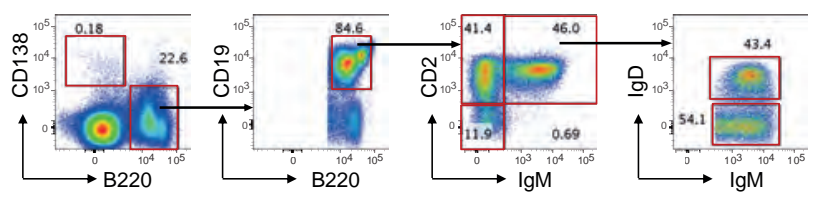

B

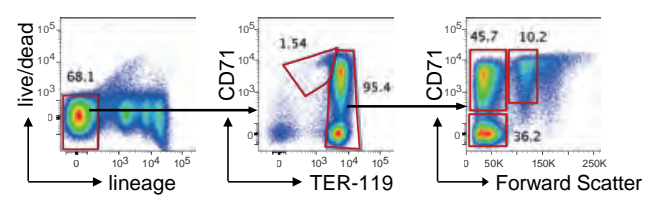

C

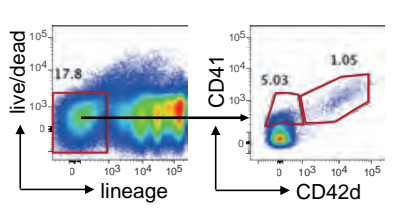

Bone Marrow

\section{D}

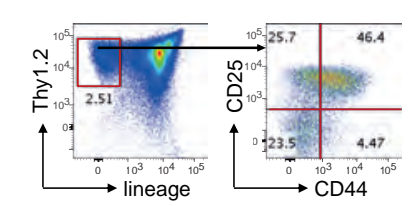

E

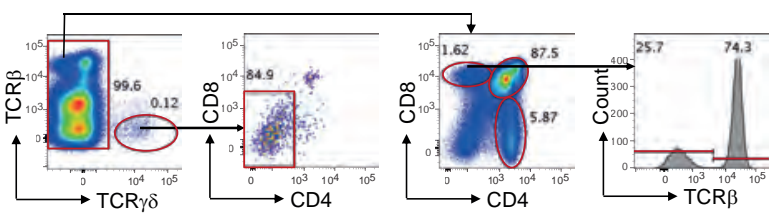

Thymus

$\mathbf{F}$

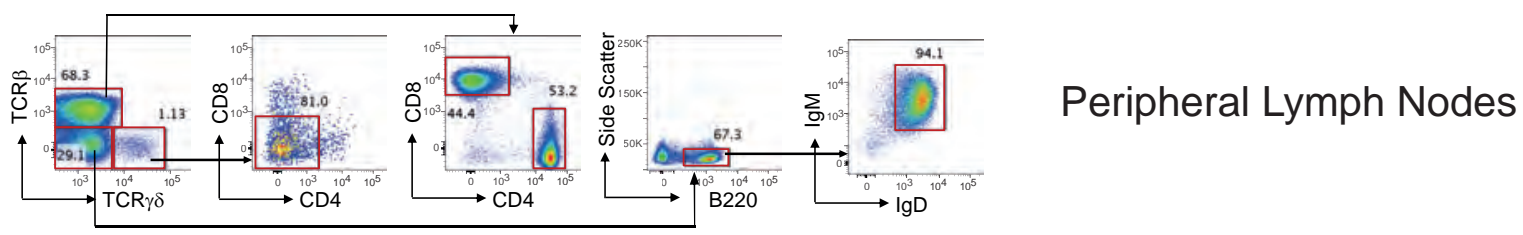

G

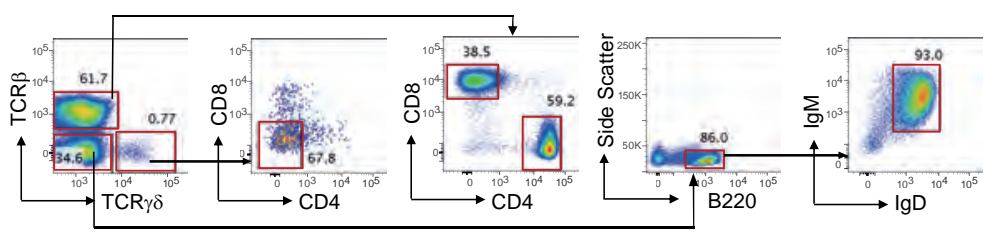

Mesenteric Lymph Nodes

H

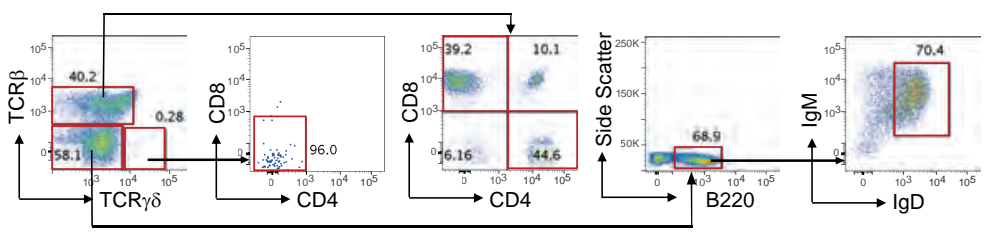

I

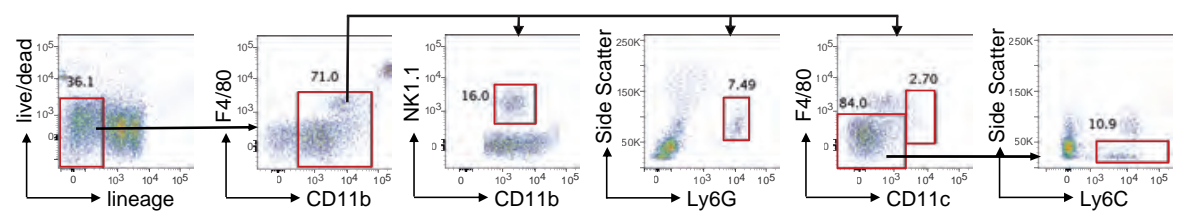

Blood 
Fig. S5. Flow cytometric gating strategies for analysis of bone marrow, thymus, lymph nodes, and blood. Cell types were identified using the following gating strategies. A-C, Bone marrow. A, plasma cells $\left(B 220^{-} \mathrm{CD} 138^{+}\right)$, pro-B $\left(B 220^{+} \mathrm{CD} 2^{-}\right.$

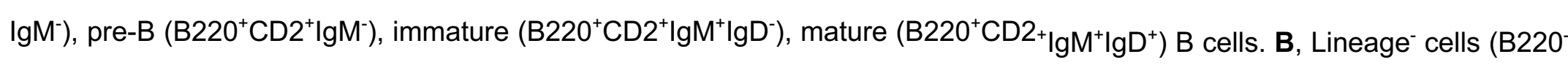

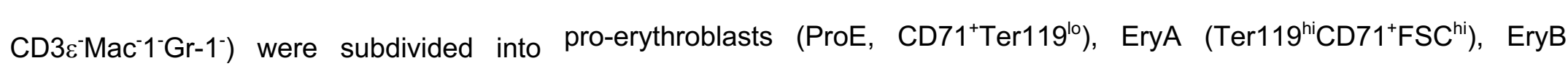
$\left(\right.$ Ter119 $\left.{ }^{\text {hi }} \mathrm{CD} 71^{+} \mathrm{FSC}^{10}\right)$ and EryC $\left(\right.$ Ter119 $\left.9^{\text {hi }} \mathrm{CD} 71^{-} \mathrm{FSC}^{10}\right)$ erythroid progenitors. C, immature (Lineage $\left.\mathrm{CD} 41^{+} \mathrm{CD} 42 \mathrm{~d}^{-}\right)$and mature (Lineage $\left.{ }^{-} \mathrm{CD} 41^{+} \mathrm{CD} 42 \mathrm{~d}^{+}\right)$megakaryoblasts. D, E, Thymus. D, Double negative (DN) thymocytes defined as Lineage ${ }^{-}(\mathrm{CD} 4$

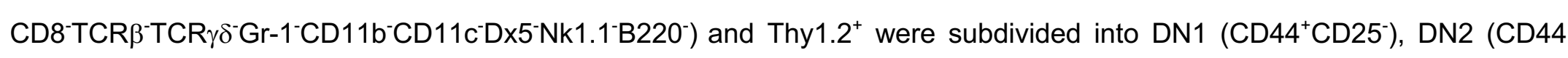
$\left.{ }^{+} \mathrm{CD} 25^{+}\right)$, DN3 $\left(\mathrm{CD} 44^{-} \mathrm{CD} 25^{+}\right)$and DN4 (CD44-CD25-). E, TCR $\gamma \delta$ thymocytes (TCR $\left.\beta^{-} \mathrm{TCR}_{\gamma} \delta^{+} \mathrm{CD}^{-}{ }^{-} \mathrm{CD} 8^{-}\right)$, TCR $\gamma \delta^{-}$cells were subdivided into double positive (DP, $\left.\mathrm{CD} 4^{+} \mathrm{CD} 8^{+}\right), \mathrm{CD} 4^{+}$single positives (SP, $\left.\mathrm{CD} 4^{+} \mathrm{CD} 8^{-}\right), \mathrm{CD} 8^{+}$intermediate single positives (ISP, CD4-CD8 $\left.{ }^{+} \mathrm{TCR} \beta^{-}\right)$, and $\mathrm{CD} 8^{+} \mathrm{SP}\left(\mathrm{CD} 4^{-} \mathrm{CD} 8^{+} \mathrm{TCR} \beta^{+}\right)$. F-H, Peripheral $(\mathrm{F})$ and mesenteric $(\mathrm{G})$ lymph nodes and blood $(\mathrm{H})$. $\gamma \delta$ T cells $\left(\mathrm{TCR} \beta^{-} \mathrm{TCR} \gamma \delta^{+} \mathrm{CD} 4^{-} \mathrm{CD} 8^{-}\right), \mathrm{TCR}_{\gamma} \delta^{-}$cells were subdivided into $\mathrm{CD} 4^{+}\left(\mathrm{TCR} \beta^{+} \mathrm{CD} 4^{+} \mathrm{CD} 8^{-}\right)$and $\mathrm{CD} 8^{+}\left(\mathrm{TCR} \beta^{+} \mathrm{CD} 4^{-} \mathrm{CD} 8^{+}\right)$

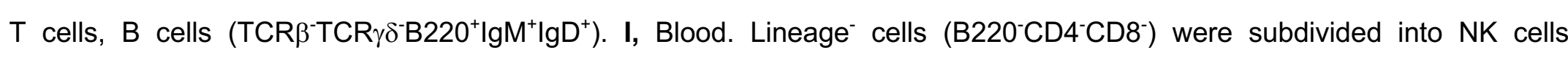
$\left(C D 11 b^{10} F 4 / 80^{-N K 1.1^{+}}\right)$, neutrophils $\left(C D 11 b^{10} F 4 / 80^{-} L_{6} 6 G^{+} S S C^{h i}\right)$, dendritic cells $\left(C D 11 b^{10} F 4 / 80^{-} C D 11 c^{+}\right)$and monocytes $\left(\mathrm{CD} 11 \mathrm{~b}^{10} \mathrm{~F} 4 / 80^{-} \mathrm{CD} 11 \mathrm{C}^{-} \mathrm{Ly} 6 \mathrm{C}^{+}\right)$. Numbers show percentage of cells falling into indicated gates. 
A

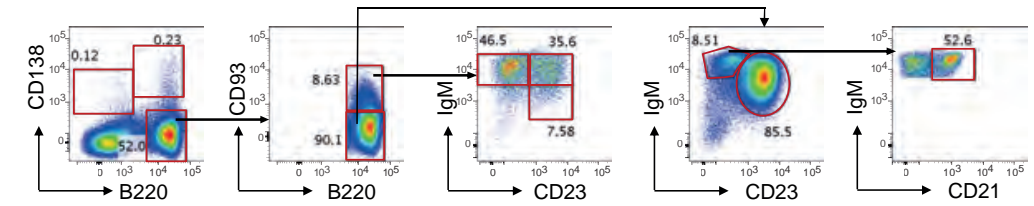

B

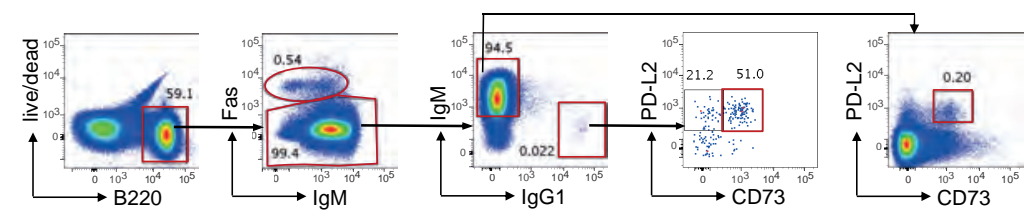

C

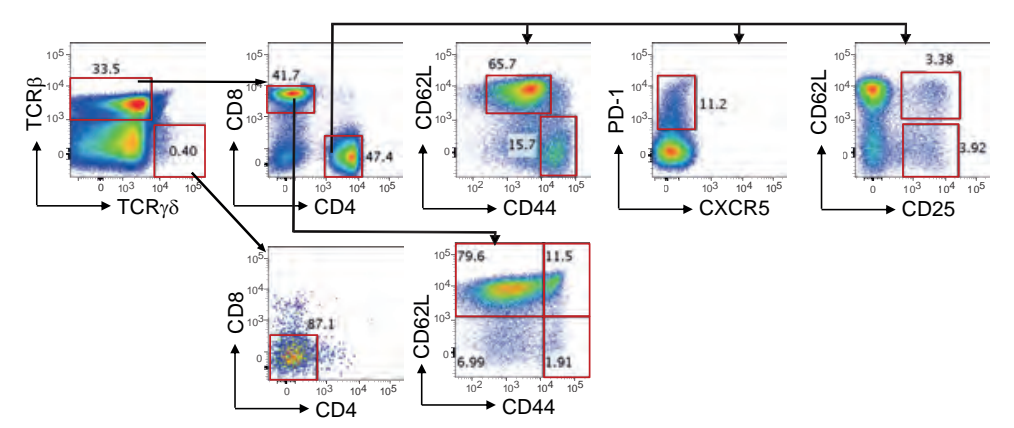

D

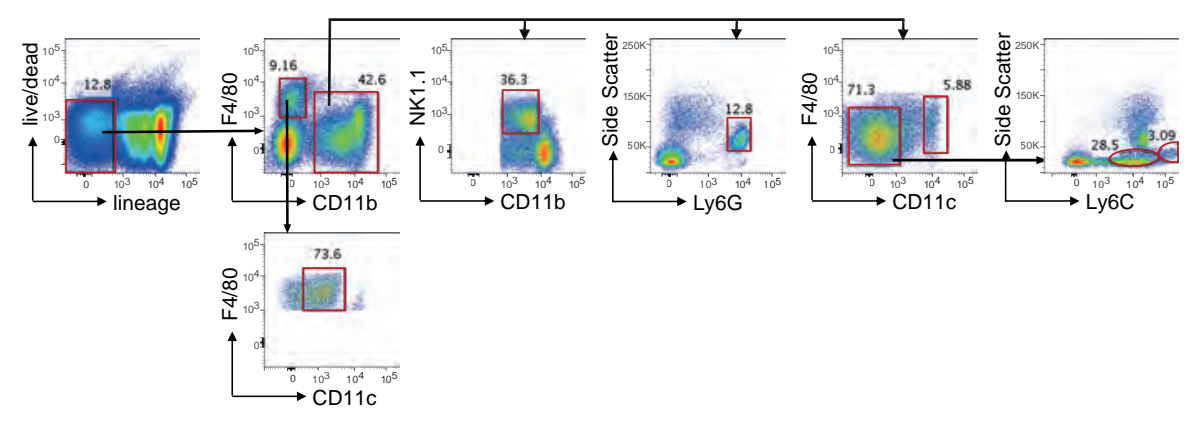

E



F

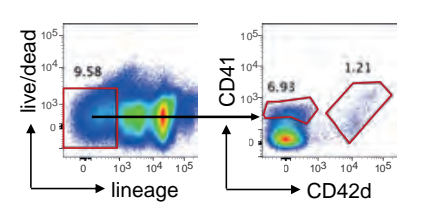

G

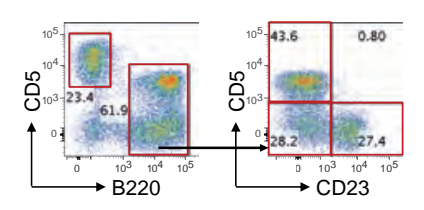

Peritoneal Cavity 
Fig. S6. Flow cytometric gating strategies for analysis of spleen and peritoneal cavity. Cell types were identified using the following gating strategies. A-F, Spleen. A, plasmablasts $\left(B 220^{+} \mathrm{CD} 138^{+}\right)$, plasma cells $\left(B 220^{-}\right.$ $\left.\mathrm{CD} 138^{+}\right)$, transitional $\mathrm{B}$ cells $\left(\mathrm{B} 22 \mathrm{O}^{+} \mathrm{CD} 93^{+}\right)$were subdivided into type $1\left(\mathrm{~T} 1, \operatorname{lgM}^{+} \mathrm{CD} 23^{-}\right), \mathrm{T}\left(\operatorname{lgM}^{+} \mathrm{CD} 23^{+}\right)$and $\mathrm{T3}$ $\left(\operatorname{lgM}{ }^{10} \mathrm{CD} 23^{+}\right)$, mature $\mathrm{B}$ cells $\left(\mathrm{B} 22 \mathrm{O}^{+} \mathrm{CD} 93^{-}\right)$were subdivided into follicular $\left(\operatorname{lgM}^{+} \mathrm{CD} 23^{+}\right)$and marginal zone $(\operatorname{lgM}$ $\left.{ }^{+} \mathrm{CD} 23^{-} \mathrm{CD} 21^{+}\right)$B cells. B, Germinal centre (GC) B cells $\left(\mathrm{B}^{2} 20^{+} \mathrm{Fas}^{+}\right)$, IgM memory B cells (MBC) (B220 ${ }^{+} \mathrm{Fas} \lg \mathrm{M}$

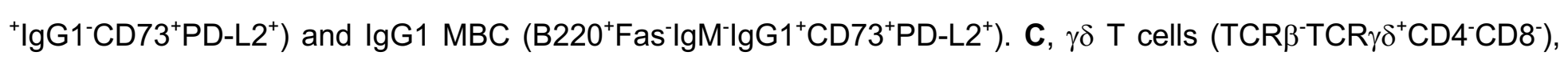
$\mathrm{TCR} \beta^{+} \mathrm{TCR} \gamma \delta^{-}$cells were subdivided into total $\left(\mathrm{CD} 4^{+}\right)$, naïve $\left(\mathrm{CD} 4^{+} \mathrm{CD} 44^{10} \mathrm{CD} 62 \mathrm{~L}^{+}\right)$and effector $(\mathrm{CD} 4$ $\left.{ }^{+} \mathrm{CD} 44^{\mathrm{hi}} \mathrm{CD} 62 \mathrm{~L}^{-}\right) \mathrm{CD}^{+} \mathrm{T}$ cells, $\mathrm{T}$ follicular helper $\mathrm{T}$ cells $\left(\mathrm{CD} 4^{+} \mathrm{PD}-1^{+}\right)$, regulatory $\mathrm{T}$ cells $\left(\mathrm{CD} 4^{+} \mathrm{CD} 25^{+} \mathrm{CD} 62 \mathrm{~L}^{+}{ }^{-}{ }^{-}\right)$, total $\left(C D 8^{+}\right)$, naïve $\left(C D 8^{+} C D 44{ }^{-} C D 62 L^{+}\right)$, central memory $\left(C D 8^{+} C D 44^{+} C D 62 L^{+}\right)$and effector memory $\left(C D 8^{+} C D 44\right.$ $\left.{ }^{+} \mathrm{CD} 62 \mathrm{~L}^{-}\right) \mathrm{CD}^{+} \mathrm{T}$ cells. D, Lineage ${ }^{-}$cells $\left(\mathrm{B} 220^{-} \mathrm{CD} 3 \varepsilon^{-}\right)$were subdivided into macrophages $\left(\mathrm{CD} 11 \mathrm{~b}^{-} \mathrm{CD} 11 \mathrm{c}^{+} \mathrm{F} 4 / 80^{+}\right)$, NK $\left(C D 11 b^{10} F 4 / 80-N K 1.1^{+}\right)$, neutrophils $\left(C D 11 b^{+} F 4 / 80^{-} L_{6} 6 G^{+} S S C^{h i}\right)$, dendritic cells $\left(C D 11 b^{+} F 4 / 80^{-} C D 11 c^{+}\right)$and

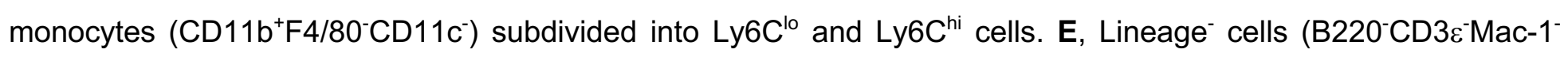
Gr-1 $1^{-}$) were subdivided into pro-erythroblasts (ProE, CD $71^{+}$Ter $\left.119^{\circ}\right)$, EryA $\left(\right.$ Ter $\left.119^{\text {hi }} \mathrm{CD} 71^{+} \mathrm{FSC} \mathrm{C}^{\mathrm{hi}}\right)$, EryB

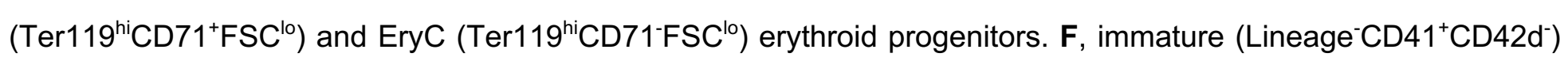
and mature (Lineage $\left.{ }^{-} \mathrm{CD} 41^{+} \mathrm{CD} 42 \mathrm{~d}^{+}\right)$megakaryoblasts. G, Peritoneal cavity. B1a (B220 $\left.{ }^{+} \mathrm{CD} 5^{+} \mathrm{CD} 23^{-}\right)$, B1b (B220

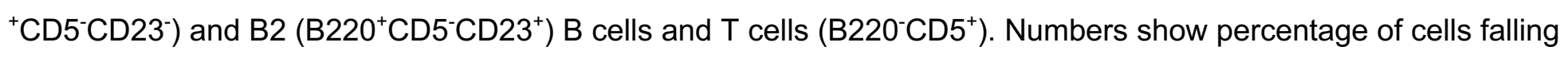
into indicated gates. 
A

B-lineage cells
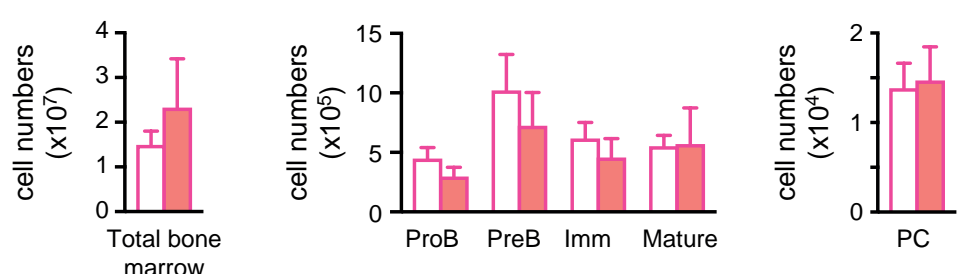

$\square$ WT

$\square$ Dp1Tyb

Erythroid cells

Megakaryocytes
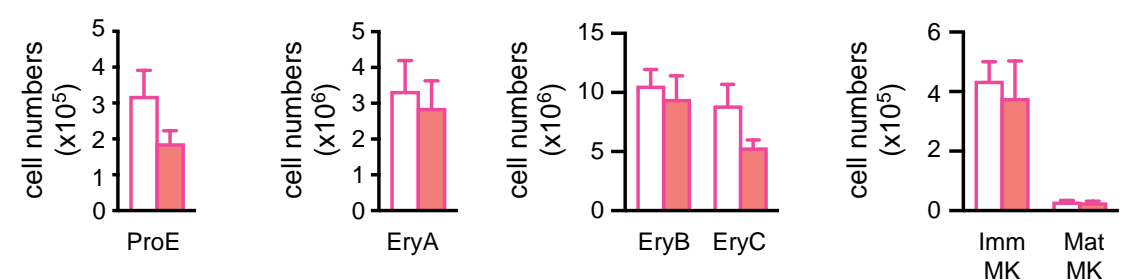

B

B-lineage cells

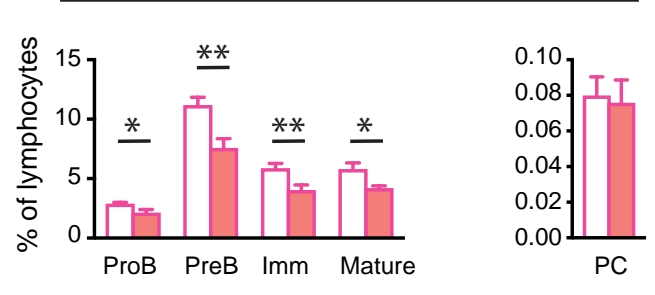

$\square$ WT

$\square$ Dp1Tyb

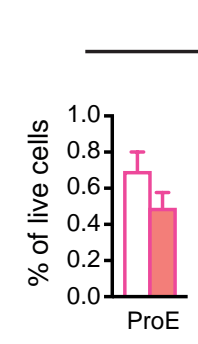

Erythroid cells

Megakaryocytes
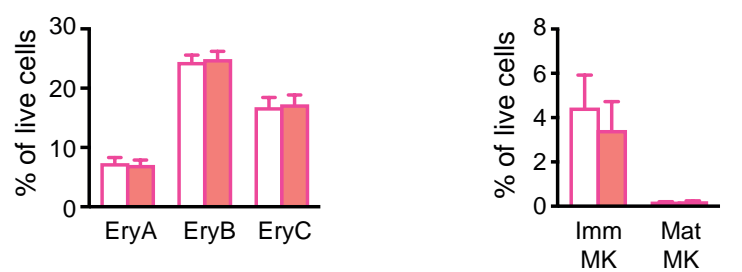

Fig. S7. Flow cytometric analysis of bone marrow cells in Dp1Tyb mice. A, Mean \pm SEM number of cells in the bone marrow of WT and Dp1Tyb mice (cohort 4) (2 tibia and 2 femurs/mouse), showing total cells, pro-B, pre-B, immature (Imm) and mature B cells, plasma cells (PC), pro-erythroblasts (ProE), EryA, EryB and EryC erythroid progenitors, and immature (Imm) and mature (Mat) megakaryoblasts (MK). B, Mean \pm SEM percentages of the populations shown in A. * $0.01<q<0.05 ;{ }^{* *} 0.001<q<0.01$. 


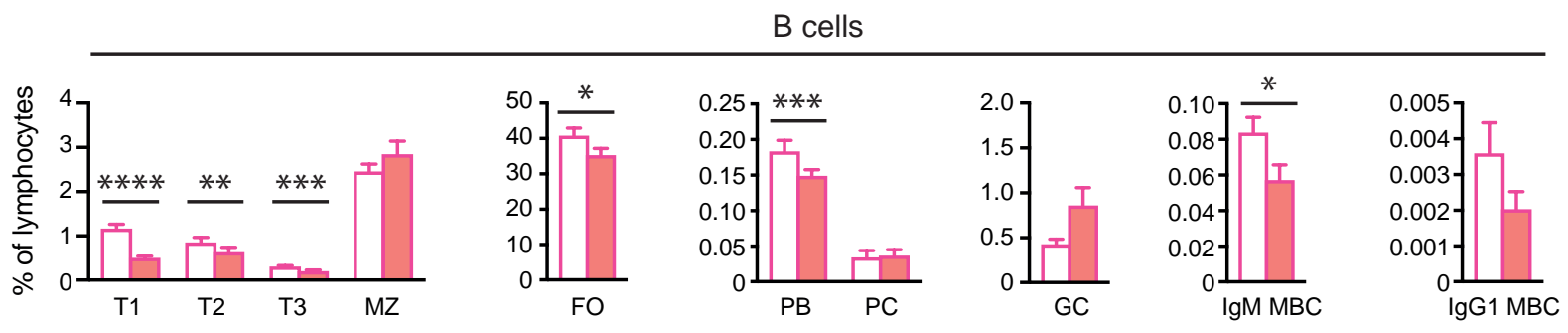

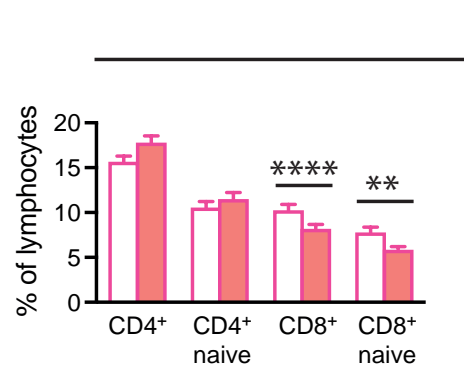

T cells

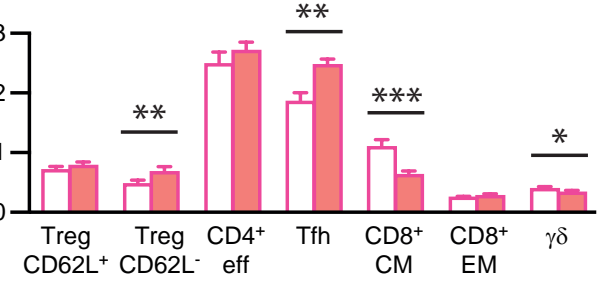

Erythroid cells

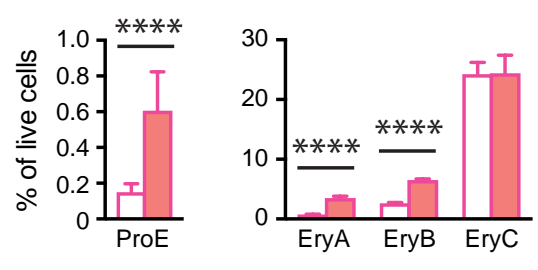

Megakaryocytes

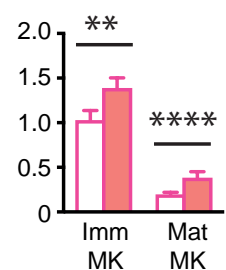

$\square \mathrm{WT}$

Myeloid cells

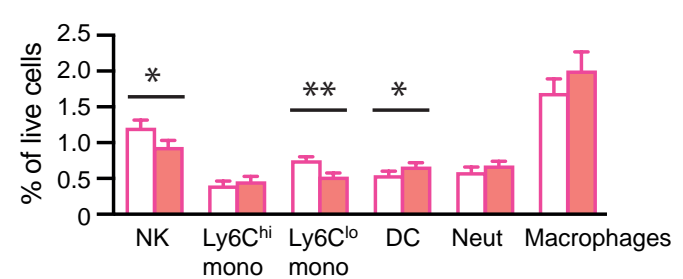

$\square$ Dp1Tyb

Fig. S8. Flow cytometric analysis of splenocytes in Dp1Tyb mice. Mean \pm SEM percentages of transitional type 1 (T1),

T2, T3, marginal zone (MZ), follicular (FO), germinal centre (GC) B cells, plasmablasts (PB), plasma cells (PC), IgM and IgG1 memory $\mathrm{B}$ cells $(\mathrm{MBC})$, and total or naive $\mathrm{CD}^{+}$or $\mathrm{CD}^{+} \mathrm{T}$ cells, $\mathrm{CD} 62 \mathrm{~L}^{+}$or $\mathrm{CD} 62 \mathrm{~L}^{-}$regulatory $\mathrm{T}$ cells (Treg), $\mathrm{CD} 4^{+}$ effector (eff) T cells, T follicular helper (Tfh) cells, $C D 8^{+}$central memory (CM) and effector memory (EM) T cells, $\gamma \delta \mathrm{T}$ cells, NK cells, Ly6C ${ }^{\text {hi }}$ and Ly6C ${ }^{l o}$ monocytes (mono), dendritic cells (DC), neutrophils (Neut), macrophages, pro-erythroblasts (ProE), EryA, EryB and EryC erythroid progenitors, and immature (Imm) and mature (Mat) megakaryoblasts (MK) in the spleen of WT and Dp1Tyb mice (cohort 4). ${ }^{*} 0.01<q<0.05 ;{ }^{* *} 0.001<q<0.01 ;{ }^{* * *} 0.0001<q<0.001 ;{ }^{* * * *} q<0.0001$. 
A Blood

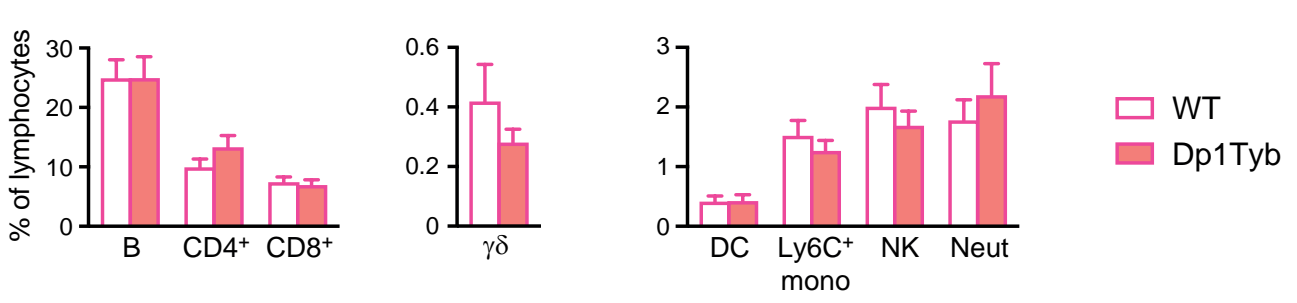

B Peripheral lymph nodes

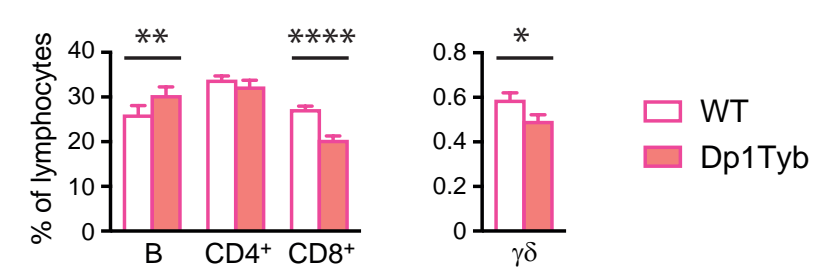

C Mesenteric lymph nodes

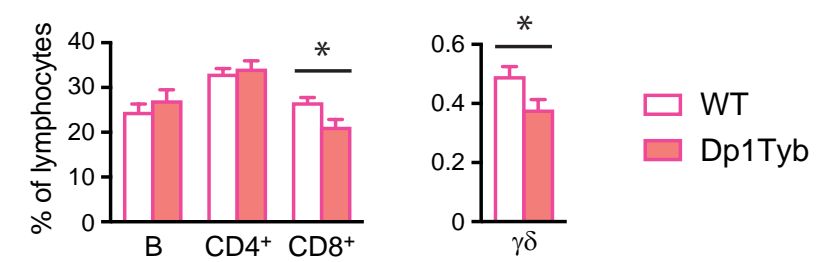

D Peritoneal cavity

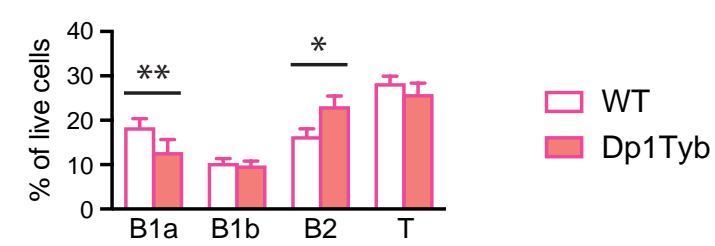

Fig. S9. Flow cytometric analysis of blood, lymph nodes and peritoneal cavity in Dp1Tyb mice. A-C, (A) Mean \pm SEM percentages of $B$ cells, $\mathrm{CD}^{+}, \mathrm{CD}^{+}$and $\gamma \delta \mathrm{T}$ cells, dendritic cells (DC), Ly6C ${ }^{+}$monocytes (mono), NK cells, and neutrophils (Neut) in the blood, (B) peripheral lymph nodes, and (C) mesenteric lymph nodes of WT and Dp1Tyb mice (cohort 4). D, Mean \pm SEM percentages of B1a, B1b and B2 B cells and T cells in the peritoneal cavity of WT and Dp1Tyb mice (cohort 4). ${ }^{*} 0.01<q<0.05 ;{ }^{* *} 0.001<q<0.01 ;{ }^{* * * *} q<0.0001$. 
A
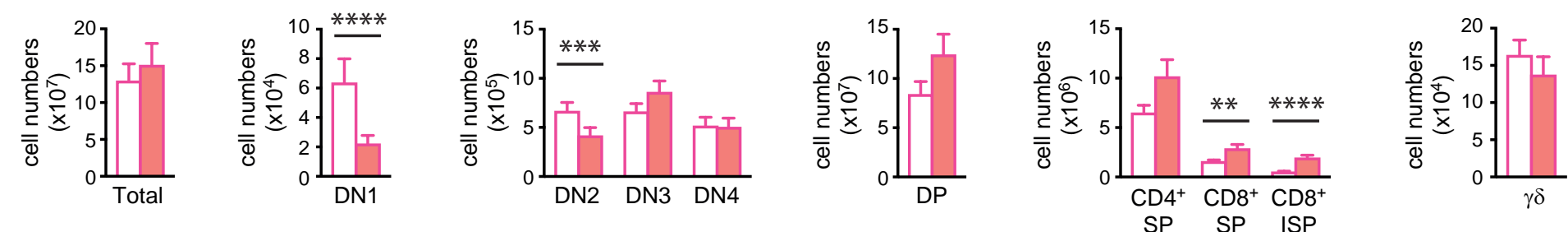

B
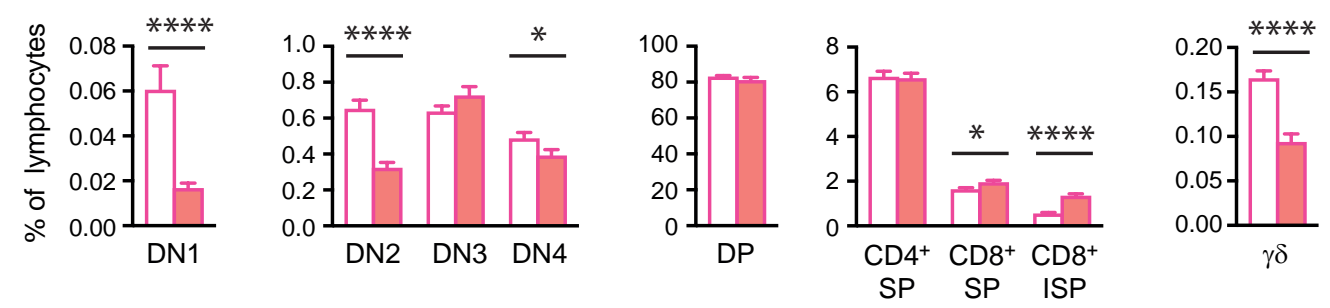

$\square$ WT

Fig. S10. Flow cytometric analysis of thymocytes in Dp1Tyb mice. A, Mean \pm SEM number of cells in the thymus of WT and Dp1Tyb mice (cohort 4), showing total cells, DN1, DN2, DN3, DN4, DP, CD4 ${ }^{+} \mathrm{SP}, \mathrm{CD}^{+} \mathrm{SP}$ $\mathrm{CD}^{+}$ISP and TCR $\gamma \delta^{+}$thymocytes. B, Mean \pm SEM percentages of the populations shown in A. * $0.01<q<0.05$; ${ }^{* *} 0.001<q<0.01 ;{ }^{* * *} 0.0001<q<0.001 ;{ }^{* * *} q<0.0001$. 
A
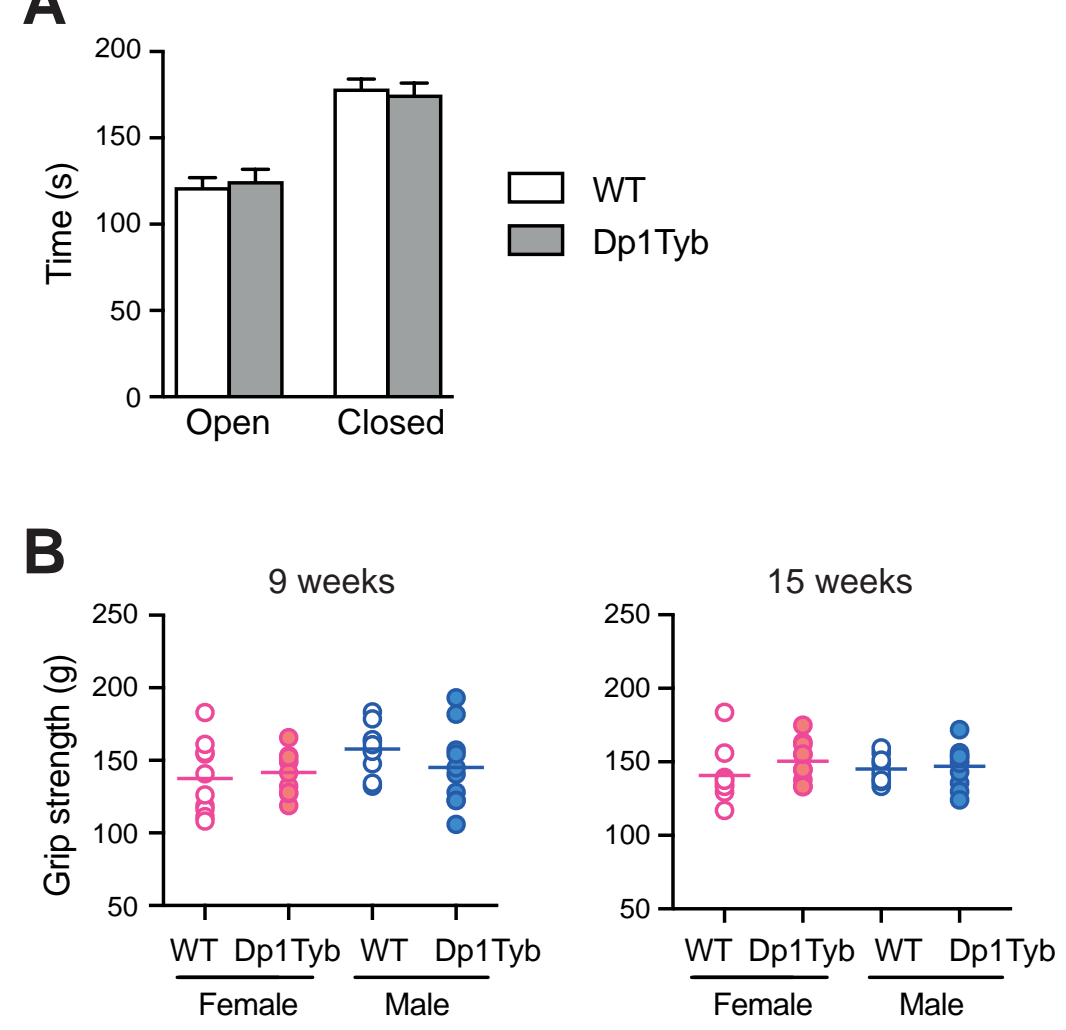

Fig. S11. Elevated zero maze and grip strength tests.

A, Mean \pm SEM time spent in the open and closed arms of an elevated zero maze by WT and Dp1Tyb mice (cohort 3). B, Grip strength of WT and Dp1Tyb mice (cohort 1) determined using all four limbs at 9 and 15 weeks of age. Horizontal lines indicate mean. 
Table S1. Statistical Analysis.

Click here to download Table S1

Table S2. Dp1Tyb mice have abnormal heads, snouts, lips and gait. A, Table shows numbers of mice that gave the expected or not expected result in each of the tests in the Combined SHIRPA and Dysmorphology (CSD) tests. Dp1Tyb and WT mice were tested at 9 and 15 weeks of age (cohort 1). Test showing statistically significant differences $(q<0.05)$ between Dp1Tyb and WT mice at either 9 or 15 weeks or both are highlighted in yellow. B, Locomotor activity measured as mean \pm sem number of squares entered by the mouse in 30 s.

A

\begin{tabular}{|c|c|c|c|c|c|c|c|c|c|}
\hline \multirow[b]{3}{*}{ Test } & \multicolumn{4}{|c|}{9 weeks } & \multicolumn{4}{|c|}{15 weeks } & \multirow[b]{3}{*}{ Comments } \\
\hline & \multicolumn{2}{|c|}{ WT } & \multicolumn{2}{|c|}{ Dp1Tyb } & \multicolumn{2}{|c|}{ WT } & \multicolumn{2}{|c|}{ Dp1Tyb } & \\
\hline & $\begin{array}{c}\text { As } \\
\text { expected }\end{array}$ & $\begin{array}{c}\text { Not as } \\
\text { expected }\end{array}$ & $\begin{array}{c}\text { As } \\
\text { expected }\end{array}$ & $\begin{array}{c}\text { Not as } \\
\text { expected }\end{array}$ & $\begin{array}{c}\text { As } \\
\text { expected }\end{array}$ & $\begin{array}{c}\text { Not as } \\
\text { expected }\end{array}$ & $\begin{array}{c}\text { As } \\
\text { expected }\end{array}$ & $\begin{array}{c}\text { Not as } \\
\text { expected }\end{array}$ & \\
\hline Tail & 19 & 1 & 14 & 6 & 17 & 4 & 10 & 10 & \\
\hline Coat & 20 & 0 & 20 & 0 & 21 & 0 & 20 & 0 & \\
\hline Forelimbs & 20 & 0 & 20 & 0 & 21 & 0 & 20 & 0 & \\
\hline Hindlimbs & 20 & 0 & 20 & 0 & 21 & 0 & 20 & 0 & \\
\hline Vibrissae & 19 & 1 & 20 & 0 & 21 & 0 & 20 & 0 & \\
\hline Head & 18 & 2 & 11 & 9 & 19 & 2 & 8 & 12 & $\begin{array}{l}\text { Abnormal } \\
\text { shape }\end{array}$ \\
\hline Ears & 20 & 0 & 20 & 0 & 21 & 0 & 20 & 0 & \\
\hline Snout Size & 20 & 0 & 9 & 11 & 20 & 1 & 13 & 7 & Decreased \\
\hline $\begin{array}{l}\text { Activity (body } \\
\text { position) }\end{array}$ & 19 & 1 & 17 & 3 & 21 & 0 & 18 & 2 & \\
\hline Tremor & 20 & 0 & 17 & 3 & 3 & 18 & 14 & 6 & $\begin{array}{l}\text { Tremor } \\
\text { present }\end{array}$ \\
\hline Faecal pellet & 19 & 0 & 20 & 0 & 21 & 0 & 20 & 0 & \\
\hline $\begin{array}{l}\text { Feet position in } \\
\text { jar }\end{array}$ & 20 & 0 & 16 & 4 & 21 & 0 & 20 & 0 & \\
\hline Transfer Arousal & 20 & 0 & 18 & 2 & 21 & 0 & 18 & 2 & \\
\hline Gait & 20 & 0 & 14 & 6 & 20 & 1 & 6 & 14 & $\begin{array}{l}\text { Lack of fluid } \\
\text { movement }\end{array}$ \\
\hline Tail Elevation & 20 & 0 & 20 & 0 & 21 & 0 & 20 & 0 & \\
\hline Startle Response & 10 & 0 & 9 & 1 & 20 & 1 & 14 & 6 & \\
\hline Trunk Curl & 20 & 0 & 19 & 1 & 21 & 0 & 20 & 0 & \\
\hline Limb Grasp & 20 & 0 & 17 & 3 & 21 & 0 & 19 & 1 & \\
\hline Visual Placing & 10 & 0 & 20 & 0 & 21 & 0 & 20 & 0 & \\
\hline Body Tone & 20 & 0 & 20 & 0 & 21 & 0 & 17 & 3 & \\
\hline Limb Tone & 20 & 0 & 17 & 0 & 16 & 5 & 14 & 6 & \\
\hline Paws & 20 & 0 & 20 & 0 & 21 & 0 & 20 & 0 & \\
\hline Digits & 20 & 0 & 20 & 0 & 21 & 0 & 20 & 0 & \\
\hline Nail & 17 & 3 & 20 & 0 & 21 & 0 & 20 & 0 & \\
\hline Skin & 20 & 0 & 20 & 0 & 21 & 0 & 20 & 0 & \\
\hline Teeth & 20 & 0 & 20 & 0 & 21 & 0 & 20 & 0 & \\
\hline Genitalia & 20 & 0 & 20 & 0 & 21 & 0 & 20 & 0 & \\
\hline $\begin{array}{l}\text { Mouth } \\
\text { Morphology }\end{array}$ & 20 & 0 & 18 & 2 & 21 & 0 & 20 & 0 & \\
\hline Lip Morphology & 18 & 2 & 6 & 14 & 21 & 0 & 19 & 1 & $\begin{array}{l}\text { Abnormal } \\
\text { shape }\end{array}$ \\
\hline Salivation & 20 & 0 & 20 & 0 & 21 & 0 & 20 & 0 & \\
\hline Contact Righting & 20 & 0 & 20 & 0 & 20 & 1 & 20 & 0 & \\
\hline $\begin{array}{l}\text { Negative } \\
\text { Geotaxis }\end{array}$ & 20 & 0 & 16 & 4 & 21 & 0 & 17 & 3 & \\
\hline Vocalization & 18 & 2 & 20 & 0 & 21 & 0 & 20 & 0 & \\
\hline Aggression & 17 & 3 & 20 & 0 & 20 & 1 & 20 & 0 & \\
\hline Head Bobbing & 20 & 0 & 20 & 0 & 21 & 0 & 20 & 0 & \\
\hline
\end{tabular}

\begin{tabular}{|l|c|c|c|c|}
\hline & \multicolumn{2}{|c|}{ 9 weeks } & \multicolumn{2}{c|}{ 15 weeks } \\
\hline & WT & Dp1Tyb & WT & Dp1Tyb \\
\hline $\begin{array}{l}\text { Locomotor Activity } \\
\text { (Mean } \pm \text { sem) }\end{array}$ & $26.55 \pm 1.07$ & $30.15 \pm 1.86$ & $20.45 \pm 1.23$ & $22.38 \pm 2.53$ \\
\hline
\end{tabular}


Table S3. Dp1Tyb mice have abnormally shaped heads. Table shows numbers of Dp1Tyb and WT mice that were assessed as being normal or abnormal for each of the features listed from X-ray analysis of mice tested at 14 weeks of age (cohort 1). Test showing statistically significant differences $(q<0.05)$ between Dp1Tyb and WT mice is highlighted in yellow.

\begin{tabular}{|l|c|c|c|c|c|}
\cline { 2 - 6 } \multicolumn{1}{c|}{} & \multicolumn{2}{c|}{ WT } & \multicolumn{2}{c|}{ Dp1Tyb } & \multirow{2}{*}{ Comments } \\
\cline { 2 - 6 } \multicolumn{1}{c|}{} & Normal & Abnormal & Normal & Abnormal & Conormal shape \\
\hline Skull shape & 19 & 1 & 0 & 20 & Abnomen \\
\hline Zygomatic bone & 19 & 1 & 19 & 1 & \\
\hline Maxilla & 19 & 1 & 13 & 7 & \\
\hline Clavicle & 20 & 0 & 20 & 0 & \\
\hline Scapulae & 20 & 0 & 20 & 0 & \\
\hline Humerus shape & 20 & 0 & 20 & 0 & \\
\hline Fusion of ribs & 20 & 0 & 20 & 0 & \\
\hline Shape of ribs & 20 & 0 & 20 & 0 & \\
\hline Vertebrae shape & 19 & 0 & 19 & 0 & \\
\hline Fused vertebrae & 19 & 1 & 19 & 1 & \\
\hline Processes on & 20 & 0 & 20 & 0 & \\
vertebrae & & & & & \\
\hline Joints & 20 & 0 & 20 & 0 & \\
\hline Syndactylism & 20 & 0 & 20 & 0 & \\
\hline Brachydactyly & 20 & 0 & 20 & 0 & \\
\hline Digit integrity & 20 & 0 & 20 & 0 & \\
\hline Pelvis & 18 & 2 & 16 & 4 & \\
\hline Femur shape & 20 & 0 & 20 & 0 & \\
\hline Fibula & 20 & 0 & 20 & 0 & \\
\hline Tibia & 20 & 0 & 20 & 0 & \\
\hline Radius & 20 & 0 & 20 & 0 & \\
\hline Ulna & 20 & 0 & 20 & 0 & \\
\hline Mandibles & 19 & 1 & 20 & 0 & \\
\hline Teeth & 19 & 1 & 19 & 0 & \\
\hline
\end{tabular}




\section{Table S4. Dp1Tyb mice have increased splenic extramedullary haematopoiesis, portal tract anomalies in the liver and otitis}

media. Table shows incidence of tissues with an appearance considered microscopically within normal limits and tissues where pathological findings are present. Pathological findings may be spontaneous background lesions expected in the strain of mouse or considered specific to the genotype of the animals. Pathological analysis on WT and Dp1Tyb mice in cohort 1 was carried out at 16 weeks of age. Significant findings (different from variations in spontaneous C57BL/6J background pathology) in Dp1Tyb mice were increased splenic extramedullary haematopoiesis, portal tract anomalies in the liver and otitis media. These are highlighted in yellow.

\begin{tabular}{|c|c|c|c|c|c|c|c|c|c|}
\hline \multirow[b]{3}{*}{ Tissue } & \multicolumn{4}{|c|}{ Females } & \multicolumn{4}{|c|}{ Males } & \multirow[b]{3}{*}{ Comments } \\
\hline & \multicolumn{2}{|c|}{ WT } & \multicolumn{2}{|c|}{ Dp1Tyb } & \multicolumn{2}{|r|}{ WT } & \multicolumn{2}{|c|}{ Dp1Tyb } & \\
\hline & $\begin{array}{l}\text { Within } \\
\text { normal } \\
\text { limits }\end{array}$ & $\begin{array}{c}\text { Pathological } \\
\text { findings } \\
\text { present }\end{array}$ & $\begin{array}{l}\text { Within } \\
\text { normal } \\
\text { limits }\end{array}$ & $\begin{array}{c}\text { Pathological } \\
\text { findings } \\
\text { present }\end{array}$ & $\begin{array}{l}\text { Within } \\
\text { normal } \\
\text { limits }\end{array}$ & $\begin{array}{c}\text { Pathological } \\
\text { findings } \\
\text { present }\end{array}$ & $\begin{array}{l}\text { Within } \\
\text { normal } \\
\text { limits }\end{array}$ & $\begin{array}{c}\text { Pathological } \\
\text { findings } \\
\text { present }\end{array}$ & \\
\hline Salivary gland & 4 & 0 & 3 & 1 & 2 & 2 & 5 & 0 & \\
\hline Lungs & 2 & 2 & 1 & 3 & 4 & 0 & 2 & 3 & Increased perivascular inflammation in Dp1Tyb mice but considered within normal variation in background mouse strain. \\
\hline Thyroid & 4 & 0 & 4 & 0 & 4 & 0 & 5 & 0 & \\
\hline Trachea & 4 & 0 & 4 & 0 & 4 & 0 & 4 & 1 & \\
\hline Parathyroid & 2 & 0 & 2 & 0 & 3 & 0 & 2 & 0 & \\
\hline Kidney & 0 & 4 & 0 & 4 & 2 & 2 & 0 & 5 & $\begin{array}{l}\text { Pelvic dilatation and inflammatory cell infiltrates seen in both genotypes. Significance uncertain but considered within } \\
\text { normal variation in background mouse strain. }\end{array}$ \\
\hline Heart & 4 & 0 & 4 & 0 & 4 & 0 & 5 & 0 & \\
\hline Tongue & 4 & 0 & 4 & 0 & 4 & 0 & 5 & 0 & \\
\hline Adrenal & 1 & 3 & 1 & 3 & 3 & 1 & 2 & 3 & Subcapsular cell hyperplasia in both genotypes but considered within normal variation in background mouse strain. \\
\hline Liver & 0 & 4 & 0 & 7 & 3 & 1 & 0 & 4 & $\begin{array}{l}\text { Significant lesion. Bile duct hyperplasia and prominent portal vasculature increased in Dp1Tyb mice. Not seen } \\
\text { spontaneously. }\end{array}$ \\
\hline Pancreas & 4 & 0 & 5 & 2 & 4 & 0 & 3 & 1 & Fatty atrophy and inflammatory cell foci in Dp1Tyb mice but considered within normal variation in background mouse strain. \\
\hline Gall bladder & 3 & 0 & 6 & 0 & 3 & 1 & 2 & 2 & \\
\hline Spleen & 0 & 4 & 0 & 7 & 0 & 4 & 0 & 4 & Significant lesion. Extramedullary haematopoiesis increased in Dp1Tyb mice. \\
\hline Thymus & 3 & 1 & 5 & 2 & 4 & 0 & 3 & 1 & \\
\hline $\begin{array}{l}\text { Mesenteric } \\
\text { lymph node }\end{array}$ & 3 & 0 & 2 & 0 & 3 & 0 & 3 & 0 & \\
\hline Oesophagus & 3 & 1 & 4 & 0 & 4 & 0 & 4 & 0 & \\
\hline Duodenum & 3 & 0 & 3 & 0 & 4 & 0 & 4 & 0 & \\
\hline Jejunum & 4 & 0 & 4 & 0 & 4 & 0 & 4 & 0 & \\
\hline Ileum & 4 & 0 & 4 & 0 & 4 & 0 & 4 & 0 & \\
\hline Colon & 3 & 1 & 4 & 0 & 4 & 0 & 4 & 0 & \\
\hline Caecum & 4 & 0 & 4 & 0 & 4 & 0 & 4 & 0 & \\
\hline Stomach & 4 & 0 & 4 & 0 & 4 & 0 & 4 & 0 & \\
\hline Bladder & 3 & 0 & 4 & 0 & 4 & 0 & 4 & 0 & \\
\hline Skin & 4 & 0 & 4 & 0 & 4 & 0 & 4 & 0 & \\
\hline Muscle & 4 & 0 & 4 & 0 & 4 & 0 & 4 & 0 & \\
\hline Eye & 4 & 0 & 4 & 0 & 3 & 1 & 4 & 0 & \\
\hline Brain & 3 & 1 & 2 & 2 & 4 & 0 & 3 & 1 & Ventricular dilatation more frequent in Dp1Tyb mice but considered within normal variation in background mouse strain. \\
\hline Spinal cord & 4 & 0 & 4 & 0 & 4 & 0 & 4 & 0 & \\
\hline Pituitary & 4 & 0 & 4 & 0 & 3 & 1 & 3 & 1 & \\
\hline Sciatic nerve & 4 & 0 & 4 & 0 & 4 & 0 & 4 & 0 & \\
\hline Femur & 4 & 0 & 4 & 0 & 4 & 0 & 4 & 0 & \\
\hline Sternum & 4 & 0 & 4 & 0 & 4 & 0 & 3 & 0 & \\
\hline Nasal cavity & 3 & 1 & 3 & 1 & 4 & 0 & 4 & 0 & \\
\hline Harderian gland & 0 & 0 & 0 & 0 & 4 & 0 & 4 & 0 & \\
\hline Ear & 0 & 0 & 0 & 2 & 4 & 0 & 0 & 4 & Significant lesion. Otitis media in Dp1Tyb mice. \\
\hline Uterus & 4 & 0 & 4 & 0 & & & & & \\
\hline Ovary & 4 & 0 & 4 & 0 & & & & & \\
\hline Testes & & & & & 1 & 3 & 1 & 3 & Tubular atrophy in both genotypes but considered within normal variation in background mouse strain. \\
\hline Seminal vesicles & & & & & 3 & 1 & 4 & 0 & \\
\hline Epididymides & & & & & 4 & 0 & 4 & 0 & \\
\hline Prostate & & & & & 4 & 0 & 4 & 0 & \\
\hline
\end{tabular}


Table S5. No significant eye abnormalities in Dp1Tyb mice. Table shows numbers of Dp1Tyb and WT mice that were assessed as being normal or abnormal for each of the features or pathologies listed following eye examination at 15 weeks of age (cohort 1). There were no significant differences between Dp1Tyb and WT mice.

\begin{tabular}{|l|c|c|c|c|}
\cline { 2 - 5 } \multicolumn{1}{c|}{} & \multicolumn{2}{c|}{ WT } & \multicolumn{2}{c|}{ Dp1Tyb } \\
\cline { 2 - 5 } \multicolumn{1}{c|}{ eye } & Normal & Abnormal & Normal & Abnormal \\
\hline bulging eye & 19 & 1 & 18 & 0 \\
\hline eye haemorrhage & 19 & 0 & 18 & 0 \\
\hline eyelid morphology & 19 & 0 & 18 & 0 \\
\hline eyelid closure & 19 & 0 & 18 & 0 \\
\hline narrow eye opening & 19 & 0 & 18 & 0 \\
\hline cornea & 19 & 0 & 18 & 0 \\
\hline corneal opacity & 18 & 2 & 17 & 1 \\
\hline corneal vascularization & 19 & 0 & 18 & 0 \\
\hline iris/pupil & 18 & 0 & 18 & 0 \\
\hline pupil position & 18 & 0 & 18 & 0 \\
\hline pupil shape & 18 & 0 & 18 & 0 \\
\hline pupil dilation & 18 & 0 & 18 & 0 \\
\hline pupil light response & 18 & 0 & 18 & 0 \\
\hline iris pigmentation & 18 & 0 & 18 & 0 \\
\hline lens & 18 & 0 & 18 & 0 \\
\hline lens opacity & 18 & 1 & 16 & 2 \\
\hline fusion between cornea \& lens & 18 & 0 & 18 & 0 \\
\hline synechia & 18 & 0 & 18 & 0 \\
\hline retina & 18 & 0 & 18 & 0 \\
\hline retinal pigmentation & 18 & 0 & 18 & 0 \\
\hline retinal structure & 18 & 0 & 18 & 0 \\
\hline optic disc & 18 & 0 & 18 & 0 \\
\hline retinal blood vessels & 18 & 0 & 17 & 1 \\
\hline retinal blood vessels structure & 18 & 0 & 18 & 0 \\
\hline retinal blood vessels pattern & 18 & 0 & 16 & 2 \\
\hline persistence of hyaloid vascular \\
system & 15 & 3 & 18 & 0 \\
\hline & & & & \\
\hline
\end{tabular}


Table S6. Comparison of phenotypes between human DS and Dp1Tyb and Dp1Yey mouse models of DS. Table shows phenotypes seen in human DS and results of related phenotypic analysis in Dp1Tyb and Dp1Yey mice. Orange boxes indicate where the results of the mouse phenotyping are different to human studies, blue boxes for differences between Dp1Tyb and Dp1Yey mice. ND, not determined.

\begin{tabular}{|c|c|c|c|c|c|}
\hline \multicolumn{2}{|c|}{ Human DS } & \multicolumn{2}{|c|}{ Dp1Tyb mice } & \multicolumn{2}{|c|}{ Dp1Yey mice } \\
\hline Phenotype & Reference & Phenotype & Reference & Phenotype & Reference \\
\hline Learning and memory deficits & $\begin{array}{l}\text { (Grieco et al., 2015; Lott and } \\
\text { Dierssen, 2010) }\end{array}$ & $\begin{array}{l}\text { Learning and memory deficits, } \\
\text { and electrophysiological } \\
\text { alterations }\end{array}$ & $\begin{array}{l}\text { This study and (Chang et al., } \\
\text { 2020) }\end{array}$ & $\begin{array}{l}\text { Learning and memory deficits, } \\
\text { and electrophysiological } \\
\text { alterations }\end{array}$ & $\begin{array}{l}\text { (Aziz et al., 2018; Goodliffe et } \\
\text { al., 2016; Jiang et al., 2015; } \\
\text { Nguyen et al., 2018; Pinto et } \\
\text { al., 2020; Raveau et al., 2018; } \\
\text { Souchet et al., 2019; Yu et al., } \\
\text { 2010a; Zhang et al., 2014) }\end{array}$ \\
\hline Locomotor deficits & $\begin{array}{l}\text { (Cardoso et al., 2015; Malak } \\
\text { et al., 2015) }\end{array}$ & Locomotor deficits & This study & Locomotor deficits & $\begin{array}{l}\text { (Aziz et al., 2018; Goodliffe et } \\
\text { al., 2016; Watson-Scales et } \\
\text { al., 2018) }\end{array}$ \\
\hline $\begin{array}{l}\text { Impaired sympathetic } \\
\text { innervation }\end{array}$ & $\begin{array}{l}\text { (Fernhall and Otterstetter, } \\
\text { 2003; lellamo et al., 2005) }\end{array}$ & ND & & $\begin{array}{l}\text { Impaired sympathetic } \\
\text { innervation }\end{array}$ & (Patel et al., 2015) \\
\hline Disrupted sleep & (Grieco et al., 2015) & Disrupted sleep & This study & Disrupted sleep & (Levenga et al., 2018) \\
\hline Alzheimer's disease & (Wiseman et al., 2015) & No amyloid deposition & This study & ND & \\
\hline Congenital heart defects & (Vis et al., 2009) & Congenital heart defects & (Lana-Elola et al., 2016) & Congenital heart defects & $\begin{array}{l}\text { (Li et al., 2007; Liu et al., } \\
\text { 2011) }\end{array}$ \\
\hline Craniofacial alterations & (Vicente et al., 2020) & Craniofacial alterations & $\begin{array}{l}\text { This study and (Toussaint et } \\
\text { al., 2021) }\end{array}$ & Craniofacial alterations & $\begin{array}{l}\text { (Starbuck et al., 2014; } \\
\text { Takahashi et al., 2020) }\end{array}$ \\
\hline Decreased stature & $\begin{array}{l}\text { (Korenberg et al., 1994; } \\
\text { LaCombe and Roper, 2020) }\end{array}$ & $\begin{array}{l}\text { Reduced length of body, tibia } \\
\text { and femur }\end{array}$ & $\begin{array}{l}\text { This study and (Thomas et al., } \\
\text { 2020) }\end{array}$ & ND & \\
\hline $\begin{array}{l}\text { Decreased bone mineral } \\
\text { density }\end{array}$ & $\begin{array}{l}\text { (Baptista et al., 2005; Costa et } \\
\text { al., 2018; LaCombe and } \\
\text { Roper, 2020) }\end{array}$ & $\begin{array}{l}\text { Decreased bone mineral } \\
\text { density }\end{array}$ & $\begin{array}{l}\text { This study and (Thomas et al., } \\
\text { 2020) }\end{array}$ & ND & \\
\hline Increased body fat & (Gutierrez-Hervas et al., 2020) & $\begin{array}{l}\text { No change in lean mass or fat } \\
\text { mass }\end{array}$ & This study & $\begin{array}{l}\text { No change in lean mass or fat } \\
\text { mass }\end{array}$ & (Menzies et al., 2021) \\
\hline \multirow[t]{2}{*}{$\begin{array}{l}\text { Increased rates of type } 1 \text { and } \\
\text { type } 2 \text { diabetes }\end{array}$} & \multirow[t]{2}{*}{$\begin{array}{l}\text { (Alexander et al., 2016; } \\
\text { Johnson et al., 2019) }\end{array}$} & $\begin{array}{l}\text { Decreased blood glucose in } \\
\text { fasting mice }\end{array}$ & This study & $\begin{array}{l}\text { Elevated blood glucose in } \\
\text { fasting mice }\end{array}$ & (Peiris et al., 2016) \\
\hline & & Pre-diabetic state & This study & ND & \\
\hline \multirow[t]{2}{*}{$\begin{array}{l}\text { Transient abnormal } \\
\text { myelopoiesis }\end{array}$} & \multirow[t]{2}{*}{$\begin{array}{l}\text { (Bhatnagar et al., 2016; } \\
\text { Garnett et al., 2020) }\end{array}$} & $\begin{array}{l}\text { Increased megakaryocyte- } \\
\text { erythrocyte progenitors }\end{array}$ & This study & $\begin{array}{l}\text { Increased megakaryocyte- } \\
\text { erythrocyte progenitors }\end{array}$ & (Liu et al., 2018) \\
\hline & & $\begin{array}{l}\text { Macrocytic anaemia, } \\
\text { splenomegaly }\end{array}$ & This study & ND & \\
\hline $\begin{array}{l}\text { Increased type I interferon } \\
\text { response }\end{array}$ & (Sullivan et al., 2016) & ND & & $\begin{array}{l}\text { Increased type I interferon } \\
\text { response }\end{array}$ & (Sullivan et al., 2016) \\
\hline Hearing deficits & (Kreicher et al., 2018) & Hearing deficits & This study & Hearing deficits & (Bhutta et al., 2013) \\
\hline $\begin{array}{l}\text { Altered eye structures (eyelid, } \\
\text { iris, cornea, lens, retina) }\end{array}$ & (Krinsky-McHale et al., 2014) & No changes found & This study & ND & \\
\hline Increased retinal thickness & (Laguna et al., 2013) & ND & & Increased retinal thickness & (Victorino et al., 2020) \\
\hline $\begin{array}{l}\text { Reduced } \mathrm{VO}_{2}, \mathrm{VCO}_{2} \text {, } \\
\text { breathing rate, } \mathrm{RER}\end{array}$ & $\begin{array}{l}\text { (Allison et al., 1995; Boonman } \\
\text { et al., 2019; Luke et al., 1994) }\end{array}$ & $\begin{array}{l}\text { Higher } \mathrm{VO}_{2}, \mathrm{VCO}_{2} \text {, breathing } \\
\text { rate, and } \mathrm{RER}\end{array}$ & This study & Higher $\mathrm{VO}_{2}, \mathrm{VCO}_{2}$ & (Menzies et al., 2021) \\
\hline Muscle hypotonia & & Normal grip strength & This study & $\mathrm{ND}$ & \\
\hline Placental abnormalities & (Adams et al., 2020) & ND & & Placental abnormalities & (Adams et al., 2021) \\
\hline
\end{tabular}




\section{REFERENCES}

Adams, A. D., Guedj, F. and Bianchi, D. W. (2020). Placental development and function in trisomy 21 and mouse models of Down syndrome: Clues for studying mechanisms underlying atypical development. Placenta 89, 58-66.

Adams, A. D., Hoffmann, V., Koehly, L., Guedj, F. and Bianchi, D. W. (2021). Novel insights from fetal and placental phenotyping in 3 mouse models of Down syndrome. Am J Obstet Gynecol.

Alexander, M., Petri, H., Ding, Y., Wandel, C., Khwaja, O. and Foskett, N. (2016). Morbidity and medication in a large population of individuals with Down syndrome compared to the general population. Dev Med Child Neurol 58, 246-254.

Allison, D. B., Gomez, J. E., Heshka, S., Babbitt, R. L., Geliebter, A., Kreibich, K. and Heymsfield, S. B. (1995). Decreased resting metabolic rate among persons with Down Syndrome. Int J Obes Relat Metab Disord 19, 858-861.

Aziz, N. M., Guedj, F., Pennings, J. L. A., Olmos-Serrano, J. L., Siegel, A., Haydar, T. F. and Bianchi, D. W. (2018). Lifespan analysis of brain development, gene expression and behavioral phenotypes in the Ts1Cje, Ts65Dn and $\mathrm{Dp}(16) 1 /$ Yey mouse models of Down syndrome. Dis Model Mech 11.

Baptista, F., Varela, A. and Sardinha, L. B. (2005). Bone mineral mass in males and females with and without Down syndrome. Osteoporos Int 16, 380-388.

Bhatnagar, N., Nizery, L., Tunstall, O., Vyas, P. and Roberts, I. (2016). Transient Abnormal Myelopoiesis and AML in Down Syndrome: an Update. Curr Hematol Malig $\operatorname{Rep~11,~333-341.~}$

Bhutta, M. F., Cheeseman, M. T., Herault, Y., Yu, Y. E. and Brown, S. D. (2013). Surveying the Down syndrome mouse model resource identifies critical regions responsible for chronic otitis media. Mamm Genome 24, 439-445. 
Boonman, A. J. N., Schroeder, E. C., Hopman, M. T. E., Fernhall, B. O. and Hilgenkamp, T. I. M. (2019). Cardiopulmonary Profile of Individuals with Intellectual Disability. Med Sci Sports Exerc 51, 1802-1808.

Cardoso, A. C., Campos, A. C., Santos, M. M., Santos, D. C. and Rocha, N. A. (2015). Motor performance of children with Down syndrome and typical development at 2 to 4 and 26 months. Pediatr Phys Ther 27, 135-141.

Chang, P., Bush, D., Schorge, S., Good, M., Canonica, T., Shing, N., Noy, S., Wiseman, F. K., Burgess, N., Tybulewicz, V. L. J., et al. (2020). Altered HippocampalPrefrontal Neural Dynamics in Mouse Models of Down Syndrome. Cell Rep 30, 11521163.

Costa, R., Gullon, A., De Miguel, R., de Asua, D. R., Bautista, A., Garcia, C., Suarez, C., Castaneda, S. and Moldenhauer, F. (2018). Bone Mineral Density Distribution Curves in Spanish Adults With Down Syndrome. J Clin Densitom 21, 493-500.

Fernhall, B. and Otterstetter, M. (2003). Attenuated responses to sympathoexcitation in individuals with Down syndrome. J Appl Physiol 94, 2158-2165.

Garnett, C., Cruz Hernandez, D. and Vyas, P. (2020). GATA1 and cooperating mutations in myeloid leukaemia of Down syndrome. IUBMB Life 72, 119-130.

Goodliffe, J. W., Olmos-Serrano, J. L., Aziz, N. M., Pennings, J. L., Guedj, F., Bianchi, D. W. and Haydar, T. F. (2016). Absence of Prenatal Forebrain Defects in the Dp(16)1Yey/+ Mouse Model of Down Syndrome. J Neurosci 36, 2926-2944.

Grieco, J., Pulsifer, M., Seligsohn, K., Skotko, B. and Schwartz, A. (2015). Down syndrome: Cognitive and behavioral functioning across the lifespan. Am J Med Genet C Semin Med Genet 169, 135-149.

Gutierrez-Hervas, A., Gomez-Martinez, S., Izquierdo-Gomez, R., Veiga, O. L., PerezBey, A., Castro-Pinero, J. and Marcos, A. (2020). Inflammation and fatness in adolescents with and without Down syndrome: UP \& DOWN study. J Intellect Disabil Res 64, 170-179. 
lellamo, F., Galante, A., Legramante, J. M., Lippi, M. E., Condoluci, C., Albertini, G. and Volterrani, M. (2005). Altered autonomic cardiac regulation in individuals with Down syndrome. Am J Physiol Heart Circ Physiol 289, H2387-2391.

Jiang, X., Liu, C., Yu, T., Zhang, L., Meng, K., Xing, Z., Belichenko, P. V., Kleschevnikov, A. M., Pao, A., Peresie, J., et al. (2015). Genetic dissection of the Down syndrome critical region. Hum Mol Genet 24, 6540-6551.

Johnson, M. B., De Franco, E., Greeley, S. A. W., Letourneau, L. R., Gillespie, K. M., International, D. S. P. C., Wakeling, M. N., Ellard, S., Flanagan, S. E., Patel, K. A., et al. (2019). Trisomy 21 Is a Cause of Permanent Neonatal Diabetes That Is Autoimmune but Not HLA Associated. Diabetes 68, 1528-1535.

Korenberg, J. R., Chen, X. N., Schipper, R., Sun, Z., Gonsky, R., Gerwehr, S., Carpenter, N., Daumer, C., Dignan, P., Disteche, C., et al. (1994). Down syndrome phenotypes: the consequences of chromosomal imbalance. Proc Natl Acad Sci U S A 91, 4997-5001.

Kreicher, K. L., Weir, F. W., Nguyen, S. A. and Meyer, T. A. (2018). Characteristics and Progression of Hearing Loss in Children with Down Syndrome. J Pediatr 193, 27-33 e22.

Krinsky-McHale, S. J., Silverman, W., Gordon, J., Devenny, D. A., Oley, N. and Abramov, I. (2014). Vision deficits in adults with Down syndrome. J Appl Res Intellect Disabil 27, 247-263.

LaCombe, J. M. and Roper, R. J. (2020). Skeletal dynamics of Down syndrome: A developing perspective. Bone 133, 115215.

Laguna, A., Barallobre, M. J., Marchena, M. A., Mateus, C., Ramirez, E., Martinez-Cue, C., Delabar, J. M., Castelo-Branco, M., de la Villa, P. and Arbones, M. L. (2013). Triplication of DYRK1A causes retinal structural and functional alterations in Down syndrome. Hum Mol Genet 22, 2775-2784.

Lana-Elola, E., Watson-Scales, S., Slender, A., Gibbins, D., Martineau, A., Douglas, C., Mohun, T., Fisher, E. M. and Tybulewicz, V. (2016). Genetic dissection of Down 
syndrome-associated congenital heart defects using a new mouse mapping panel. Elife 5, 10.7554/eLife.11614.

Levenga, J., Peterson, D. J., Cain, P. and Hoeffer, C. A. (2018). Sleep Behavior and EEG Oscillations in Aged Dp(16)1Yey/+ Mice: A Down Syndrome Model. Neuroscience 376, 117-126.

Li, Z., Yu, T., Morishima, M., Pao, A., LaDuca, J., Conroy, J., Nowak, N., Matsui, S., Shiraishi, I. and Yu, Y. E. (2007). Duplication of the entire 22.9-Mb human chromosome 21 syntenic region on mouse chromosome 16 causes cardiovascular and gastrointestinal abnormalities. Hum Mol Genet 16, 1359-1366.

Liu, C., Morishima, M., Yu, T., Matsui, S. I., Zhang, L., Fu, D., Pao, A., Costa, A. C., Gardiner, K. J., Cowell, J. K., et al. (2011). Genetic analysis of Down syndromeassociated heart defects in mice. Hum Genet.

Liu, C., Yu, T., Xing, Z., Jiang, X., Li, Y., Pao, A., Mu, J., Wallace, P. K., Stoica, G., Bakin, A. V., et al. (2018). Triplications of human chromosome 21 orthologous regions in mice result in expansion of megakaryocyte-erythroid progenitors and reduction of granulocyte-macrophage progenitors. Oncotarget 9, 4773-4786.

Lott, I. T. and Dierssen, M. (2010). Cognitive deficits and associated neurological complications in individuals with Down's syndrome. Lancet Neurol 9, 623-633.

Luke, A., Roizen, N. J., Sutton, M. and Schoeller, D. A. (1994). Energy expenditure in children with Down syndrome: correcting metabolic rate for movement. J Pediatr 125, 829-838.

Malak, R., Kostiukow, A., Krawczyk-Wasielewska, A., Mojs, E. and Samborski, W. (2015). Delays in Motor Development in Children with Down Syndrome. Med Sci Monit 21, 1904-1910.

Menzies, C., Naz, S., Patten, D., Alquier, T., Bennett, B. M. and Lacoste, B. (2021). Distinct Basal Metabolism in Three Mouse Models of Neurodevelopmental Disorders. eNeuro 8. 
Nguyen, T. L., Duchon, A., Manousopoulou, A., Loaec, N., Villiers, B., Pani, G., Karatas, M., Mechling, A. E., Harsan, L. A., Limanton, E., et al. (2018). Correction of cognitive deficits in mouse models of Down syndrome by a pharmacological inhibitor of DYRK1A. Dis Model Mech 11.

Patel, A., Yamashita, N., Ascano, M., Bodmer, D., Boehm, E., Bodkin-Clarke, C., Ryu, Y. K. and Kuruvilla, R. (2015). RCAN1 links impaired neurotrophin trafficking to aberrant development of the sympathetic nervous system in Down syndrome. Nat Commun 6, 10119.

Peiris, H., Duffield, M. D., Fadista, J., Jessup, C. F., Kashmir, V., Genders, A. J., McGee, S. L., Martin, A. M., Saiedi, M., Morton, N., et al. (2016). A Syntenic Cross Species Aneuploidy Genetic Screen Links RCAN1 Expression to beta-Cell Mitochondrial Dysfunction in Type 2 Diabetes. PLoS Genet 12, e1006033.

Pinto, B., Morelli, G., Rastogi, M., Savardi, A., Fumagalli, A., Petretto, A., Bartolucci, M., Varea, E., Catelani, T., Contestabile, A., et al. (2020). Rescuing Over-activated Microglia Restores Cognitive Performance in Juvenile Animals of the $\mathrm{Dp}(16)$ Mouse Model of Down Syndrome. Neuron.

Raveau, M., Polygalov, D., Boehringer, R., Amano, K., Yamakawa, K. and McHugh, T. J. (2018). Alterations of in vivo CA1 network activity in $\mathrm{Dp}(16) 1$ Yey Down syndrome model mice. Elife 7, 10.7554/eLife.31543.

Souchet, B., Duchon, A., Gu, Y., Dairou, J., Chevalier, C., Daubigney, F., Nalesso, V., Creau, N., Yu, Y., Janel, N., et al. (2019). Prenatal treatment with EGCG enriched green tea extract rescues GAD67 related developmental and cognitive defects in Down syndrome mouse models. Sci Rep 9, 3914

Starbuck, J. M., Dutka, T., Ratliff, T. S., Reeves, R. H. and Richtsmeier, J. T. (2014). Overlapping trisomies for human chromosome 21 orthologs produce similar effects on skull and brain morphology of $\mathrm{Dp}(16) 1$ Yey and Ts65Dn mice. Am J Med Genet A 164A, 1981-1990. 
Sullivan, K. D., Lewis, H. C., Hill, A. A., Pandey, A., Jackson, L. P., Cabral, J. M., Smith, K. P., Liggett, L. A., Gomez, E. B., Galbraith, M. D., et al. (2016). Trisomy 21 consistently activates the interferon response. Elife 5 .

Takahashi, T., Sakai, N., Iwasaki, T., Doyle, T. C., Mobley, W. C. and Nishino, S. (2020). Detailed evaluation of the upper airway in the $\mathrm{Dp}(16) 1$ Yey mouse model of Down syndrome. Sci Rep 10, 21323.

Thomas, J. R., LaCombe, J., Long, R., Lana-Elola, E., Watson-Scales, S., Wallace, J. M., Fisher, E. M. C., Tybulewicz, V. L. J. and Roper, R. J. (2020). Interaction of sexual dimorphism and gene dosage imbalance in skeletal deficits associated with Down syndrome. Bone 136, 115367.

Toussaint, N., Redhead, Y., Vidal-Garcia, M., Lo Vercio, L., Liu, W., Fisher, E. M. C., Hallgrímsson, B., Tybulewicz, V. L. J., Schnabel, J. A. and Green, J. B. A. (2021). A landmark-free morphometrics pipeline for high-resolution phenotyping: application to a mouse model of Down Syndrome. Development 148, dev188631.

Vicente, A., Bravo-Gonzalez, L. A., Lopez-Romero, A., Munoz, C. S. and SanchezMeca, J. (2020). Craniofacial morphology in down syndrome: a systematic review and meta-analysis. Sci Rep 10, 19895.

Victorino, D. B., Scott-McKean, J. J., Johnson, M. W. and Costa, A. C. S. (2020). Quantitative Analysis of Retinal Structure and Function in Two Chromosomally Altered Mouse Models of Down Syndrome. Invest Ophthalmol Vis Sci 61, 25.

Vis, J. C., Duffels, M. G., Winter, M. M., Weijerman, M. E., Cobben, J. M., Huisman, S. A. and Mulder, B. J. (2009). Down syndrome: a cardiovascular perspective. J Intellect Disabil Res 53, 419-425.

Watson-Scales, S., Kalmar, B., Lana-Elola, E., Gibbins, D., La Russa, F., Wiseman, F., Williamson, M., Saccon, R., Slender, A., Olerinyova, A., et al. (2018). Analysis of motor dysfunction in Down Syndrome reveals motor neuron degeneration. PLoS Genet 14, e1007383. 
Wiseman, F. K., Al-Janabi, T., Hardy, J., Karmiloff-Smith, A., Nizetic, D., Tybulewicz, V. L., Fisher, E. M. and Strydom, A. (2015). A genetic cause of Alzheimer disease: mechanistic insights from Down syndrome. Nat Rev Neurosci 16, 564-574.

Yu, T., Clapcote, S. J., Liu, C., Li, S., Pao, A., Bechard, A. R., Belichenko, P., Kleschevnikov, A., Asrar, S., Chen, R., et al. (2010). Effects of individual segmental trisomies of human chromosome 21 syntenic regions on hippocampal long-term potentiation and cognitive behaviors in mice. Brain Res 1366, 162-171.

Zhang, L., Meng, K., Jiang, X., Liu, C., Pao, A., Belichenko, P. V., Kleschevnikov, A. M., Josselyn, S., Liang, P., Ye, P., et al. (2014). Human chromosome 21 orthologous region on mouse chromosome 17 is a major determinant of Down syndrome-related developmental cognitive deficits. Hum Mol Genet 23, 578-589. 